Florida International University FIU Digital Commons

$3-25-2015$

\title{
Workplace Aggression: A Reconceptualization of The Construct \& an Exploration of Strain Based Outcomes
}

Jason K. Steinert

Florida International University, jstei005@fiu.edu

DOI: $10.25148 /$ etd.FI15050208

Follow this and additional works at: https://digitalcommons.fiu.edu/etd

Part of the Industrial and Organizational Psychology Commons

\section{Recommended Citation}

Steinert, Jason K., "Workplace Aggression: A Reconceptualization of The Construct \& an Exploration of Strain Based Outcomes" (2015). FIU Electronic Theses and Dissertations. 1796.

https://digitalcommons.fiu.edu/etd/1796 


\title{
FLORIDA INTERNATIONAL UNIVERSITY
}

\author{
Miami, Florida
}

WORKPLACE AGGRESSION: A RECONCEPTUALIZATION OF THE CONSTRUCT \& AN EXPLORATION OF STRAIN BASED OUTCOMES

A dissertation submitted in partial fulfillment of the requirements for the degree of DOCTOR OF PHILOSOPHY

in

PSYCHOLOGY

by

Jason Kenneth Steinert

2015 
To: Dean Michael R. Heithaus

College of Arts and Sciences

This dissertation, written by Jason Kenneth Steinert, and entitled Workplace Aggression: A Reconceptualization of The Construct \& an Exploration of Strain Based Outcomes, having been approved in respect to style and intellectual content, is referred to you for judgment.

We have read this dissertation and recommend that it be approved.

$\begin{array}{r}\hline \text { Jesse Michel } \\ \hline \text { Chockalingam Viswesvaran } \\ \hline \text { Nathan Hiller } \\ \hline \text { Valentina Bruk-Lee, Major Professor }\end{array}$

Date of Defense: March 25, 2015

The dissertation of Jason Kenneth Steinert is approved.

\begin{tabular}{r} 
Dean Michael R. Heithaus \\
College of Arts and Sciences \\
\hline Dean Lakshmi N. Reddi \\
University Graduate School
\end{tabular}

Florida International University, 2015 
(C) Copyright 2015 by Jason Kenneth Steinert

All rights reserved. 


\section{DEDICATION}

I dedicate this dissertation to my wife Solange and to my two children, Dolce and Alessio. Thank you for the unwavering support, encouragement, and patience. You tolerated the late nights, the lost weekends, and the emotional rollercoaster that characterized this challenging process. Yet throughout it all, you stood right by my side, held me up, and encouraged me forward. Also, to my mother Alice, thank you for all of the sacrifice, and for being a constant source of support and encouragement. Your belief in me and your focus on my future have been a true inspiration. I would also express my thanks and gratitude to Señora Margarita. Your support helped to make my realization of this dream possible; and your struggles have served as a motivation to me, and a reminder to take nothing for granted in this life. Throughout this process it has become clear that without the dedication of my family and close friends (thank you Kevin Rutherford and Dr. Kerry Newness), this journey may have proven insurmountable. Together WE did it. Thank YOU!! 


\section{ACKNOWLEDGMENTS}

I wish to thank the members of my committee for their support and patience throughout the entire process of my dissertation. Each member of my committee provided me with their own unique and integral insights into the development and execution of this project. Dr. Jesse Michel provided me with the ideal balance of challenge and support. Dr. Nathan Hiller challenged me to think outside of the box, and to consider that which isn't necessarily obvious. Dr. Chockalingam Viswesvaran challenged me to think and write like a $\mathrm{PhD}$. I would also like to thank my Major Professor, Dr. Valentina Bruk-Lee, whose guidance and support has been vital to my completion of this dissertation. Finally, I would like to thank Lara Wilson, for without her support and constant willingness to help, it would not have been possible to meet deadlines and finish this degree. Lara and everyone in the psychology office are the unsung hero's of this process, and I thank you all. 


\begin{abstract}
OF THE DISSERTATION
WORKPLACE AGGRESSION: A RECONCEPTUALIZATION OF THE

CONSTRUCT \& AN EXPLORATION OF STRAIN BASED OUTCOMES
\end{abstract}

by

Jason Kenneth Steinert

Florida International University, 2015

Miami, Florida

Professor Valentina Bruk-Lee, Major Professor

The examination of Workplace Aggression as a global construct conceptualization has gained considerable attention over the past few years as organizations work to better understand and address the occurrence and consequences of this challenging construct. The purpose of this dissertation is to build on previous efforts to validate the appropriateness and usefulness of a global conceptualization of the workplace aggression construct.

This dissertation has been broken up into two parts: Part 1 utilized a Confirmatory Factor Analysis approach in order to assess the existence of workplace aggression as a global construct; Part 2 utilized a series of correlational analyses to examine the relationship between a selection of commonly experienced individual strain based outcomes and the global construct conceptualization assessed in Part 1. Participants were a diverse sample of 219 working individuals from Amazon's Mechanical Turk participant pool. 
Results of Part 1 did not show support for a one-factor global construct conceptualization of the workplace aggression construct. However, support was shown for a higher-order five-factor model of the construct, suggesting that it may be possible to conceptualize workplace aggression as an overarching construct that is made up of separate workplace aggression constructs. Results of Part 2 showed support for the relationships between an existing global construct workplace aggression conceptualization and a series of strain-based outcomes. Utilizing correlational analyses, additional post-hoc analyses showed that individual factors such as emotional intelligence and personality are related to the experience of workplace aggression. Further, utilizing moderated regression analysis, the results demonstrated that individuals experiencing high levels of workplace aggression reported higher job satisfaction when they felt strongly that the aggressive act was highly visible, and similarly, when they felt that there was a clear intent to cause harm.

Overall, the findings of this dissertation do support the need for a simplification of its current state of measurement. Future research should continue to examine workplace aggression in an effort to shed additional light on the structure and usefulness of this complex construct. 
I. INTRODUCTION

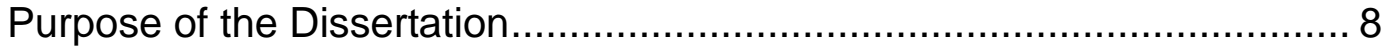

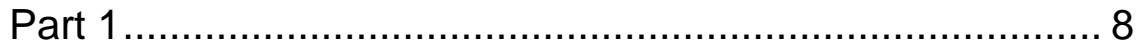

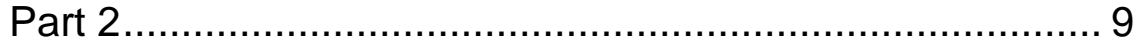

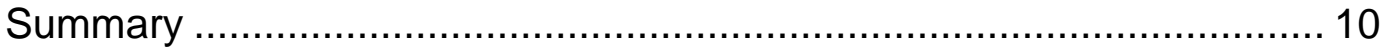

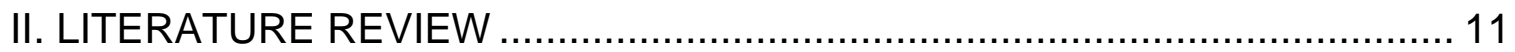

Workplace Aggression and Stress ............................................. 12

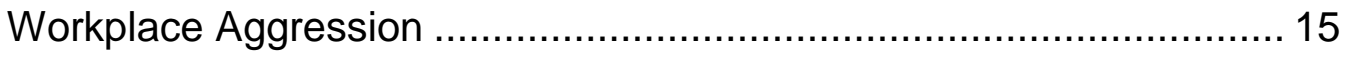

Abusive Supervision .......................................................... 16

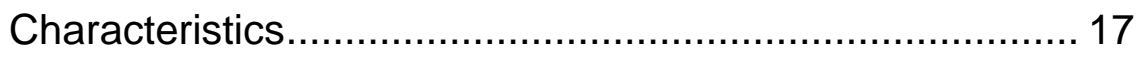

Organizational//ndividual Outcomes................................. 19

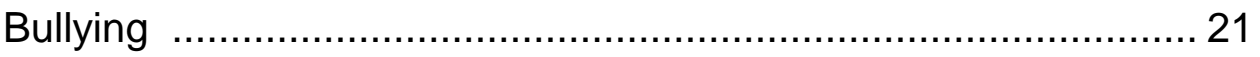

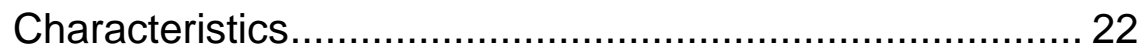

Organizational/Individual Outcomes................................ 24

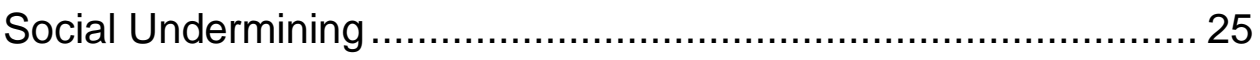

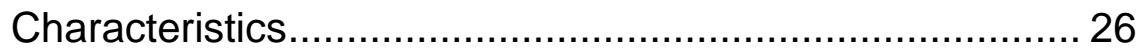

Organizational//ndividual Outcomes................................ 28

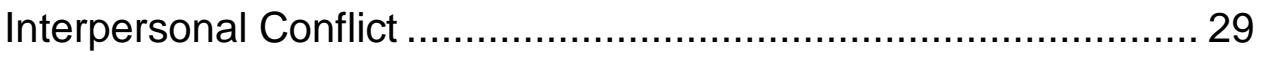

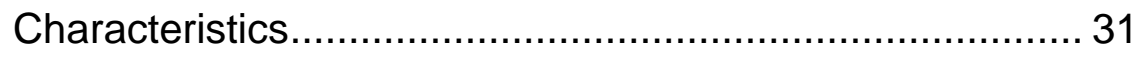

Organizational/Individual Outcomes................................ 32

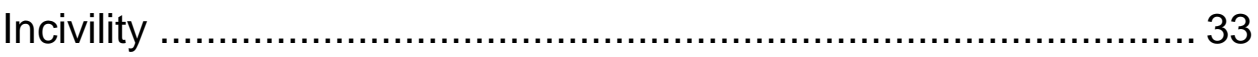

Characteristics........................................................ 35

Organizational//ndividual Outcomes.................................. 37

Workplace Aggression: Existing Measurement Concerns.................... 40 Individual Attributions and Characteristics ................................ 40

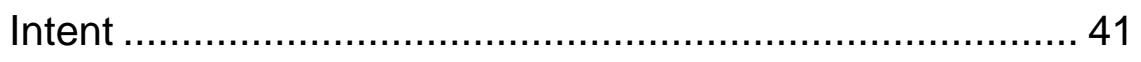

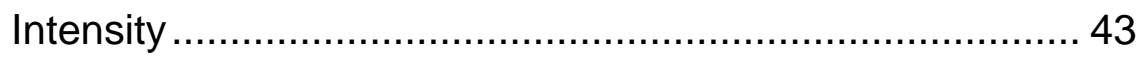

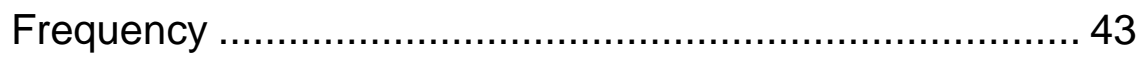

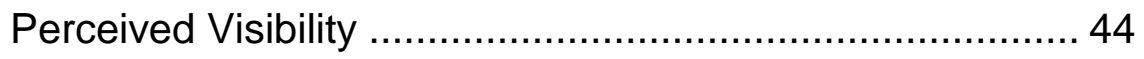

Power Relationship ....................................................... 46 
Workplace Aggression: Item Review............................................... 48

Overarching Model of Workplace Aggression ................................... 50

Workplace Aggression and Strain Based Outcomes............................ 53

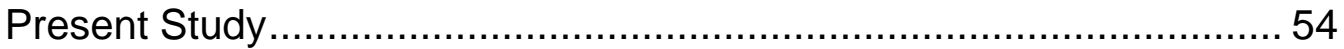

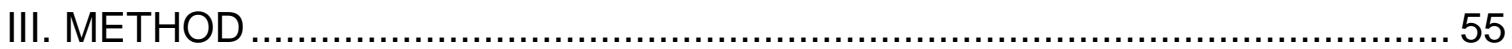

Participants and Procedures ........................................................... 55

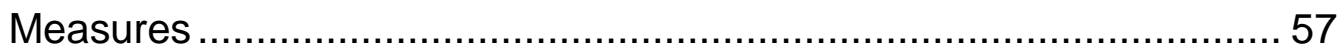

Time 1: Five Measures of Workplace Aggression ...................... 57

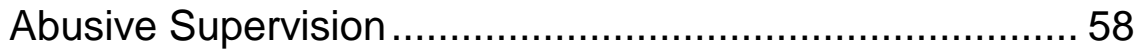

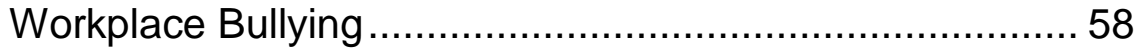

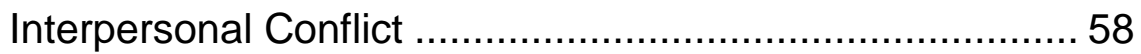

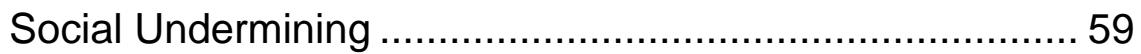

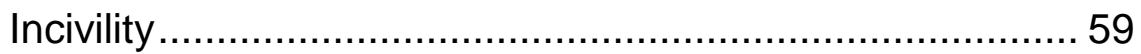

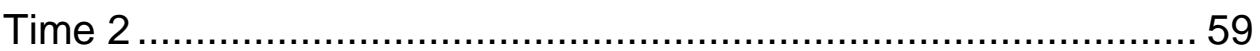

Workplace Aggression and Moderators Scale (WAAMS)... 59

Attitudinal Strain - Job Satisfaction ...................................... 60

Behavioral Strain - Turnover Intern.................................. 61

Organizational Citizenship Behavior (OCB)...................... 61

Counterproductive Work Behavior (CWB) ........................ 61

Psychosomatic Health (PSI) ........................................... 62

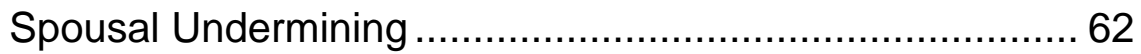

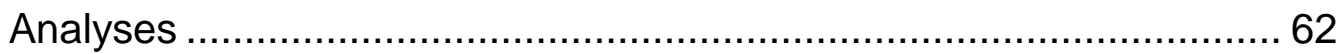

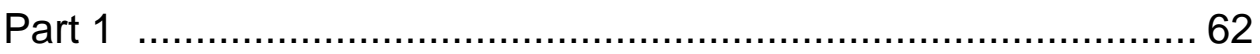

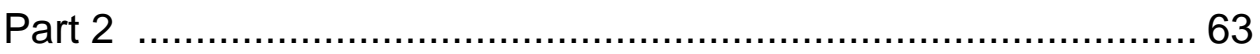

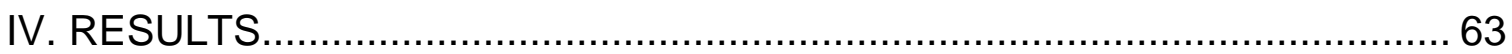

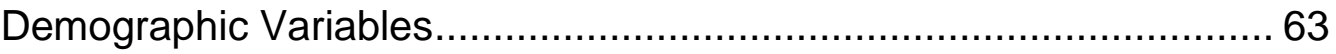

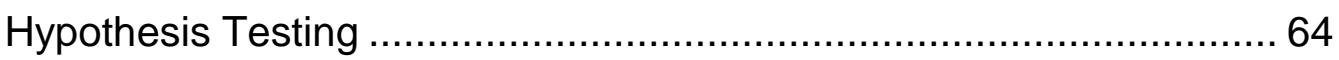

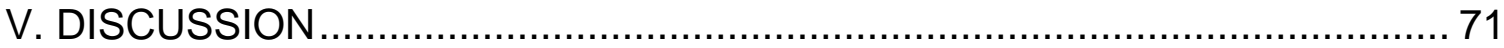

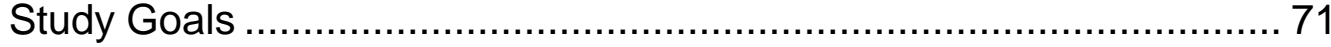

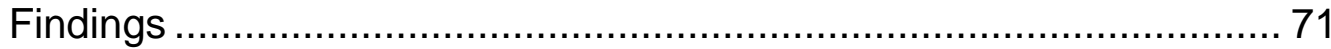

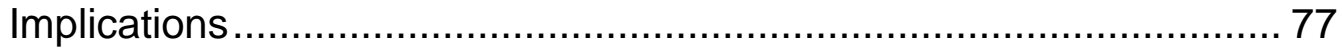




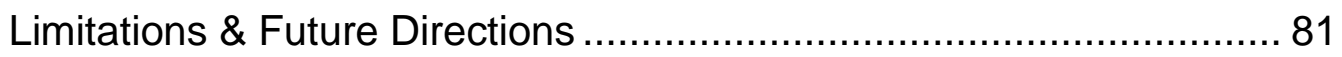

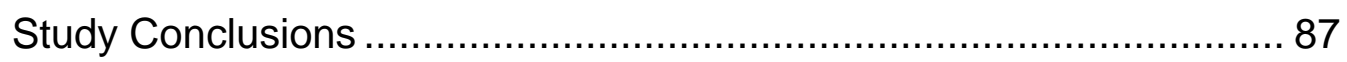

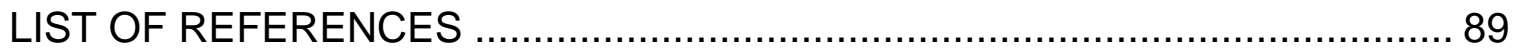

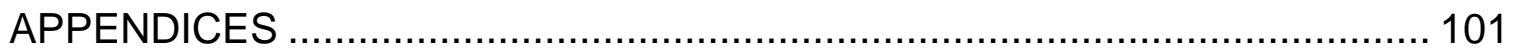

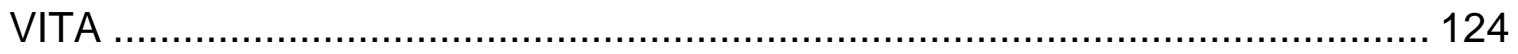




\section{LIST OF TABLES}

TABLE

PAGE

1. Construct Definitions, Assumptions and Sample Overlapping Items ........... 113

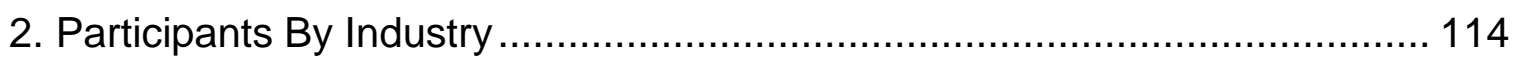

3. Means, Standard Deviations, Coefficient Alphas and Correlations

Between all Study Variables .................................................................... 115

4. Means, Standard Deviations, Coefficient Alphas and Correlations

Between all Study Variables (continued) ................................................... 116

5. Summary of Results from the CFA Analyses.......................................... 117

6. Moderated Regression Analyses for Workplace Aggression, Strain Based

Outcomes and Workplace Aggression Nuance Variables as Moderators ........ 118

7. Moderated Regression Analyses for Workplace Aggression, Strain Based

Outcomes and Workplace Aggression Nuance Variables as Moderators (continued).

8. Sample of Organizational Responses to Workplace Aggression, as

Reported by Participants 120 


\section{LIST OF FIGURES}

FIGURE

PAGE

1. Workplace Aggression Global Construct Model ........................................ 9

2. Workplace Aggression Global Construct Main Effect Outcome Model ........... 10

3. Intent moderates the relationship between workplace aggression and job satisfaction

4. Perceived visibility moderates the relationship between workplace aggression and job satisfaction

5. Moderated regression analyses for workplace aggression, strain based outcomes and workplace nuance variables as moderators 123 


\section{CHAPTER I: INTRODUCTION}

Workplace aggression is a topic of increasing importance in an everexpanding and ever-regulated workplace environment. Workplace aggression is defined by Loeber and Hay (1997) as any behavior that causes or threatens to cause harm to an individual in the work environment. Whether the aggression is expressed through verbal, physical, or behavioral means, the implications on the employees and employer are detrimental and cannot go unnoticed, especially in light of its prevalence and impact in the work domain. Over the past 50 years, research into this construct has become increasingly common, exerting a growing influence on other associated streams of inquiry aimed at understanding the link between this construct and work based outcomes. Thus, as organizations are understandably concerned with factors that may adversely impact employee performance and well-being, research conducted and funded by scholars, organizations, and government agencies, has begun to focus on the prevalence of this construct and its associated outcomes. One such example of a prevalence study is a 1993 US national study conducted by Northwestern National Life Insurance Company which reported that an estimated 16 million instances of reported/experienced psychological aggression by US workers had occurred (VandenBos \& Bulatao, 1996). Further, a study by O'Connell, Young, Brooks, Hutchings, and Lofthouse (2000) reported that $95 \%$ of nurses working in Australian hospitals had experienced some form of verbal aggression more than once during the 12 month preceding the study. Additionally, according to a 2003 British National Audit Office survey found that both violence and aggression 
accounted for nearly $40 \%$ of health and safety incidents reported by healthcare workers (Oostrom \& Mierlo, 2008).

More recently, Schat, Frone and Kelloway (2006) estimated that about 47 million Americans experience some form of physical or psychological workplace aggression each year. Specifically, Schat, Frone and Kelloway (2006) found that nearly $40 \%$ of the US workplace experienced various forms of psychological aggression including being yelled at, insulted, or threatened. This survey also found that nearly $6 \%$ of the US workforce, or approximately 7 million workers, experienced some form of physical workplace aggression such as being slapped, kicked, or even attacked with a weapon. Further, Schat, Frone and Kelloway (2006) found that about $96 \%$ of those 7 million workers reported also experiencing some form of concurrent psychological aggression stemming from a coworker or supervisor. However, while aggression may present itself in many forms in the workplace, it is the psychological forms of aggression that are reported at a higher frequency and are generally though to be precursors to physical forms of workplace aggression (LeBlanc \& Kelloway, 2002).

Having established that workplace aggression is an element of significant concern to organizations, the next step is to offer a thorough conceptualization of the workplace aggression construct along with some of its most common manifestations. The first, and perhaps most important step in this process comes with considering that workplace aggression researchers have typically conceptualized this construct as a stressor. More specifically, Bowling and Beehr (2006) suggest that various types of occupational stressors (e.g., role conflict; 
role overload; role ambiguity; work constraints; and job autonomy) are predictive of an individual's decision to take part in acts of workplace aggression. Further supporting its conceptualization as a stressor, workplace aggression has been defined as a variable that has a significant impact on an individual in their given environment and one that generally results in some sort of negative emotional reaction from the target of the aggressive behavior (DeLongis, Folkman, \& Lazarus, 1988; Spector, 1998). These emotional reactions may vary in intensity over time and can take the form of anger, frustration, or anxiety (Hershcovis, 2011; Nixon, 2011). In this same vein, according to the stimulus-response definition of stress (Pearsall, Ellis, \& Stein, 2009), when an individual experiences a stressor such as workplace aggression, they will appraise that stressor and exhibit a unique negative response in the form of a strain. Central to the present study are these negative emotional responses that manifest in a variety of strain-based outcomes, including increased turnover intent and decreased job satisfaction (Spector \& Jex, 1998). Thus, as research has clearly demonstrated a significant link between workplace aggression, individual emotional responses, and a series of negative workplace outcomes, the rational in conceptualizing this construct as a stressor becomes clearer.

Therefore, having briefly discussed the conceptualization of workplace aggression as a stressor (see chapter 2 for a more thorough discussion), this construct will now be considered in the context of five separate, but related constructs commonly considered as manifestations or types of workplace aggression: abusive supervision (Tepper, 2000), bullying (Einarsen, 2000), 
incivility (Anderson \& Pearson, 1999), social undermining (Duffy, Ganster, \& Pagon, 2002), and interpersonal conflict (Spector \& Jex, 1998). The first of these construct manifestations, abusive supervision, is defined as a "subordinate's perceptions of the extent to which supervisors engage in the sustained display of hostile verbal and nonverbal behaviors, excluding physical contact" (Tepper, 2000 , p. 178). Abusive supervision has been shown to affect nearly $13.6 \%$ of US workers (Schat, Frone \& Kelloway, 2006) and manifests in a variety of ways, including: angry outbursts directed at the subordinate; mocking or ridiculing the subordinate in public; scapegoating behaviors in which the subordinate is forced to take the blame for an action not their own; and failing to give appropriate credit to a subordinate for success (Keashly, Trott \& McLean, 1994). In terms of the consequences to the subordinate, Tepper (2000) found that abusive supervision was related to a variety of individual outcomes ranging from psychological distress to work-family conflict.

Bullying, the second construct manifestation, has been defined by Einarsen (2000) as a situation in which an individual is repeatedly subjected to negative acts including: constant abuse by co-workers or supervisors; teasing or offensive/hurtful remarks; ridicule; and exclusion from social groups at work. According to a 2010 study by the Workplace Bullying Institute (WBI), an estimated 53.5 million US workers (or $35 \%$ ) reported that they had been bullied at work; with an additional $15 \%$ of US workers reporting that they had witnessed the occurrence of bullying in their workplace. Further, in a European study aimed at exploring the prevalence of bullying among nurses and assistant nurses in a 
Norwegian psychiatric ward, it was found that nearly $10 \%$ of nurses reported that they felt exposed to bullying at work (Matthiesen, Raknes, \& Røkkum, 1989). This same study also found the experience of bullying among this population was significantly correlated to a variety of individual outcomes including burnout, psychological complaints, and poor somatic health.

The third construct manifestation, social undermining, has been defined by Duffy, Ganster, and Pagon (2002), as any behavior that is intended to hinder an individual's ability to establish and maintain the following: a favorable reputation; success in their work; and positive interpersonal relationships at work. While research assessing the prevalence of social undermining is limited, a recent study by Duffy, Ganster, Shaw, Johnson and Pagon (2006) showed that social undermining is strongly related to multiple individual-level and group-level outcomes, including job dissatisfaction, depression, counterproductive work behaviors, and turnover intent.

Incivility, the fourth construct manifestation, has been defined by Andersson and Pearson (1999) as deviant acts that are low in severity and characterized by a vague intent to harm the individual. These verbal or nonverbal acts are generally manifested in the form of offensive and impolite behaviors directed at another organizational member. According to Marks (1996), nearly $89 \%$ of the respondents surveyed in a national poll considered incivility a serious problem in their workplace and nearly $78 \%$ of respondents reported that workplace incivility is a more significant problem now compared to 10 years preceding the poll. In terms of the consequences to the individual, Pearson, 
Anderson and Weger (2001) found that workplace incivility is strongly linked to various behaviors and feelings ranging from social isolation to depression.

The final of the five construct manifestations of workplace aggression explored in this dissertation, interpersonal conflict, has been defined by Spector and Jex (1998) as an organizationally based stressor characterized by disagreements that occur between employees (e.g., a negative social interaction). According to Keenan and Newton (1985), interpersonal conflict is one of the leading sources of work stress and generally occurs when two individuals or peers have one or more disagreements that result in the experience of stress. Additionally, Schwarts and Stone (1993) found that negative social interactions with co-workers are responsible for about $75 \%$ of the at-work situations described by employees as damaging to their workperformance/work-life. From an individual outcome perspective, interpersonal conflict is most commonly experienced by an individual in the form of decreased job satisfaction, feelings of depression, and an increase in ones intent to turnover (Spector \& Jex, 1998).

While each of the five construct manifestations discussed above have been defined as distinctly separate types of workplace aggression, it is the abundance of overlap between them that will become the focus of this dissertation. Therefore, in an effort to explore and ultimately explain this significant overlap, a distinct, overarching model of workplace aggression will be presented. This model, first proposed by Hershcovis (2011), was intended to explore the conceptualizations, uncover the overlap, and propose future 
directions for workplace aggression research. More specifically, the Hershcovis (2011) model proposes that the most commonly utilized assessment of workplace aggression with five different but related constructs, is inadequate in its ability to contribute to our existing knowledge base. Therefore, with the support of meta-analytic evidence, Hershcovis (2011) re-conceptualized workplace aggression to allow for a singularly focused understanding of the relationship between this construct and associated negative work based outcomes. This re-conceptualization was derived from Hershcovis (2011) proposition that workplace aggression may be more useful in a research context if each of the five most common overlapping construct manifestations were combined into one global conceptualization of the workplace aggression construct.

Following the lead of Hershcovis' (2011), and her proposition of a global construct conceptualization of workplace aggression, Nixon (2011) developed the "Workplace Aggression and Moderators Scale (WAAMS)." The WAAMS is based on a combination of items taken from each of the five primary scales used to assess abusive supervision, bullying, social undermining, incivility, and interpersonal conflict. With the primary goal of providing researchers with a singular measure of workplace aggression, the WAAMS was designed to be representative of the unique characteristics of each of the five separate construct manifestations, minus the item and conceptual overlap. 


\section{Purpose of the Dissertation}

In the context of the above discussion and when considering the current economic climate, the notion of a global construct conceptualization of workplace aggression and associated measurement technique is particularly appealing. In response to economic constraints, organizations have become increasingly concerned with bottom line outcomes. In order to assure that organizational objectives are reached, organizations have become increasingly aware of the need to pinpoint negative behavioral patterns that threaten organizational/individual success and well-being. Therefore, in order address the obvious need of organizations to better understand and address the occurrence and consequences of workplace aggression, both the Hershcovis (2011) model and WAAMS Scale (Nixon, 2011) will be utilized. More specifically, the primary goal of this dissertation is to build on the efforts of these two researchers in order to validate the appropriateness and usefulness of a global conceptualization of the workplace aggression construct. In order to accomplish this goal, this dissertation has been broken up into two separate, but ultimately related parts. Part 1 is designed to assess the existence of workplace aggression as a global construct. Part 2 is intended to examine the relationship between a selection of commonly experienced individual strain based outcomes and the global construct conceptualization assessed in Part 1.

Part 1. While there are many different conceptualizations of workplace aggression, five different but related constructs arise most frequently in the research. Thus, the aim of this dissertation will be to investigate the assertion 
that workplace aggression can be assessed as a singular, global construct rather than five separate constructs. The most popular scales of the five workplace aggression components will be administered to study participants. A confirmatory factor analysis (CFA) technique will be utilized for the current study, whereby all of the items for each of the five scales will be loaded onto a single factor and the presence of any conceptual overlap between each of the individual factor measures will be evaluated.

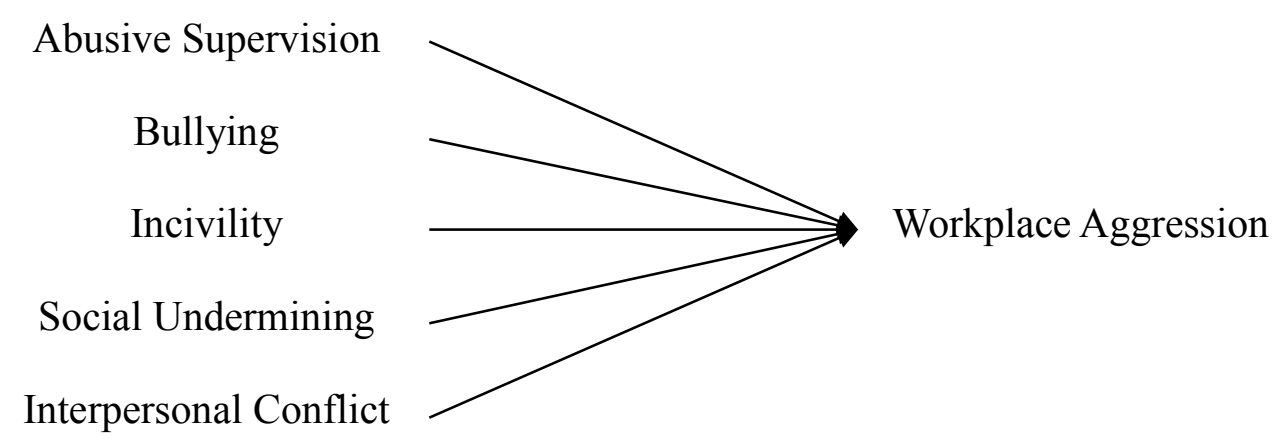

Figure 1: Workplace Aggression Global Construct Model

Part 2. On the basis of the support provided by Part 1 for a global construct conceptualization of workplace aggression, the aim of Part 2 is to explore the proposed relationship between this conceptualization of workplace aggression and a variety of strain based outcomes including: job satisfaction; turnover intent; organizational citizenship behaviors (OCB's); counterproductive work behaviors (CWB's); psychosomatic health; and the quality of interpersonal relationships in the home domain. 


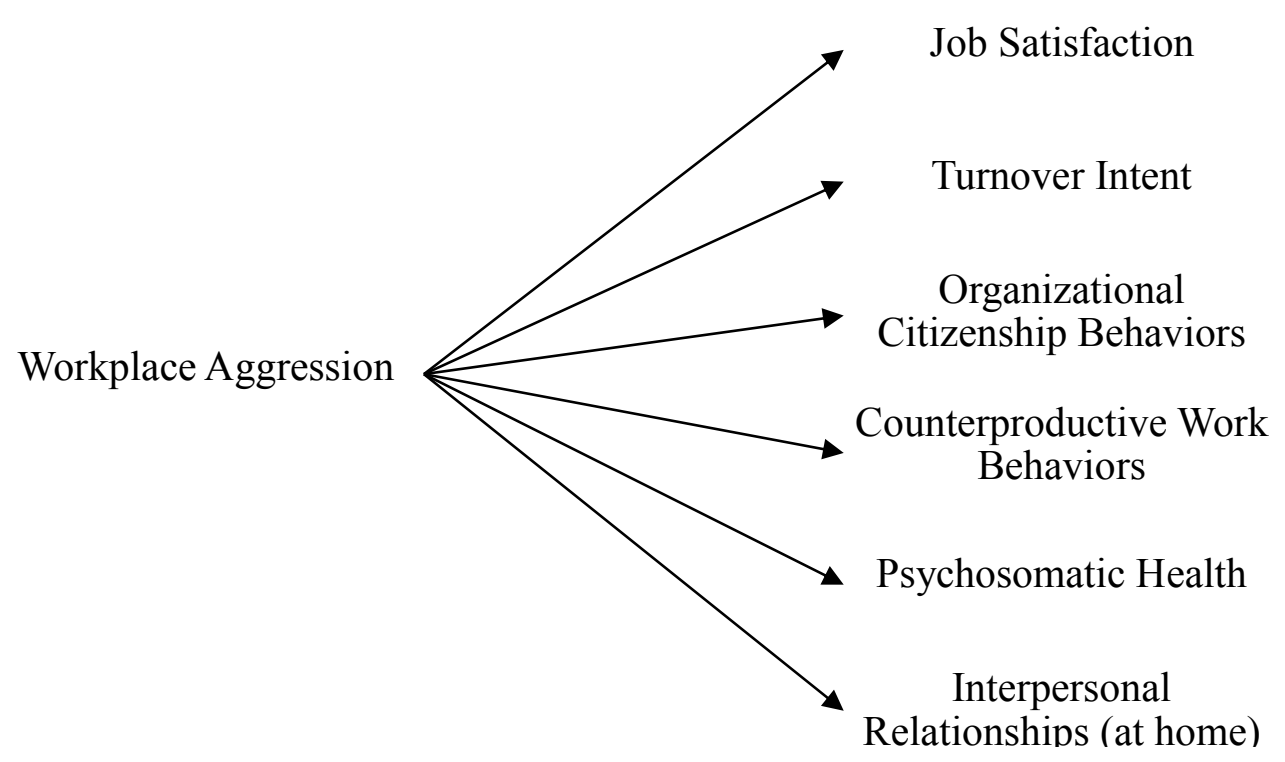

Figure 2: Workplace Aggression Global Construct Main Effect Outcome Model

\section{Summary}

In summary, this dissertation has two main objectives. The objective of Part 1 is to unify the conceptualization of workplace aggression into a global construct (Hershcovis, 2011; Nixon, 2011). The objective of Part 2 is to explore the relationship between a single workplace aggression construct and various personal and organizational strain based outcomes.

The next chapter will provide a thorough review of the existing literature into workplace aggression, the associated strain based outcomes, and individual factors relating to the experience of aggression. The chapter will begin with a discussion of stressors, followed by an exploration of workplace aggression, in the context of stress. Workplace aggression will then be examined with a thorough discussion of each of five commonly accepted construct manifestations of the workplace aggression construct. Next, the overlap between each of these construct manifestations will be considered in an effort to provide support for the 
global construct conceptualization of workplace aggression (Hershcovis, 2011; Nixon, 2011). The third and final section of this chapter will work off of the assumption that workplace aggression is a global construct based on a combination of each of the five different but related constructs manifestations, and will consider multiple strain-based variables as proposed outcomes of this global construct conceptualization of workplace aggression.

\section{CHAPTER II: LITERATURE REVIEW}

This chapter will present a review of the workplace aggression literature and will outline several hypotheses relating workplace aggression and individual/organizational outcomes. The literature review section will begin with a general discussion of stressors, followed by a discussion of workplace aggression in the context of a stress. Workplace aggression will be described according to the five most commonly accepted conceptualizations: abusive supervision, bullying, incivility, social undermining, and interpersonal conflict. Each of these conceptualizations will further be broken down by prevalence, characteristics, and general implications at the individual and organizational levels. Next, the overlap between each of these conceptualizations will be considered in an effort to provide support for the global construct conceptualization of workplace aggression (Hershcovis, 2011; Nixon, 2011). The current dissertation, therefore, has two primary objectives: 1) to integrate and consolidate the various conceptualizations of workplace aggression using a confirmatory factor analysis (CFA), and 2) to provide validity justification for a single overarching construct of workplace aggression. 
The purpose of the final section of this chapter will be to provide evidence to suggest workplace aggression is a global construct comprised of the five commonly accepted conceptualizations mentioned above. Further, the global workplace aggression construct will be used to examine the relationship between aggression and multiple strain-based work outcomes including: 1) job satisfaction; 2) turnover intent; 3) psychosomatic health; 4) OCB's; 5) CWB's; and 6) interpersonal relationships at home.

\section{Workplace Aggression and Stress}

In order to understand workplace aggression as a stressor, it is necessary to understand the conceptual evolution of stress from a historical and research perspective. The most logical starting point for developing such an understanding is with the concept of 'homeostasis', a term refined by Cannon (1932) to describe the body's effort to restore physiological and psychological normalcy whenever a deviation such as a stressor had been experienced by an individual. Tied to the idea of homeostasis, Seyle (1956) described the general adaptive syndrome, which proposes the notion that humans do many things both internally and externally in an effort to cope with the pressures of life (e.g., physiological and psychological adaptations or changing one's environment). This process is comprised of three distinct, interrelated phases: Alarm, resistance, and exhaustion. The first phase, the alarm phase is the point at which a person's physiological response to the stressor begins and he or she utilizes all available resources to manage the stressor. The second phase, the resistance phase, is the phase in which the body begins to first recognize that all of its resources may 
not be necessary to respond to the situation. Finally, during the third phase, the exhaustion phase, the body begins to recognize that its physiological resources have been depleted and makes a second attempt to gather its resources in an effort to manage the stressor. It is important to note that if this second attempt to mobilize resources fails, a "disease of adaptation" can result, which essentially implies that there has been substantial and often irreversible impairment to the individual's physiological systems (Seyle, 1946). In other words, the person has been taxed by the stressor to such a degree that they are no longer able to manage the experience of the stressor and they are likely to experience a series of negative strain based outcomes (Folkman \& Lazarus, 1986).

More specific to the present study and the proposed relationships between workplace aggression and individual outcomes, it is important to recognize the research of Lazarus (1966) and Folkman (1984). Lazarus (1966) was the first to suggest that the experience of stress is the result of a transaction between an individual and their environment. More specifically, the transactional theory is based on the assumption that the impact of a stressor is dependent on an individuals' appraisal of that stressor and their ability to cope with said stressor (Lazarus \& Cohen, 1977). This process can be broken down into three levels of: 1) the primary appraisal which is an individuals' evaluation of the significance of the stressor; 2) the secondary appraisal which is an individuals' evaluation of their ability to manage the stressor; and 3) the coping phase, which is an individuals' effort to manage the stressor, albeit successfully or unsuccessfully (Folkman, Lazarus, Gruen \& DeLongis, 1986). However, Folkman (1984) 
suggested that stress cannot be defined singularly as a property of the person or of the environment, nor can it be simplified into a stimulus-response process (Jex, Beehr, \& Roberts, 1992). Rather, he suggests that in order to truly understand the complex nature of the stress construct, it is essential that the entirety of the person/environment relationship be considered. In order to overcome this research limitation, Folkman (1984) expanded the transactional theory of stress by offering the process-oriented concept of stress, which was derived from cognitive theory (Lazarus, 1966). This advancement in the study of stress highlights the dynamic between the person and their environment and the constantly evolving bidirectional relationship with each impacting and affecting a response on the other. More specifically, the cognitive process oriented conceptualization proposes that each experience of stress is followed by a series of cognitive appraisals: 1) Will this situation or stimuli deplete my capabilities or resources?; 2) Will the stimuli have the potential for personal benefit or not?; and 3) How might I best cope with this situation or stimuli? (Lazarus \& Folkman, 1984).

Strains, which occur when an individual is unable to manage the experience of a stressor, are an individuals' negative response to a stressful experience (Seyle, 1946; Folkman, et. al., 1986). Strains can be divided into three main categories: psychological, physical, and behavioral: Psychological strain has been defined by Spector, Dwyer, \& Jex (1988) as an affective or emotional response (e.g., anxiety, hostility, frustration, depression, etc.). Physical strain has been defined by Ganster and Schaubroeck (1991) as an outcome 
related to health and well-being (e.g., blood pressure, back-pain, headaches, etc.). Mathieu and Zajac (1990) defined behavioral strain as a notable and recognizable decrease in job performance (e.g., absenteeism, turnover, substance abuse, etc.). Within the context of the present study, each of these categories of strain-based outcomes will be assessed in greater detail in the pages to follow. Thus, in light of this discussion of stress, an exploration of the construct of workplace aggression, one of the more relevant and challenging forms of a workplace stressor, is a logical next step in developing a framework for the propositions of this dissertation.

\section{Workplace Aggression}

When considering workplace aggression within the context of a stressor, existing research has almost always separated the overarching construct into five primary constructs (Hershcovis, 2011): abusive supervision (Tepper, 2000); incivility (Anderson \& Pearson, 1999); bullying (Einarsen, 2000); social undermining (Duffy, Ganster, \& Pagon, 2002); and interpersonal conflict (Spector \& Jex 1998). Each construct represents a separate, equally relevant, and often interrelated aspect of overall workplace aggression. In fact, researchers (Hershcovis, 2011; Nixon, 2011) have recently called for a reconciliation of the construct, whereby workplace aggression should be treated as a singular construct that is defined and assessed as a function of a combination of its five sub-constructs. Therefore, in order to justify this singular construct conceptualization of workplace aggression, it is first necessary to examine each of the individual sub-components. A thorough discussion of each construct 
definition and prevalence, the characteristics of the construct in the work domain, and the individual (e.g., job satisfaction, psychosomatic health, and interpersonal conflict at home) and organizational strain based outcomes (e.g., turnover intent, OCB's, CWB's) will be presented. The following section will include an examination of the first of these sub-components, the construct of abusive supervision.

Abusive Supervision. In order to understand what makes supervision abusive, it is first necessary to understand the conceptual meaning of supervision and its intended outcomes from an organizational standpoint. Along these lines, supervision was first defined by Burton (1930), as a globally accepted business practice characterized by the empowerment of subordinates to take on responsibilities and maintain a level of autonomy in their work, accomplished through training, corrective feedback, and motivation. Supervision has further been defined as the process of providing a subordinate with clearly defined tasks and responsibilities accompanied by distinct performance expectations/objectives (Khan, Qureshi \& Ahmad, 2010). This clarity in task and objectives is provided through a number of commonly employed supervisory techniques ranging from participative decision making/management (Vroom \& Yetton ,1973) to the payfor-performance approach (Gerhart \& Rynes, 2003). In participative decision making/management, the supervisor and subordinate work collaboratively to define tasks and task-goals (Vroom \& Yetton, 1973). In the pay-for-performance approach the supervisor uses monetary incentives as a means of motivating the subordinate to reach his or her task-oriented goals (Gerhart \& Rynes, 2003). 
However, regardless of the approach, the ultimate goal of a supervisor is to have a direct and positive impact on his or her subordinates (Rooney, Gottlieb \& Newby-Clark, 2008).

Integrating the components of general supervision, researchers have begun to hone in on variations of supervision that can be considered abusive. Abusive supervision was first defined by Hornstein (1996), as supervision that occurs when the supervisor gains control over a subordinate through intimidation and by causing fear. Tepper (2000) refined Hornstein's (1996) definition, referring to abusive supervision as any "sustained display of hostile verbal and non-verbal behaviors, excluding physical contact" (p.178). For the purposes of this dissertation, abusive supervision will be defined using Tepper's (2000) conceptualization.

Finally, in terms of prevalence, research has shown an increasingly high prevalence of abusive supervision, with a reported $13.6 \%$ or the American workforce suffering from the negative affects of abusive supervision with some frequency (Schat, Frone, \& Kelloway, 2006). Further, research has shown that abusive supervision comes at a significant price to an organization, with the cost (ranging from increased absenteeism, to increased utilization of healthcare, to decreases in productivity) estimated at nearly $\$ 23.8$ billion annually (Tepper, Duffy, Henle, \& Lambert, 2006).

Characteristics. Although abusive supervision has often been conceptualized as a one-sided construct, it actually involves the reciprocation of behaviors and should, therefore, be considered a relational concept. Thus, given 
the relational conceptualization of abusive supervision, some researchers suggest that the behavior response patterns of the targets are retaliatory in nature, and focused onto the supervisor, and, or the organization (Mitchell \& Ambrose, 2007). This type of reaction is referred to as a direct response to abusive supervision (Restubog, Scott, \& Zagenczyk, 2011). Other research findings suggest that targets have an indirect response pattern, and focus their behavioral response away from the source of the abuse and onto a target in the home environment, such as a spouse (Restubog, Scott, \& Zagenczyk, 2011). The aim of this displaced aggression is to alleviate their emotions without risking their job or further damaging the dynamics with their supervisor (Hoobler \& Brass, 2006). The indirect response type is based on two streams of research: 1) that spillover that can occur between the work and home domains (Williams \& Alliger, 1994); and 2) the transactional model of stress and coping which suggests that a target may have the tendency to refocus their emotions away from the source of the distress and onto individuals in their home environment (Lazarus \& Folkman, 1984).

In terms of its manifestation, while there are physical and non-physical forms of abuse, abusive supervision is more often manifested through nonphysical forms. One of the most common non-physical types of abuse is verbal abuse, which is typically associated with a supervisor directing rude and disgraceful words directly or indirectly at a subordinate (Khan, Qureshi, \& Ahmad, 2010). Verbal abuse may occur in a public or one-on-one setting, and is generally associated with the intent to insult and hurt the feelings of a 
subordinate (Nueman \& Baron, 1997). Abusive supervision can manifest in a variety of forms including ridiculing subordinates in front of others, giving the silent treatment, public criticism, threats, withholding important information, breaking work related promises/commitments, intimidation, and the use of disparaging language (Zellars, Tepper, \& Duffy, 2002).

Organizational/Individual Outcomes. At the individual level, research has shown abusive supervision to be linked to a variety of strain based outcomes including decreased job satisfaction and increased distress (Tepper, 2000). Further, drawing from Seyle's (1974) definition of psychological distress (e.g., a state of mind that is characterized by negative thoughts and feelings relating to anxiety, fear, and depression), Restubog, Scott, and Zagenczyk (2011) found the experience of abusive supervision to have a positive correlation with psychological distress in the work environment. Additionally, Ashforth (1997) found that abusive supervision was positively linked to a series of negative psychological strain outcomes ranging from experiencing feelings of helplessness to experiencing high levels of emotional exhaustion. Further, Zellars, Perrewé, and Hochwarter (2000) suggested that job strains are classically associated with abusive supervision, and manifest in the individual in the form of a series of inter-related outcomes including emotional exhaustion and increased blood pressure. Along these same lines, Shirom, Toker, Berliner, and Shapira (2006) found that emotional exhaustion is negatively related to health outcomes. Additionally, in a study of Canadian students, Schat, Desmarais, and Kelloway (2006) found that abusive supervision is negatively related to 
psychological and physical health. Finally, utilizing the transaction theory of stress (Lazarus \& Folkman, 1984), a study by Restubog, Scott, and Zagenczyk (2011) found that abusive supervision is positively related to interpersonal conflict in the home environment in the form of a variety of spousal undermining behaviors (e.g., criticizing \& demeaning).

At the organizational level, researchers have studied the performance implications of abusive supervision as they relate to outcomes of OCB, CWB, turnover intent, and organizational commitment (Ashforth, 1997; Tepper, 2000; Tepper, Carr, Breaux, Geider, Hu, \& Hua, 2009). First, abusive supervision is positively related to turnover intention and this relationship has been linked to a $5 \%$ increase in the operating cost of organizations (Griffeth, Hom, \& Gaertner, 2000). In a study of Slovanian police officers, Duffy, Ganster, and Pagon (2002) found a positive relationship between the experience of abusive supervision and CWB's in study participants, which is also detrimental and costly to the organization. This relationship between abusive supervision and CWB has also been substantiated in a number of additional studies (e.g., Sulea, Fine, Fischmann, Sava \& Dumitru, 2013; Schaubhut, Adams, \& Jex, 2004), offering additional evidence to support the relevance and importance of abusive supervision research. When considering the more positive side of employee performance, researchers found that some employees go above and beyond the expectations described in their job description (i.e., OCB). Several studies with diverse samples, have found evidence to suggest abusive supervision is negatively related to OCB. One of these studies sampled a group of Chinese 
telecommunication employees and another sampled Air National Guardsmen (Aryee, Chen, Sun, \& Debrah, 2007; Zellars, Tepper, \& Duffy, 2002). As can be seen from the above review of the extant literature, there is clear evidence that abusive supervision, as a form of workplace aggression, is associated with a wide variety of profoundly impactful and potentially damaging individual and organizational. Now that a conceptual understanding and definition of abusive supervision has been established, the discussion will now shift to another form of aggression, bullying in the workplace. The next section will address the prevalence, characteristics, and outcomes associated with bullying.

Bullying. Bullying is a construct that has drawn considerable attention over the past 30 years and is defined as the abuse and/or criticism of an individual, in a private or public setting, that serves to demean or humiliate the individual (Adams, 1992). More recently, Einarsen (2000) refined Adams' (1992) definition and suggested that bullying manifests as "systematic aggression and violence targeted towards one or more individuals by one individual or by a group" (p. 381). Key to this definition, and receiving consistent support from researchers, is the belief that bullying is a high frequency behavior in the workplace. To this point, in a study conducted by Mikkelesen and Einarsen (2002), about $88 \%$ of a 224 person sample of Danish manufacturing workers reported that they had experienced at least one act commonly associated with bullying over the course of the previous six month period. From those reporting at least one act of bullying, about $8 \%$ of respondents reported that they had been exposed to at least one act of bullying per week during the previous six month 
period. Taken together, these findings provide support for the claim that bullying in the workplace is not only common but also recurrent in nature (Olweus, 1991; Einarsen, 2000). However, while these findings on prevalence are substantial, it is important to note that more moderate estimates ranging anywhere between $10 \%$ and $20 \%$ have been found in a recent meta-analysis (Nielsen, Matthiesen, \& Einarsen, 2010).

Characteristics. Leymann (1990), in discussing bullying alongside psychological terror, offered that there are five possible characterizations of bullying behaviors, each focused on damaging the target in some way: 1) actions directed at damaging the reputation of the target; 2) actions focused on negatively affecting the ability of the target to perform work tasks; 3) actions aimed at hindering the ability of the target to communicate with co-workers; 4) actions directed at damaging the social circumstances of the target; and 5) threats or actions in the form of coercion or physical assault aimed at the target. More specific to the nature of the bullying behavior, Brodsky (1976) offered that the target of bullying is often subjected to behaviors including being teased, badgered, or insulted.

From the developmental standpoint, bullying has often been described as a gradually escalating process that may be deliberate or unconscious, whereby bullying behaviors increase in frequency and intensity over a period of time. According to Vie, Glaso, and Einarsen (2011), the first phase of the process is one in which the bullying may be subtle and even indirect and, therefore, difficult for the target to recognize as negative in nature. However according to the same 
authors, the process worsens with the behaviors becoming more intense and direct in nature. At this point, the bullying enters its second phase, a period marked by an increase in the frequency of the bullying behavior. During this phase, the target has fully developed an awareness of the bullying behavior. As feelings of humiliation increase as a result of the ridicule at the hands of the perpetrator, the target is likely to begin isolating themselves in an effort to avoid the negative behavior (Leyman, 1996). As the bullying behavior continues to escalate in frequency and magnitude, the process enters its third phase. This phase is characterized by feelings of being pilloried by the increasingly harsh attacks. The target often begins to feel that they are unable to escape the bullying behaviors. It is at this point that the target may begin to experience individual level stress related outcomes or symptoms commonly associated with the increase in frequency and magnitude common to bullying.

Adding to the conceptual understanding of bullying, Olweus $(1978,1991$, 1993), known for work with schoolyard bullying, has suggested that bullying implies that there is an actual power/strength difference between the target and perpetrator of the bullying behavior. Along these same lines, Neidl (1996) suggested that without a consideration of the power difference, it is not possible to completely understand the origin and or experience of the bullying behavior. Further, Neidl (1996) proposed that an individual will only be exposed to bullying should they perceive themselves as unable to defend themselves or escape from the situation. According to Neidl (1996), it is this dependency on the perpetrator 
that characterizes the significance of understanding the power relationship between target and perpetrator in a given situation.

Organizational/Individual Outcomes. As demonstrated in the previous section, research has continually shown a high frequency of bullying behaviors in the workplace, with the associated behaviors linked to a wide variety of organizational and individual strain-based outcomes. Specifically, from the organizational perspective, research examining workplace bullying has shown this construct to be significantly linked with various outcomes including increased turnover intent and increased absenteeism (Mikkelsen \& Einarseon, 2002; Hauge, Skogstad \& Einarsen, 2010). However, the bulk of research remains focused on individual strain-based outcomes, beginning with a 1976 study by Brodsky, who was the first to suggest that a very real negative link exists between the experience of bullying and the health and well-being of bullying victims. Further, Brodsky (1976) found that the dynamic of this bullying encounter is frequently characterized by the target feeling disempowered in their ability to confront the perpetrator and ultimately end the bullying behavior. Additionally, and also from the attitudinal standpoint, research has also shown that bullying is related to a decrease in job satisfaction (Mikkelsen \& Einarseon, 2002). Generally speaking, it can be inferred that individuals confronted with bullying behaviors tend to feel a loss of power and control in their work environment, and therefore, are likely to become dissatisfied with many or all elements within the work context. 
When focusing on the individual strain-based health outcomes, research has shown that targets often report significant consequences to their overall health and well-being (Matthiesen \& Einarsen, 2001). Specifically, research has shown that those employees who experience bullying are more likely to report mental fatigue and a variety of psychosomatic symptoms than their co-workers who are not exposed to the same bullying experience (Agervold \& Mikkelsen, 2004). Additionally, Mikkelsen and Einarseon (2002) found that bullying was positively correlated with psychological health complaints, including symptoms of anxiety and depression; and moderately correlated with psychosomatic health complaints, including dizziness, stomachaches, and chest pain. Furthermore, Vie, Galso, and Einarsen (2011) discovered the existence of a strong positive correlation between an employee's experience of bullying and the experience of a variety of psychosomatic (e.g., decreased appetite, headaches, and fatigue) and psychological health complaints (e.g., nervousness). As can be seen from past research, workplace bullying has been strongly linked to a wide variety of strain-based outcomes, each of which can impact the ability of an individual and the organization to function in a manner that is indicative of a healthy process. Having established a clear working definition of the construct, and presented a thorough discussion of its impact at the individual and organizational level, the next workplace aggression construct to be considered will be social undermining.

Social Undermining. In order to understand social undermining, it is first important to understand and define the source of this construct as the social relationships that exist between people in a given context (i.e., interpersonal 
relationships) (Duffy, Ganster, \& Pagon, 2002). Workplace interpersonal relationships are defined as any positive or negative interaction that occurs between employees within or outside of the formal work context. These relationships are essential in determining how an organization functions and performs, both internally (e.g., communication between co-workers) and externally (e.g., effective customer service; Duffy, et al., 2002). Social undermining, thus, focuses on the negative side of social relationships at work.

Although first introduced by Vinokur and Van Ryn (1993), social undermining was conceptually defined by Rook (1984) as "problematic exchanges" between members of a work group characterized by behaviors on the part of a perpetrator that result in target level feelings of distress and a propensity to distrust the perpetrator. More recently, the construct of social undermining has been defined by Duffy, et. al. (2002) as "behaviors intended to hinder, over time, the ability to establish and maintain positive interpersonal relationships, work-related success, and favorable reputation (p. 332)."

Characteristics. Having established an operational definition of social undermining, it is next necessary to establish those characteristics required to establish the existence and or experience of this construct in a work context. According to Duffy, et. al. (2002), there are four primary elements needed to confirm the existence of social undermining. First, a behavior is not classified as social undermining if it is not perceived as such by the target. In a work context, for example, social undermining would occur if a co-worker or supervisor failed to provide information to an employee that is necessary for completion of a work 
task and the employee perceived or recognized the behavior as being ill intentioned.

The second essential element in the classification of behavior/s as social undermining is the gradual process by which they impact the target. In other words, these behaviors are characterized by their low intensity, reoccurring nature, and cumulative impact effect on the target. In a work context, if the information necessary for task completion is withheld from an employee one time, then that behavior would not be undermining. However, if information is withheld from the employee by the same perpetrator on multiple occasions, then that same behavior would fall within the construct domain (Duffy, et. al., 2002).

The third element required to characterize a behavior as social undermining is the direct or indirect nature of the behavior (Duffy, et. al., 2002). Direct forms of social undermining are highlighted by their clear intent to cause harm and distress to the target (i.e.., making negative and or damaging comments about an individual, rejection of ideas, etc.). Indirect forms of social undermining, on the other hand, are often subvert in nature and may be difficult to recognize as social undermining (i.e., preventing someone from performing a work task by withholding relevant information; or making a conscious choice not to stand-up for a co-worker or subordinate in a situation where they may be wrongly blamed or made liable for a undesirable work outcome).

The fourth and final element essential in the proper characterization of a behavior as social undermining is the verbal/physical differentiation. Verbal behaviors can range from the act of making derogatory and or hurtful/damaging 
comments about an individual (active) to an intentional failure to provide relevant task related work information to an individual (passive). Physical behaviors, on the other hand, are those that are aimed at causing direct harm to the target through intentionally failing to provide necessary work-task related resources, such as safety devices or tools, thus slowing or even halting work progress (Duffy, et. al., 2002).

Organizational/Individual Outcomes. Duffy, et. al., (2002) categorized the outcomes associated with the experience of social undermining by one of two source types: the supervisor and the coworker. The rationale behind this differentiation is based on the concept of within domain exacerbation (Major, Zubek, Cooper, Cozzarelli \& Richards, 1997), which proposes that undermining behaviors from a specific source responsible for providing support to the target, such as a supervisor, will be linked to higher levels of negative outcomes. In order to assess this, Duffy, et al., (2002) first considered the supervisor as the perpetrator, and found that with this source, social undermining behaviors were positively related to a series of individual and organizational outcomes, including active and passive CWB's, decreased organizational commitment, and somatic complaints. Next, they considered the coworker as the source of the social undermining, and found similar behavioral outcomes, including active and passive CWB's and somatic complaints. However, they did not find support for a relationship between coworker social undermining behaviors and organizational commitment. These findings seem to suggest that when undermining behaviors originate from the level of the coworker, they may be perceived as less of a 
threat and their intent less clear in the eyes of the target. In comparison, the undermining behaviors originating from the supervisor are generally perceived as more threatening. In support of this notion, Duffy, et. al., (2002), citing the workplace social contract literature of Morrison and Robinson (1997), suggested that social undermining behaviors perceived as violations of the workplace social contract (e.g., the "unwritten agreement of acceptable and unacceptable workplace behaviors) may result in a variety of negative organizational and individual sourced strain-based outcomes.

Overall, it seems quite apparent that research must pay particular attention to uncovering and understanding the source of social undermining behaviors in order to fully understand the magnitude and orientation of their impact on the individual and the organization. As can be inferred from the aforementioned literature, the implications of social undermining are undoubtedly significant and demands organizational attention. The evidence supporting the prevalence and potential for causing individual and organizational harm is undeniable. Now that social undermining has been defined and discussed, the next construct to be considered will be interpersonal conflict.

Interpersonal Conflict. Spector and Jex (1998) defined interpersonal conflict as an organizational stressor underlined by overt or covert employee disagreements, either verbal or physical in nature. More recently, Barki and Hartwick (2001) took the definition further and proposed that in order for a behavior to be classified as interpersonal conflict, each of the following four properties must be satisfied: disagreement, interdependence, negative emotion, 
and interference. The first property, disagreement, occurs when individuals differ in their opinions, values, goals, objectives, etc. (Barki \& Hartwick, 2001). The second property, interdependence, refers to the process whereby goal attainment of one or more individuals is dependent, at least in part, on the actions of another individual or individuals (Barki \& Hartwick, 2001). The third property, negative emotion, is related to an individual or individuals' experience of negative emotions as a result of conflict (Barki \& Hartwick, 2001). The fourth and final property, interference, occurs when the actions of one or more individuals impact the objectives of another individual or individuals (Barki \& Hartwick, 2001). However, upon further analysis, while Barki and Hartwick found negative emotion, interference, and disagreement to be strongly correlated with one another, the same was not found with interdependence. Thus, this property was dropped from their conceptualization of this construct. The resulting framework consisted of the components of negative emotion, disagreement, and interference.

In an early study of the prevalence of interpersonal conflict in the workplace, Keenan and Newton (year) found $16.2 \%$ of their sample reported that interpersonal conflict to be a significant stressor in their workplace. In this study, interpersonal conflict was the third most frequently reported form of organizational stress. In further support of it prevalence, a study assessing the experience of stressors in the workplace, reported that $25 \%$ of its respondents reported that issues of an interpersonal nature are the most troublesome stressor they had experienced in their work environments (Smith \& Sulsky, 1995). 
Additionally, in a self-report study focused on the occurrence of various forms of workplace conflict, respondents reported experiencing stressors of an interpersonal nature on $50 \%$ of their workdays (Hahn, 2000). Accordingly, as it is apparent that this construct does have a real and profound impact on individuals, the next step is to uncover the key characteristics of this construct in the work context.

Characteristics. With a clear definition of interpersonal conflict established, the next step is to examine its characterization as one of two possible types (Pinkley, 1990; Jehn, 1994; \& Jehn, 1995). The first type of interpersonal conflict, task conflict, is associated with differing viewpoints or perspectives that may exist between individuals on the objectives relating to a given work task. In particular, if a work team is assigned with the task of redesigning a company logo, interpersonal conflict of the task type could arise should members of the team disagree in their view over how to proceed with the logo design process (e.g., differences in the interpretation of the assignment or differences in their preference for the logo design). The second conflict type, relationship conflict, is associated with emotional and or personality differences between two or more individuals. For example, if a work team is assigned the task of fundraising for an upcoming corporate event, and one or more members of the group exhibit an unwillingness and or discomfort with the social networking element of this process, any disagreement that arises between individuals could be attributed to relationship conflict stemming from differences in personality type (e.g., high vs. low in extraversion). 
Thus, having established a working definition of this construct, as well as highlighting its key characteristics, the next logical step in the discussion of this construct is to shift the focus onto a discussion of the most commonly associated individual and organizational strain-based outcomes.

Organizational/Individual Outcomes. From the organizational perspective, Spector and Jex (1998) considered this construct alongside a series of behavioral based organizational level outcomes including: intention to quit, decreased job performance, and absenteeism. Their findings demonstrated that interpersonal conflict is shown to have a positive relationship with the intention to quit. Along these same lines, the findings of Frone (2000) demonstrated a positive correlation between interpersonal conflict and intention to quit, and a negative correlation between organizational commitment and interpersonal conflict. Chen and Spector (1992) reported similar findings, with a strong positive correlation found between turnover intent and the experience of interpersonal conflict. Further, multiple studies have reported the existence of a positive relationship between the experience of interpersonal conflict and CWB's including: deviance (Robinson \& Bennett, 1995), antisocial behaviors (Giacalone \& Greenberg, 1997), and interpersonal aggression (Chen \& Spector, 1992).

From the individual perspective, Spector and Jex (1998) considered a series of individual level outcomes including decreased job satisfaction and negative health outcomes (e.g., anxiety and depression). The findings of this study demonstrated that employees reporting higher levels of interpersonal conflict at work, also displayed lower levels of job satisfaction. Further, according 
to the findings of Bolger, DeLongis, Kessler and Schilling (1989), interpersonal conflict is the most important stressor having an influence on an individual's experience of psychological distress. Additionally, a research has also demonstrated a positive correlation between interpersonal conflict and stress (Frone, 2000; Heinisch \& Jex, 1997; Spector \& Jex, 1998). Spector, Dwyer, and Jex (1988) also found a positive correlation to exist between interpersonal conflict and the outcomes of anxiety and frustration. In addition, Bruk-Lee and Spector (2006) found that interpersonal conflict is positively correlated with overall negative emotions. Further, both Frone (2000) and Hahn (2000) found that a positive correlation exists between the experience of conflict in the workplace and reported somatic (health) symptoms. Finally, both Spector and Jex (1998) and Frone (2000) found a negative correlation between job satisfaction and interpersonal conflict.

Overall, it can be inferred from these findings, both at the organizational and individual levels, that interpersonal conflict has consistently demonstrated a strong link to a variety of strain-based outcomes. The literature presented provides a clear picture of the interpersonal conflict construct in terms of definition, prevalence, characteristics, and associated outcomes. The final workplace aggression construct that will be discussed using the same process is incivility.

Incivility. Before exploring the construct of incivility, it is important to provide context by defining its counterpart, civility. Civility is most simply defined as being respectful and courteous to an individual or individuals. In the work 
context, civility has been defined by Pearson, Andersson, and Porath (2000) as a behavior "that helps to preserve the norms for mutual respect at work; it comprises behaviors that are fundamental to positively connecting with another, building relationships and empathizing" (p. 125). Specifically, civility is demonstrated through a series of acts aimed at demonstrating genuine concern for and awareness of your coworkers (i.e., humility; Carter, 1998). A civil act in the workplace could be something as simple as holding the door for someone or as substantial as providing an accommodation to a coworker in need. Central to a positive and successful work environment is the ability of workers to collaborate and strive toward common goals; to facilitate the individual skills of respective workers; and to remain sensitive and responsive to an organization's established norms of acceptable behavior (Solomon, 1998).

Early researchers commonly defined incivility as "low intensity antisocial behavior that occurs at work" (LaGrange, Ferraro, \& Supancic, 1992, p. 312). Most recently, Pearson, Andersson, and Wegner (2001) defined incivility as "lowintensity deviant behavior with ambiguous intent to harm the target, in violation of workplace norms for mutual respect. Uncivil behaviors are characteristically rude and discourteous, displaying a lack of regard for others" (p. 1397). With Marks (1996) reporting that approximately $89 \%$ of respondents in a US News and World Report survey indicate incivility as a significant workplace problem, this has become one of the most frequently studied constructs of workplace aggression (as cited in Pearson, Andersson, \& Porath 2000). In further support of the prevalence of incivility, a study examining the 644 members of a southeastern 
Bar Association, $66 \%$ of the participants reported that unprofessional conduct and incivility were significant problems in their work environment (Wegner, 1996). Additionally, Cortina, Magley, Williams and Langhout (2001) found that $71 \%$ of public-sector employees surveyed reported some experience of workplace incivility during the previous 5-year period. These numbers support the notion that incivility in the workplace is a real problem for organizations

Having established a definition of incivility, the focus turns to establishing a context in which acts of civility are replaced by acts of incivility and how that transformation impacts the organization and the individuals within the organization. In other words, the following questions must be answered: 1) how does incivility manifest; and 2) once it becomes a real factor in the workplace, what implications does it hold for the organization and for the workers?

Characteristics. Incivility is characterized by the manner in which it disrupts patterns of work and ultimately work-flow. In particular, workplace incivility is linked to a decrease in satisfaction with the organization and individual performance on key work tasks. Further, researchers have suggested that incivility can act as a "gateway" to other forms of workplace aggression which may have an even more significant, damaging, and long lasting impact on the individual and organization (Pearson, Andersson, \& Porath 2000). As a blatant act of disregard for other individuals in the workplace, incivility involves a violation of organizational norms with the clear and implicit intent of disrupting or preventing the existence of "mutual respect". Furthermore, incivility is best characterized as an interpersonal event that occurs between two or more 
individuals or groups of individuals (i.e., a social interactions process; Pearson, et. al., 2000). The characteristics of incivility make it a difficult for researchers and managers to detect and fully comprehend. Inherent in the construct is the belief that incivility is ambiguous in its intent to harm, it has low intensity, and typically originates from a supervisor or person of high profile while directed at a subordinate, or person of lower organizational profile.

In order to further characterize this construct as a source of disruption to the "mutual respect" between individuals in the workplace, research has suggested that there are two specific conditions contributing to this process: 1 ) shifts in the social context, and 2) organizational pressure (Pearson, et. al., 2000). Shifts in the social context are thought to be changes to the psychological contracts that exist in the workplace. These psychological contracts are intended to be reflective of a mutually beneficial and symbiotic relationship between employees, co-workers, and their organization. However, these psychological contracts are susceptible to shifts/changes in individuals perception about what is in their own best interest vs. what is in the best interest of the organization (e.g., loyalty, retention, entitlements, etc.). It is this perceptual shift that can contribute to the development/manifestation of uncivil behavioral patterns (Pearson et. al., 2000).

Organizational pressure is most typically associated with organizational uncertainty originating from corporate downsizing, restructuring, technology innovations, and cost/spending constraints, etc. (Pearson, et. al., 2000). These organization level changes contribute to feelings of anger and fear, and may 
result in a reduction of organizational commitment, and diminished attention to detail on key work tasks. In other words, when an individual feels pressure from their organization, that pressure can be appraised as unrealistic or difficult to manage, and thus, the individual may display diminished motivation or feel decreased alignment with their organization.

As a result of each of these shifts, an individual's reaction will take one of two forms: a direct response type or an indirect response type (Andersson \& Pearson, 1999). A direct response type would occur when one individual questions the reputation of another. An indirect response type, on the other hand, occurs when someone withholds information from another that is relevant to the completion of a job task.

Organizational/Individual Outcomes. From the organizational perspective, the implications of incivility range from employee dissatisfaction and a failure to meet organizational performance objectives, to high rates of absenteeism and turnover intention (Andersson \& Pearson, 1999). The research suggests that employees who experience incivility may be more likely to leave their job in order to avoid the negative experience and atmosphere. This increase in turnover intent and subsequent voluntary turnover may contribute to higher absenteeism, as well as negative implications on a company's customer base (Neuman \& Baron, 1998). In other words, should an employee grow tired of incivility in the work domain and choose to leave their job, the customers they serve will be indirectly affected by the experience of incivility and associated strain-based organizational outcomes (e.g., turnover intention). Of additional 
significance is the perception often held by organizational leaders, that incivility is less significant in the grand scheme of workplace aggression and thus, does not require that the same attention be paid to in creating solutions to combat its existence/occurrence (Pearson, et. al., 2000). Therefore, if employees begin to recognize that the leadership has turned a blind eye to the existence of incivility, then they are more likely to become disengaged and dissatisfied with the organization, thus negatively impacting organizational outcomes. Overall, the existence of incivility from an organizational standpoint has implications that are far reaching, well beyond the walls of the organization. These organizational implications, as with other forms of workplace aggression, can turn a seemingly innocuous form of workplace aggression into a very real and significant concern for an organization (Pearson, et. al., 2001). Lastly, according to Kamp and Brooks (1991), if incivility were to go unchecked (e.g., vandalism in the workplace) the negative behaviors associated with it might contribute to the reconceptualization of organizational norms (e.g., vandalism becomes an acceptable workplace behavior). If this were to occur, individuals may engage in more frequent acts of incivility, viewing them as a socially acceptable norm in the workplace. Further, individuals may become disengaged from the organization and from their individual work responsibilities. Regardless of which response were to occur, there would likely be significant consequences to the organization in the form of reduced organizational level performance, diminished productivity, and a reduction in customer satisfaction (Pearson, et. al., 2001). 
From the individual standpoint, incivility has been linked with a variety of strain-based outcomes including negative affective states, withdrawal, anxiety, and depression (Pearson, et al., 2001). Pearson et al., (2001) utilized a sampling approach in which they collected self report information from participants pertaining to their own perceptions of, and feelings relating to, the experience of incivility. The responses of their participants included feelings of withdrawal, anger, uncertainty as to why the organization had seemingly condoned the incivility, and even a desire to reciprocate the incivility onto the perpetrator(s). However, research has cautioned that these individual outcomes may not be entirely generalizable and may, instead, be due to the following target perceptions: individual differences such as personality type, temperament, and impulsiveness (Baumeister, Heatherton, \& Tice 1994; Hynan \& Grush, 1986); the power difference between the perpetrator and target of incivility (Patchen, 1993); and gender differences (Porath \& Pearson, 2000). Specifically, with regard to gender differences associated with incivility (Pearson, et. al., 2000), research suggests that men are most likely to be the perpetrator of incivility, nearly $70 \%$ of the time, while women are perpetrators of incivility only $30 \%$ of the time. Research also suggests that men are more likely to respond to incivility aggressively (Eagly \& Steffen, 1986), whereas women are more likely to remove themselves from the situation (Fletcher, 1999).

Overall, existing research has shed considerable light on the existence of incivility in the workplace and its' implications on organizations and individuals. The same evidence has also been provided for each of the other four constructs 
considered central to developing a complete understanding on the workplace aggression construct. Therefore, as each construct has been thoroughly defined, their prevalence and characteristics discussed, and their relevant strain-based outcomes uncovered, the focus will shift to assimilating this information in an effort to provide justification for the central theme of this dissertation, the overarching global conceptualization of workplace aggression. The next step, central in establishing sufficient justification for the proposed global conceptualization, is a thorough discussion of the areas in which the five workplace aggression constructs overlap with one another in terms of target attributions, characteristics, and scale items.

\section{Workplace Aggression: Existing Measurement Concerns}

It is the position of this dissertation that the justification for the proposed global construct conceptualization of workplace aggression can best be understood through a thorough consideration of three key areas in which each of the five constructs overlap with one another: attributions (i.e., intent, intensity, frequency, perceived visibility, and power relationship); characteristics; and scale items. Thus, the following discussion will focus on a sampling of overlap in each of these three areas in order to provide further support to the notion that measurement in its current state is fragmented, and therefore, should be unified.

Individual Attributions and Characteristics. While the present study will not specifically test attribution variables as moderators, as was proposed by Hershcovis (2011), their mention is particularly relevant in developing a complete picture of measurement issues surrounding the proposed global construct 
conceptualization of workplace aggression. In attempt to overcome the challenges associated with the measurement of workplace aggression, Hershcovis (2011) suggested that a logical way to proceed with the proposed reconceptualization of workplace aggression would be to utilize some of the overlap features as moderators between the singular construct conceptualization of workplace aggression and significant work related outcomes. Furthermore, Hershcovis (2011) proposed that by adopting this strategy, it would allow for the primary difference between each of the factors to rest in the way in which a target perceives the workplace aggression: in terms of the intent; the intensity; the frequency; the perceived visibility; and the power relationship. For further clarification and a list of proposed linkages between these individual attributions variables and the five constructs of workplace aggression discussed in this study, please refer to Table 1.

Intent. The first attribution variable, intent, comes from Baron's (1977) definition of human aggression and refers to the perception held by the target of the perpetrator's intent or desire to cause harm through their aggressive behavior. Potential for blame is a key attribution and is commonly associated with revenge behaviors (Aguino, Tripp, \& Bies, 2001). The implications of this process are clear, suggesting that if a target perceives a clear intent to cause harm on the part of the perpetrator, then the likelihood of taking part in some form of revenge behavior is greater. As a result, these retaliatory or revenge behaviors can be damaging at both the individual and organizational levels. When considering the five proposed constructs of workplace aggression, intent is an attribution element 
typically associated with each of the following: social undermining, where the intent is clear; incivility, where the intent is ambiguous; bullying, where the intent is assumed but not explicitly stated; and abusive supervision, where in certain manifestations, the intent may be implied. When considering the construct of social undermining, intent is implicit in the definition, which suggests that associated behaviors are "intended to hinder" (Duffy, et. al., 2002). Similarly, according to Leymann (1990), bullying is characterized by actions that are focused on damaging the target in some negative way (e.g., their ability to work; their reputation; their social circumstances; their ability to communicate with others; or, in the most extreme of circumstances, their physical or psychological well being). Likewise, incivility is characterized by its "ambiguous intent to harm the target" (Pearson, et al., 2001). Finally, when considering abusive supervision, specifically when it manifests in the form of verbal abuse, this construct is generally associated with an intent to affront or hurt the feelings of a target, often in a social setting (Neuman \& Barons, 1998).

Noticeably absent from the discussion around the intent attribution is the construct of interpersonal conflict, perhaps because interpersonal conflict is characterized by a disagreement between two individuals (Spector \& Jex, 1998), or because of the challenges in quantifying intent in situations of interpersonal conflict. One challenge that arises involves a disagreement, which implies differences in the way two individuals think about or interpret something. A second challenge involves interdependence, which occurs when the ability of one person to reach their goals is dependent on the actions of another. Sometimes in 
instances of interpersonal conflict an individual's emotional reaction to conflict can complicate the situation. Another challenge, interference, occurs when the actions of one individual impact the objectives or another. Taken together, it becomes obvious how these various challenges serve to complicate efforts to quantify the manifestation of this construct (Barki \& Hartwick, 2001).

Intensity. The next attribution variable, intensity, refers to the target's perception of the severity of the aggressive behavior enacted by the perpetrator (Barling, 1996). However, unique to this attribution is the way in which it seems to differ in accordance with each of the five constructs of workplace aggression. The behaviors associated with workplace incivility are characterized by their low severity and gradually increasing intensity (Anderson \& Pearson, 1999). One of the most widely accepted definitions of abusive supervision is a "sustained display of hostile... behavior (Tepper, 2000 p.178)". Though it is not implicit in the definition, abusive supervision includes a cumulative effect on the target, becoming more intense with each encounter. Similarly, social undermining is defined as "behaviors intended to hinder, over time" (Duffy, et., al., 2002), and is characterized by it's the duration of the behavior and the cumulative effect on the target. Alternatively, bullying is characterized by its high severity and immediate intensity (Einarsen, 2000). While such clear construct differences may exist in terms of the exact levels and onset of intensity, there has been consistency among researchers in the belief that should an individual perceive an aggressive behavior as intense, then the strain-based outcomes they experience are likely to 
be severe, and will have an immediate and lasting impact on the individual and organization (Hershcovis, 2011).

Frequency. The third attribution variable, frequency, refers to the number of times an aggressive behavior occurs in a given time frame (i.e., in one week, in one month, in one year, etc). Most commonly associated with the factor of bullying, frequency suggests that a behavior that is perceived to occur at a greater frequency is more significant in terms of its outcomes than a behavior that occurs at a lower frequency. While frequency is not implicitly stated in the definitions of the other four constructs of workplace aggression (i.e., abusive supervision, social undermining, incivility, interpersonal conflict) each is characterized by behaviors that do not occur in isolation. Instead, these constructs are repeated and sustained over some period of time. When considering the outcomes of each form of workplace aggression further, it can be fairly assumed that in order to result in increased absenteeism, decreased job satisfaction, etc., the behaviors occur at some frequency, whether defined or not. However, frequency has received less attention as an attribution variable because researchers have had a challenge teasing out the influence of the frequency attribution from the influence of the intensity attribution on negative work outcomes (Hershcovis, 2011). In other words, when considering the nature of the aggressive act, it is often difficult to determine whether the impact of the behavior on an individual is due to the intensity of the act or due to the frequent at which the act occurs. 
Perceived Visibility. The fourth attribution variable, perceived visibility, refers to the covert (e.g., subtle and passive)/overt (direct and active) nature of the aggressive behavior (Baron, Neuman, \& Geddes, 1999). In other words, this attribution refers to the perception held by the target of how aware other individuals are of the aggressive behavior directed toward them. Key to understanding this attribution variable is whether the aggressive act is overt, and therefore recognized by the target and perceived as apparent to the work group (Verona, Reed, Curtin, \& Pole, 2007); or, whether the aggressive act is covert, and perceived by the target as less obvious to self and others (Verona, et al., 2007). However, it is important to note that with each of the workplace aggression constructs, the behaviors themselves may occur in isolation or in a group setting, and it is this distinction that contributes to the perceptions of the target as to the visibility of the aggressive act.

Bullying can manifest in multiple ways; either as aggression targeted by one individual on another individual, targeted by one individual on multiple individuals, targeted by multiple individuals on one individual, or targeted by multiple individuals on multiple individuals (Einarsen, 2000). Therefore, the perceived visibility of the act is dependent on which variation of the aggressive behavior is experienced by the target or targets. When examining the construct of abusive supervision, it is generally thought to be an aggressive act targeted on a single individual by a supervisor (Tepper, 2000). However, abusive supervision can also occur with multiple targets, or in group settings. In other words, should there be multiple targets, or should the abusive supervision by focused on one 
target, but spill over into a group setting, this will impact the target/s perceptions of the visibility of the aggressive act. Inherent in the definition, interpersonal conflict, can be either covert or overt in form (Spector \& Jex, 1998) and can occur between two or more individual. When occurring between two individuals, the targets perception is more likely to be that the behaviors are not obvious to others. However, those behaviors can spill over into the larger work team, thereby making them more obvious to others, and, at the same time, activating the target's perceptions of how visible the aggressive act may be to the larger group or work team. Further, incivility, which is characterized by its obvious display of a lack of regard for others (Pearson, Andersson, \& Wagner, 2001), can occur when one individual shows a lack of respect to another, or at a larger scale, when that lack of respect is focused on a work team. In the former instance, the perception of the target would likely be that the aggressive behavior is not obvious, and therefore relatively invisible to others within a work team. However, if the actions of the perpetrator carry over to the larger group context, the perceptions of visibility will likely change, with the target/s feeling that others are aware of their experiences. Finally, the most clearly defined of the constructs, in terms of the visibility of the aggressive acts, social undermining is characterized by behaviors that occur in a social context, between members of a work team, and are therefore visible to others (Vinokur \& Van Ryn, 1993). Conversely, abusive supervision is generally perceived to be less visible to others as it is a behavior that occurs between two or more individuals. However, 
if abusive behavior occurs on a larger scale, and the aggression takes place in a group setting, the target's perceptions of visibility may change.

Power Relationship. The final attribution variable, power relationship, refers to the power dynamic that exists between the perpetrator and the target. This power relationship variable refers to the discrepancy in assigned role within a work group. In other words, when considering the occurrence of workplace aggression between a supervisor and subordinate compared with the occurrence of workplace aggression between two peers, the power difference between supervisor and subordinate has been linked with a higher frequency of negative individual outcomes (Hershcovis \& Barling, 2010). The one construct that best signifies this power difference is abusive supervision, with its required definitional component of a role/title difference between the perpetrator and the target of the aggressive behavior. However, while not specific in terms of role/title difference, bullying is another construct which is predicated on a difference in power between two individuals, with the perpetrator possessing/demonstrating obvious power/influence/control over the target (Mikkelsen \& Einarsen, 2001). Likewise, while not implicitly stated in its definition, social undermining is also based on behaviors of a perpetrator that are intended to hinder the targets in their ability to have success in their job. Clear in this dynamic is the effort of one individual, the perpetrator, to gain power by undermining the position of the target (Duffy, et. al., 2002). Similarly, interpersonal conflict is based on disagreements between individuals (Spector \& Jex, 1998), which could occur between individuals of different or similar power status. In the same way, workplace incivility is 
characterized by deviant work-place behaviors (Pearson, Andersson, \& Wagner, 2001), which are themselves rooted in the power difference that exists between the perpetrator and target of incivility (Patchen, 1993). More specifically, incivility typically originates from a supervisor or person of high profile while directed at a subordinate, or person of lower organizational profile (Pearson, et. al., 2000).

Workplace Aggression: Item Review. Workplace aggression research, in the current context, works under the assumption that the examination of individual constructs affords a unique and singular perspective into one particular area of workplace aggression. However, upon closer examination of scale items specific to each of the individual constructs, multiple areas of item overlap become apparent.

The following is a sampling of such examples of item overlap: social undermining, incivility, and abusive supervision all contain items with reference to putting the target down in some way; social undermining and bullying both contain items with reference to insulting the target; social undermining, incivility, abusive supervision, and bullying all contain items with reference to slandering the target; and, lastly, bullying, abusive supervision, and social undermining all contain items with reference to the incompetence of the target. See Table 1 for a list of items, by construct, that overlap with items from other constructs.

Furthermore, in addition to the item overlap, there is also significant overlap in the structure of the scales, each of which is in from the perspective of the target, and each of which is focused on the frequency of the aggressive act. More specifically, the Workplace Incivility Scale (Cortina, Magley, Williams, \& 
Langhout, 2001) is from the perspective of the target, is based on a 5-point likert scale ( $1=$ never, $2=$ once or twice, $3=$ once or twice per week, $4=$ most days, $5=e v e r y$ day) and is focused on assessing with what frequency that individual experiences items associated with this construct. Similarly, the Social Undermining scale (Duffy, Ganster, \& Pagon, 2002), is constructed in a similar fashion, with the perspective that of the target, the identical 5 item response options, and a focus on the frequency of the targets experience with social undermining. Likewise, the Negative Acts Questionnaire-Revised (Einarsen, 2009), assesses bullying through the lens of the target, and with the frequency of the aggressive behavior in mind. Further, this scale, like the Social Undermining Scale and Workplace Incivility Scale, utilize the same 5 items response options. The Interpersonal Conflict at Work Scale, which only differs from the other 3 already discussed scales in item response options, takes a nearly identical approach to assessing the frequency of a targets experience with interpersonal conflict. Finally, the Abusive Supervision Scale (Tepper, 2000), takes a similar approach to the other scales in assessing abusive supervision through the lens of the target. However this scale differs significantly in the 5 item response options, which, while also focused on frequency of the aggressive behavior, are statement based responses (e.g., 1 = "I cannot remember him/her ever using this behavior with me"; 2 = "He/she very seldom uses this behavior with me"; $3=$ "He/she occasionally uses this behavior with me"; 4 = "He/she uses this behavior moderately often with me"; 5 = "He/she uses this behavior very often with me"). 
Thus, having established that there are clear areas of overlap between each of the five constructs of workplace aggression in terms of attribution and construct similarities, items, and scale characteristics, the focus will shift to the central proposition of this dissertation, that workplace aggression can be conceptualized as a singular global construct. The following sections will be centered on synthesizing the above evidence as a demonstration of the appropriateness of this global workplace aggression conceptualization.

\section{Overarching Model of Workplace Aggression}

Having established the general conceptualization of workplace aggression as five different but related constructs, the next step in the present study is to focus on the overlap between each of these constructs. In doing so, support will be offered to suggest that workplace aggression can be assessed as a global construct. Central in establishing this overlap, has been the work of Hershcovis (2011), whose meta-analysis demonstrated that the overlap between the constructs, in terms of outcomes, is considerable enough to warrant a reconceptualization of the workplace aggression construct. It is important to note that in order to establish this overlap, Hershcovis (2011) was particularly interested in considering the relationships between four of the five constructs (e.g., abusive supervision, incivility, interpersonal conflict, and bullying) and work outcomes (e.g., job satisfaction, turnover intent, psychological well-being, physical well-being, and affective commitment). Hershcovis (2011) excluded social undermining from her study as she did not believe that there is a significant enough body of research into this construct to adequately consider it 
alongside the other four constructs, each of which has a more substantial associated body of research. However, for the purposes of the present study, social undermining will be considered alongside the other four constructs as the arguments that have already been present offer adequate support to the inclusion of this construct in the conceptualization of workplace aggression. Further, and critical to the central proposition of this study, social undermining is one of five constructs that were included in the development of the WAAMS Scale (Nixon, 2011), which will be factor analyzed in part one of this study, and used again in part 2 of the present study to assess a series of strain based outcomes.

Having established the outcome overlap between these constructs, Hershcovis (2011) chose the Bowling and Beehr (2006) model of workplace mistreatment as a starting point. Instead of replicating the model exactly, Hershcovis (2011) replaced the source variables or independent variables with a one-factor construct of workplace aggression. The rational for a one-factor structure was supported by the understanding that each factor can also be assessed in terms of their theoretical overlap in addition to their overlap in work outcomes. Specifically, as clarified in Table 1, there is considerable overlap between the characteristics of each of the factors of workplace aggression, a reality that cannot be dismissed when considering the construct of workplace aggression and establishing a greater understanding of its components (Hershcovis, 2011). 
Drawing upon future directions outlined by Hershcovis (2011), Nixon (2011) developed a scale that was based on the combination of each of the five constructs of workplace aggression. This scale was designed to tap into the characteristics representative of each construct alone, as well as the characteristics that represented a clear overlap between constructs. Known as the WAAMS, this scale was designed to measure a global construct conceptualization of workplace aggression. One significant limitation of this study however, was that a clear demonstration of the actual overlap that existed between the five constructs of workplace aggression utilized by the author, was not provided. Thus, it is the intent of the present study to expand upon the work of Nixon (2011) and to consider the actual factor structure of the same five constructs of workplace aggression utilized by Nixon (2011). In accordance with this aim, the current dissertation will set out to test the factor structure of the global workplace aggression construct in an effort to provide additional support to the WAAMS scale (Nixon, 2011). Moreover, the appropriateness of its use as an instrument to assess workplace aggression as one global construct conceptualization will be examined. Therefore, the following hypothesis has been offered concerning the proposed overlap that exists within the workplace aggression framework:

$H 1$ : Abusive supervision, social undermining, incivility, interpersonal conflict, and bullying will be positively correlated and one single factor of workplace aggression will emerge from the data. 
With the central hypothesis proposed, the attention will now shift to Part 2 of this dissertation, which will serve as a validation of the global conceptualization of workplace aggression. Based on the research previously cited, a series of hypotheses are proposed to further assess the construct validity of the WAAMS scale. More specifically, construct validity can be established by exploring the nomological network of the WAAMS as it relates to strain outcomes. Further, convergent validity will be established by demonstrating that the WAAMS is correlated with other measures of similar constructs (e.g., to the specific 5 workplace aggression measures).

\section{Workplace Aggression and Strain Based Outcomes}

Drawing from the existing literature, a variety of attitudinal, behavioral, psychosomatic, and interpersonal outcomes commonly associated with the experience of workplace aggression, have been proposed (Jex \& Beehr, 1991). These outcomes range from psychosomatic health (Spector \& Jex, 1998); to behavioral strains such as intent to turnover (Bowling \& Beehr, 2006); OCB's (Lee \& Allen, 2002); CWB's (Bennett \& Robinson, 2000); attitudinal strains such as job satisfaction (Spector, 1985); and interpersonal relationships at home (Roberts \& Feetham, 1982). Thus, the following set of hypotheses has been offered:

$\mathrm{H} 2$ : Workplace aggression will be negatively related to job satisfaction. H3: Workplace aggression will be positively related to turnover intent. $\mathrm{H} 4$ : Workplace aggression will be negatively related to organizational citizenship behaviors. 
H5: Workplace aggression will be positively related to counterproductive workplace behaviors.

H6: Workplace aggression will be negatively related to psychosomatic health.

$\mathrm{H} 7$ : Workplace aggression will be negatively related to the quality of interpersonal relationships in the home domain.

H8: The WAAMS will be positively correlated with individual level constructs of workplace aggression, including: abusive supervision, social undermining, incivility, interpersonal conflict and bullying.

\section{Present Study}

As noted earlier, the present study is broken up into two interrelated parts. Part 1 is intended to examine evidence in support of a global construct conceptualization of workplace aggression, first proposed by Hershcovis (2011), and advanced by Nixon's (2011) scale development. The aim of Part 2 is to gather additional construct validity evidence for the use of the Nixon (2011) scale by testing its association with multiple individual and organizational strain-based outcomes (i.e., job satisfaction, turnover intent, OCB's, CWB's, psychosomatic health, and interpersonal relationships in the home domain).

Further, this dissertation is interested in demonstrating that subsequent research pursuits, focused on exploring workplace aggression, would benefit from utilizing a global construct conceptualization, in terms of the following: 1) defining and characterizing its features and elements; 2) magnifying its importance in the literature as a significant workplace consideration; and 3) 
linking the experience to behavioral, somatic, and psychological outcomes. In its current state, achieving these objectives in conceptualizing workplace aggression is challenging at best, and a fragmented approach has been the only option to this point. Through a reconciliation of this construct in terms of characteristics and item assessment this study will position researchers to consider each of these areas more thoroughly, with greater ease, and with less room for misinterpretation.

\section{CHAPTER III: METHOD}

\section{Participants and Procedure}

Participants were 400 working individuals recruited using Amazon's Mechanical Turk participant pool. The Mechanical Turk was chosen as it is a system that has demonstrated significant advantages as a participant/sample source. One such advantage is that it has been shown to produce reliable date and demographically diverse samples (Buhrmester, Kwang, \& Gosling, 2011; Mason \& Suri, 2012; Paolacci, Chandler, \& Ipeirotis, 2010). Additionally, the Mechanical Turk system allows participants' responses to remain anonymous, thus reducing response distortion. Further, the broad scope of the system generates employee data that is based on multiple organizations and across occupations, as opposed to data that is from a single or small number of organizations and occupations.

Data were collected in two waves separated by two weeks to help alleviate concerns regarding common method variance (Podsakoff, MacKenzie, Lee \& Podsakoff, 2003). Participants with an active Amazon Mechanical Turk 
account were able to access the study link from the system website. As a condition of participation and prior to accessing the survey materials, participants were required to verify that they were over the age of 18 , live in the U.S., were employed 35 hours per week or more, and had a consistent direct supervisor for a minimum of two months prior to their participation in the study.

Once the participant was qualified to participate they were provided with an electronic informed consent. Only after completing the four verification items and affirming their desire to participate in the study on the informed consent, were participants directed to the Time 1 study materials, in which they indicate their degree of agreement to items contained in a series of scale. Time 1 included each of the five scales most commonly used to assess the five most accepted forms of workplace aggression: the abusive supervision scale (Tepper, 2000), the NAQ-R of workplace bullying (Einarsen, et. al., 2009), the interpersonal conflict at work scale (Spector \& Jex, 1998), the social undermining scale (Duffy, Ganster, \& Pagon, 2002), and the WIC scale of workplace incivility (Cortina, Magley, Williams, \& Langhout, 2001). The factor structure and conceptual overlap of each of these five measures of workplace aggression: abusive supervision; bullying; incivility; social undermining; interpersonal conflict; was assessed in Time 1 (Please see Appendix A for the exact scale items). Of the 400 participants registered to participate in this study, 219 participants completed the required verification items referenced above and associated survey materials for Time 1 and Time 2 . 
Time 2 utilized a singular factor workplace aggression scale developed by Nixon (2011) in order to examine the relationship between a series of individual and organizational strain based outcomes: attitudinal (job satisfaction), behavioral (turnover intent, OCB's, \& CWB's), psychosomatic strain, and quality of interpersonal relationships in the home domain. More specifically, the following scales were utilized in time 2: the WAAMS scale of workplace aggression (Nixon, 2011); the Job Satisfaction scale (Hackman \& Oldham, 1975); the Turnover Intent scale (Spector, Dwyer, \& Jex, 1988); the Organizational Citizenship and Counterproductive Work Behaviors scale (2009); the PSI scale of psychosomatic health (Spector \& Jex, 1998); and the Spousal Undermining Scale (Restubog, Scott, \& Zagenczyk, 2011).

Once the participant completed the scale items, they were presented with a series of questions relating to demographic information. The demographic items asked the participant to indicate their age, gender, ethnicity/race, and whether they are in a supervisor or non-supervisor role. Completion of the survey materials was expected to require no more than 45 minutes. To ensure confidentiality, at no point during the study was any identifying participant information collected. To encourage participation, individuals who registered for this study received $\$ 0.50$ for participation in Part 1 and an additional $\$ 1.00$ for participation in Time 2.

\section{Measures}

Time 1: Five Measures of Workplace Aggression. Part 1 considered the factor structure and conceptual overlap of the five most commonly utilized 
measures of workplace aggression: abusive supervision (Tepper, 2000); bullying (Einarsen \& Raknes, 1997); interpersonal conflict (Spector \& Jex, 1998); social undermining (Duffy, Ganster, \& Pagon, 2002); and incivility (Cortina, Magley, Williams, \& Langhout, 2001).

Abusive Supervision. Tepper's (2000) 15-item measure of abusive supervision was used. Each of the scale items begins with the statement, "My boss ... " Answer choices are based on a 5-point frequency response scale, where answer options range from 1 "I cannot remember him/her ever using this behavior with me" to 5 "He/she uses this behavior very often with me." A sample item from this scale is "Makes negative comments about me to others." The internal consistency reliability of this scale for the present study was .96.

Workplace Bullying. The 22-item Negative Acts Questionnaire-Revised (NAQ-R (Einarsen, Hoel \& Notelaers, 2009)) was used. Participants utilized a 5point frequency response scale, with answer choices ranging from ' $1=$ Never' to ' $5=$ Daily." A sample item from this scale is "During the last month, how often have you been subjected to the following negative acts in the workplace? i.e., Someone withholding information which affects your performance." The internal consistency reliability of this scale for the present study was .97 .

Interpersonal Conflict. Spector and Jex's (1998) 4-item Interpersonal Conflict at Work Scale was used. The 5-point frequency response format for this scale contains answer choices ranging from ' $1=$ Never' to ' $5=$ Daily.' A sample item for this scale is "How often do you get into arguments with others at work?" The internal consistency reliability of this scale for the present study was .90 . 
Social Undermining. The 26 -item Social Undermining scale developed by Duffy, Ganster, and Pagon (2002) was used. This scale is divided into two subscales, the first of which assesses undermining by supervisors, with 13 items, and the second, undermining by coworkers, with 13 items. Participants utilized a 5-point frequency based response scale, ranging from 'Never' to 'Everyday.' A sample item from the supervisor subscale is "How often has your supervisor intentionally insulted you?", and from the coworker subscale is "How often has the coworker closest to you intentionally spread rumors about you?" The internal consistency reliability of this scale for the present study was .98 .

Incivility. An adapted version of the 7-item Workplace Incivility Scale (WIS) developed by Cortina, Magley, Williams, and Langhout (2001) was used. Participants utilized a 5-point likert frequency response scale, with answer choices ranging from ' $1=$ Never' to ' $5=$ Everyday.' A sample item from this scale is "Made demeaning or derogatory remarks about you?" The internal consistency reliability of this scale for the present study was .92 .

Time 2: This phase utilized a singular factor workplace aggression scale developed by Nixon (2011) to examine the relationship between a series of individual and organizational strain based outcomes: attitudinal (job satisfaction), behavioral (turnover intent, OCB's, \& CWB's), psychosomatic strain, and quality of interpersonal relationships in the home domain.

Workplace Aggression and Moderators Scale (WAAMS). The 37-item WAAMS scale was used. This scale is comprised of 7 aggressive behavior items (based on items from existing workplace aggression measures) including verbal 
aggression (e.g., abusive supervision), intimidation (e.g., bullying), social exclusion (e.g., social undermining), rude behavior (e.g., incivility), interpersonal conflict, and physical aggression (e.g., abusive supervision or bullying). Each of these aggressive behavior items forms its own subscale and is further comprised of each of the four perceptions based moderator scales including intensity, intention attributions, relationship power, and perceived visibility. Participants responded to the workplace aggression items on a 6-point frequency response scale with answer choices ranging from ' $1=$ Not at all' to ' $6=5$ or more times'. A sample item from the aggressive behavior portion of the scale is "How many times have you experienced verbal aggression at work (for example, someone yelled at, ridiculed, insulted you, or told you that you were incompetent) in the past month?" Participants responded to the intention attributions, intensity and perceived visibility items on a 5-point agreement response scales with answer choices ranging from ' $1=$ strongly disagree' to ' $6=$ strongly agree'. Participants responded to the relationship power item by entering a number to represent the number of times (acts) they have experienced the form of workplace aggression referred to in the given subscale at the hand of customer/patient, co-worker, or supervisor. The average coefficient alphas for the workplace aggression, intensity, intention attributions and perceived visibility subscales in the present study were $.87, .90, .90$ and .86 respectively.

Attitudinal Strain - Job Satisfaction. The Hackman and Oldham (1975) 3-item general scale was used. Participants responded to statements on a 5point Likert response scale with answer choices ranging from ' 1 = Strongly 
Disagree' to ' 5 = Strongly Agree'. A sample item from this scale is "I am generally satisfied with the kind of tasks I do at my job." The internal consistency reliability of this scale for the present study was .79 .

Behavioral Strain - Turnover Intent. The 1-item Turnover Intent scale developed by Spector, Dwyer, and Jex (1988) was used. Participants responded to the item on a 5-point Likert response scale with answer choices ranging from ' $1=$ Never' to '6=Extremely Often'. The single item from this scale is "How often have you seriously considered quitting your job?

Organizational Citizenship Behavior (OCB). OCB was assessed with the 20 item OCB-C scale developed by Fox, Spector, Goh, Bruursema and Kessler (2012). Participants utilized a 5-point frequency based response scale, with answer choices ranging from ' $1=$ Never' to ' $5=$ Everyday.' A sample item from this scale is "Lent a compassionate ear when someone had a work problem." The internal consistency reliability of this scale for the present study was .94.

Counterproductive Work Behavior (CWB). CWB was assessed with the 19-item Bennett \& Robinson (2000) Interpersonal and Organizational Deviance Scale. This scale is divided into two subscales, the first of which is a 7 item scale assessing CWB's at the individual level (CWB-I), and the second, a 12 item scale assessing CWB's at the organizational level (CWB-O). Participants responded to the item on a 7-point frequency response scale with answer choices ranging from ' $1=$ Never' to '7=Daily'. A sample item from the CWB-I scale is "Made fun of someone at work." A sample item from the CWB-O scale is "Put little effort into 
your work." The internal consistency reliability of the overall scale for the present study was .97 .

Psychosomatic Health (PSI). The 12-item Physical Symptoms Inventory (PSI) developed by Spector and Jex (1998) was used to assess psychosomatic health. Participants responded to the statements and indicate frequency of symptomatology on a 5 point response scale, with answer choices ranging from ' $1=$ Not at all' to ' $5=$ Every day.' A sample item from this scale is "Headache." The internal consistency reliability of this scale for the present study was .89 .

Spousal Undermining. Interpersonal Relationships in the home environment was assessed with the 5-item Spousal Undermining Scale by Restubog, Scott, and Zagenczyk, (2011). Participants utilized a 7-point Likert response scale, with answer choices ranging from '1 = He/she cannot remember using this behavior towards me to ' $7=\mathrm{He} /$ she always uses this behavior towards me.' A sample item from this scale is "Acted in an unpleasant or angry manner towards me." The internal consistency reliability of this scale for the present study was .93.

\section{Analyses}

Part 1: In order to test Hypothesis 1, data were entered into Mplus (Muthen \& Muthen, 1998) and a confirmatory factor analysis was utilized to determine the factor structure of the items and conceptual overlap of the five most commonly utilized measures of workplace aggression: abusive supervision (Tepper, 2000); bullying (Einarsen \& Raknes, 1997); interpersonal conflict (Spector \& Jex, 1998); social undermining (Duffy, Ganster, \& Pagon, 2002); and 
incivility (Cortina, Magley, Williams, \& Langhout, 2001). More specifically, the aim of the CFA was to test or confirm hypothesis 1, which states: Abusive supervision, social undermining, incivility, interpersonal conflict, and bullying will be positively correlated and one single factor of workplace aggression will emerge from the data. The use of this technique helped to establish whether each of the aforementioned constructs of workplace aggression are in fact sufficiently related to justify and validate the singular construct conceptualization of workplace aggression proposed in the WAAMS scale.

Part 2: Correlational analysis were conducted to test the hypothesized linkages between workplace aggression and each of the following strain-based outcomes (Hypotheses 2-7): job satisfaction; turnover intern' organizational citizenship behavior; counterproductive work behaviors; psychosomatic health; and the quality interpersonal relationships in the home environment. Finally, an additional correlational analysis was run to determine how closely related the WAAMS was to each of the individual measures of workplace aggression.

\section{CHAPTER IV: RESULTS}

\section{Demographic Variables}

The means, standard deviations, coefficient alphas, and Pearson correlations between all study variables are presented in Tables $3 \& 4$. With regard to demographic variables, $54 \%$ of participants were between the ages of $35-44$ years; followed by $20.1 \%$ of participants between the ages of $45-54 ; 11.4 \%$ between the ages of $25-24$; and $10.5 \%$ between the ages of $55-64$. In regards to industry representation across participants, $32.9 \%$ reported working in the 
Technology industry; followed by $28.8 \%$ selecting the Other answer choice; and $14.2 \%$ representing the Education industry (see Table 2). Race was mainly spread between two categories, with $68.5 \%$ of participants' reports that they were Caucasian and 21\% reporting that they were Asian American/Pacific Islander. Gender was split evenly between male and female participants, with $51.6 \%$ reporting that they were male, and $48.4 \%$ reporting that they were female.

\section{Hypothesis Testing}

A Confirmatory Factor Analysis (CFA) was conducted Using Mplus (Muthen \& Muthen, 1998) to compare our hypothesized one factor conceptualization of workplace aggression to the existing five factor conceptualization. Specifically, we tested three separate models: a single-factor model in which all workplace aggression items, taken from each of the five separate workplace aggression constructs, loaded onto a common latent construct; a five factor model, which is the most common conceptualization of workplace aggression, in which the five latent constructs remained separate; and a higher-order five factor model in which the one latent factor model affects the five latent factor constructs. Guided by the recommendations of Hu and Bentler (1999), the maximum-likelihood-based standard root squared residual (SRMR) and the supplemental root mean square error of approximation (RMSEA) were used. The decision to use the RMSEA was on account of its ability to account for parsimony, and due to the fact that a confidence internal can be calculated around its value. According to the Hu and Bentler (1999) strategy, a model of good fit is indicated by a RMSEA of .06 or lower, and a SRMR of .09 or lower. 
Additionally, as models that differ in regard to the number of latent factors are not necessarily nested, the Akaike Information Criterion (AIC; Hu \& Bentler, 1999) was used to in lieu of Chi Square $\left(x^{2}\right)$ Differences to compare the 1 and 5 factor models. Lower values on the AIC indicate a better fitting model.

The results of the CFA, which can be seen in Table 5, indicated that the one factor model, in which all workplace aggression items from the 5 factor model loaded onto a common latent construct, did not fit well: with $x^{2}(2627, N=$ $190)=9011.84, \mathrm{p}<.001 ; \mathrm{SRMR}=.07 ;$ and RMSEA $=.11(90 \% \mathrm{Cl}$ of RMSEA $=$ $[.111, .116])$. The results of the CFA for the five factor model, in which the five latent workplace aggression constructs remained as separate constructs also did not fit well, with $x^{2}(2617, N=190)=7710.61, p<.001$; SRMR $=.06$; and RMSEA $=.10(90 \% \mathrm{Cl}$ of RMSEA $=[.099, .104])$. Finally, the results of the CFA for the higher-order five factor model, in which the one latent workplace aggression factor affects the five latent factor workplace aggression constructs, did not fit well, but did fit slightly better than both the one and five factor models: with $X^{2}(2622, N=190)=7719.05, p<.001 ;$ SRMR $=.06 ;$ RMSEA $=.10(90 \% \mathrm{Cl}$ of RMSEA $=[.099, .104])$. More specifically, the SRMR of .06 falls within the range recommended by Hu \& Bentler (1999). Next, the AIC was examined in order to further compare the three models, with the following results: one factor model AIC $=27476.24 ;$ five factor model $A I C=26195.01 ;$ and the higher-order five factor model AIC $=26193.45$. Based on these collective results, there is little support for the one factor model, with the only fit demonstrated by the SRMR of .070; there is slightly more support for the five factor model, with fit demonstrated 
by the SRMR of .064 and a lower AIC of 26195.01 compared to an AIC of 27476.24 from the one factor model; and there is slightly more support for the higher-order five factor model, with fit demonstrated by the SRMR of .064 and an AIC of 26193.45, which is lower than both the one factor and five factor models. Therefore, when considering the results associated with each of the three possible models, the SRMR of .06 and AIC value 26193.45 demonstrates partial support for the higher-order five-factor model, and seems to suggest that there may be a higher order latent construct associated with workplace aggression.

Correlational analyses were computed to test Hypotheses 2, 3, 4, 5, 6 , and 7. Hypothesis 2 through Hypothesis 7 proposed that workplace aggression would be negatively related to job satisfaction $(\mathrm{H} 2)$, positively related to turnover intent $(\mathrm{H} 3)$, negatively related OCB's $(\mathrm{H} 4)$, positively related to CWB's $(\mathrm{H} 5)$ and physical symptoms ( $\mathrm{H6}$ ), and negatively related to the quality of interpersonal relationships in the home domain $(\mathrm{H} 7)$. As shown in Table 4, workplace aggression was positively related to higher reports of physical symptoms $(r=.45$, $p<.01)$, turnover intent $(r=.44, p<.01)$, CWB's $(r=.62, p<.01)$, and negative relationships in the home domain $(r=.46, p<.01)$. Workplace aggression was also found to be negatively related to job satisfaction $(r=-.29, p<.01)$. However, there was no support for the proposed negative relationship between workplace aggression and OCB's. Thus, Hypotheses 2, 3, 5, 6 and 7 were fully supported by the data.

Further, a correlational analysis was computed to test Hypothesis 8, which proposed that the WAAMS workplace aggression measure would be positively 
correlated with individual level constructs of workplace aggression, including abusive supervision, social undermining, incivility, interpersonal conflict and bullying. As shown in Table 3, the WAAMS was positively related to abusive supervision $(r=.62, p<.01)$, social undermining $(r=.67, p<.01)$, incivility $(r=.67$, $\mathrm{p}<.01)$, interpersonal conflict $(r=.64, p<.01)$ and bullying $(r=.72, p<.01)$.

Additional analyses were run to explore the relationship between various individual characteristic variables, emotional intelligence (EI) and the Five-Factor Model of personality (openness to experience, conscientiousness, extraversion, agreeableness, and emotional stability; Goldberg, 1990) and the experience of workplace aggression. Costa and McCrae (1992) further defined each of these traits as the following: agreeableness is characterized by kindness, generosity, etc.; extraversion is characterized by assertiveness, a tendency to be social and bold; conscientiousness is characterized by determination, self-discipline and reliability; emotional stability is characterized by depression and anxiety (e.g., psychological/emotional distress); and openness to experience is characterized by creativity, curiosity, etc. The results of this set of analyses found workplace aggression to be negatively correlated with $\mathrm{EI}(r=-.32, p<.01)$. This would suggest that individuals high in emotional intelligence are less likely to report workplace aggression than those who may be lower on emotional intelligence. Of the Big Five personality traits, workplace aggression was found to be negatively correlated with agreeableness $(r=-.30, p<.01)$, conscientiousness $(r=-.39$, $p<.01)$, emotional stability $(r=-.26, p<.01)$ and openness to experience $(r=-.25$, $p<.01)$. This would suggest that people high in four of the five classically defined 
personality types are less likely to report an experience of workplace aggression, with the one exception being those individuals who are extraverted. This will be explored further in the discussion section.

Analyses were also run to explore the relationship between the presence of aggressive organizational cultural norms (Douglas \& Martinko, 2001; Kelloway \& Day, 2005) and the same individual strain based outcomes explored with workplace aggression. Aggressive norms were found to be negatively correlated with job satisfaction $(r=-.35, p<.01)$; and positively correlated with physical symptoms $(r=.28, p<.01)$, negative interpersonal relationships in the home domain $(r=.19, p<.01)$, CWB's $(.33, p<.01)$, and turnover intent $(r=.43, p<.01)$. This would suggest that a workplace environment, where aggression is the norm, is likely to contribute to an individual's experience of a variety of strain-based outcomes. The nature of this relationship will be explored further in the discussion section.

Further, in order gain a greater understanding of an individuals' personal experience with workplace aggression, additional analyses were run to examine the attribution/perception component of workplace aggression suggested by Hershcovis (2011) and Nixon (2011). With regard to the other WAAMS subscales and strain based outcomes, of the four attributions suggested, the following three were considered for analysis: intent, intensity, and perceived visibility. The intention attribution subscale was positively related to CWB's $(.50, p<.01)$, turnover intent $(r=.36, p<.01)$, physical symptoms $(r=.31, p<.01)$, negative interpersonal relationship in the home domain $(r=.36, p<.01)$; and negatively 
related to job satisfaction $(r=-.25, p<.01)$. The perceived visibility attribution subscale was positively related to CWB's $(r=.46, p<.01)$, OCB's $(r=.25, p<.01)$, turnover intent $(r=.24, p<.01)$, physical symptoms $(r=.26, p<.01)$ and negative interpersonal relationships in the home domain $(r=.31, p<.01)$; and negatively related to job satisfaction $(r=-.20, p<.01)$. The intensity attribution subscale was positively correlated with CWB's $(r=.40, p<.01)$, OCB's $(r=.17, p<.05)$, turnover intent $(r=.32, p<.01)$, physical symptoms $(r=.32, p<.01)$, negative interpersonal relationships in the home domain $(r=.32, p<.01)$; and negatively related to job satisfaction $(r=-.29, p<.01)$. This would suggest that the relationship between the experience of workplace aggression and strain-based outcomes is impacted by the perceptions of the target, with perception potentially functioning as a moderator of the relationship.

Consequently, a series of hierarchical regressions were conducted to test for the moderating effect of various intent attributions on the relationship between workplace aggression and a series of strain based outcomes (see Figure 5) in SPSS (Aiken \& West, 1991). The results of these analyses can be seen in Tables 6 \& 7. A 3-step approach was utilized, where the independent variable (workplace aggression) was entered in step one; the independent variable and the moderator (intent, intensity or perceived visibility) in step two; and the interaction term (workplace aggression $\mathrm{x}$ moderator) in step three. All main effect variables were centered prior to calculating the interaction terms (Cohen, Cohen, West \& Aiken, 2003). Moderation was indicated when the there was a significant increase in variance explained for the strain based outcome when the interaction 
term was entered into step three of the hierarchical regression analysis. In instances where moderation was identified, the interactions terms were graphed and the simple slopes were calculated. The results demonstrated a significant increase in variance explained in job satisfaction $(\beta=.24, p<.05)$ when the intent interaction term was entered into the regression. Further, the unstandardized simple slopes for participants at +1 standard deviation above and -1 standard deviation below the mean in intent were $b=-.08, \mathrm{SE}_{b}=.04, \mathrm{p}<.05$ and $\mathrm{b}=-.25, \mathrm{SE}_{\mathrm{b}}=.08, \mathrm{p}<.001$, respectively. The results also demonstrated $\mathrm{a}$ significant increase in variance explained in job satisfaction $(\beta=.24, p<.01)$ when the perceived visibility interaction term was entered into the regression. In this case, the unstandardized simple slopes for participants at +1 standard deviation above and -1 standard deviation below the mean in visibility were $b=-$ $.10, \mathrm{SE}_{\mathrm{b}}=.04, \mathrm{p}<.01$ and $\mathrm{b}=-.27, \mathrm{SE}_{\mathrm{b}}=.07, \mathrm{p}<.001$. Support was not shown for any of the other proposed moderated relationships.

Additional analyses were run to evaluate the existence of workplace programs designed to address workplace aggression. When asked about whether or not their organization had a program in place to respond to workplace aggression, $68 \%$ of participants responded yes. Of those participants, $43 \%$ reported that they were specifically aware of the programs. These same participants were also asked to describe what such programs might look like. Each participant response was considered for this item and was grouped according to similarities in type of response. From these groupings four major response categories emerged, including: counseling programs; mediation 
processes; training programs; and written/verbal warning systems. A sampling of responses falling into each of these categories appears in Table 8.

\section{CHAPTER V: DISCUSSION}

\section{Study Goals}

The primary goal of this dissertation was to unify an often disjointed conceptualization of workplace aggression based on a explosion of terms, into a global construct (Hershcovis, 2011; Nixon, 2011). The secondary goal of this study was to explore the relationship between an existing global construct measure of workplace aggression and a variety of individual and organizational strain-based outcomes.

\section{Findings}

While there was not support for a one-factor measure of workplace aggression, the results of the higher-order five-factor model were partially supported, with an SRMR of .06 that falls within the range recommended by $\mathrm{Hu}$ \& Bentler (1999), and an AIC smaller than that of the one factor and five factor models of the construct. This would suggest that while it may not be possible to evaluate workplace aggression as a global construct, it may be possible to consider workplace aggression as an overarching construct that is made up of the five individual constructs. In other words, the aggression construct can viewed in a similar fashion to personality and its "Big Five" typology where personality is the higher order factor that is evaluated by considering five separate factors or parts (e.g., agreeableness, neuroticism, openness to experience, conscientiousness and extraversion). More specifically, workplace 
aggression can be viewed as the higher order factor that is comprised or made up of five separate factors: abusive supervision, bullying, incivility, social undermining and interpersonal conflict. The measure utilized in this study, the WAAMS (Nixon, 2011), was constructed in a fashion consistent with the higherorder five-factor model that found support in the present study. In other words, much like the scale design suggested by the higher-order five-factor model, the WAAMS scale is based on a categorization of seven aggressive behaviors (e.g., verbal aggression, intimidation, exclusion, undermining, rudeness, interpersonal conflict and physical aggression) derived from each of five existing workplace aggression measures (e.g., abusive supervision, interpersonal conflict, bullying, incivility and social undermining).

Further, while there was no support for the main hypothesis of this study, which proposed a one factor global conceptualization of workplace aggression, the findings around the positive relationship between the WAAMS and each of the separate workplace aggression constructs do highlight the significance of a reasonably well fitting higher-order five-factor model. More specifically, these findings suggest that workplace aggression, as a singular construct conceptualization, is in fact significantly related to each of its "parts". As such, future research should continue to explore the current state of workplace aggression research, and should continue working towards a unified conceptualization of this construct (Hershcovis, 2011; Nixon, 2011).

These findings provide the groundwork for subsequent exploration of the workplace aggression through the lens of a global construct conceptualization. 
More specifically, the individual findings did show support for a positive relationship between the WAAMS and CWB's, physical symptoms, negative interpersonal relationships at home and turnover intent and support for a negative relationship between WAAMS and job satisfaction. These findings suggest that as the experience of workplace aggression increases there will also be an increase in the following: counterproductive behaviors an increase in reported physical symptomatology such as depression and anxiety; an increase in various forms of interpersonal conflict at home; an increase in negative workplace behaviors; an increase in the likelihood to leave the organization; and a decrease in job satisfaction by the target of the aggression. Combined, these relationships have significant implications from the perspective of the individual and the organization. More specifically, when an individual recognizes that a workplace environment or situation has started to impact their well-being or the quality of their relationships at home, it can be assumed that the individual will react, and that reaction can have a variety of potential adverse effects on the organization. However, the absence of support for a negative relationship between the WAAMS and OCB's is unexpected, and can perhaps be attributed to the participants' interpretation of scale items. This will be explored further in the limitations section of the discussion.

In order to further explore the nature of the relationships proposed in this study, a series of additional analyses were performed, the first of which considered the relationship between a global conceptualization of workplace aggression and individual attributes including emotional intelligence and 
personality. The rational in this being that emotionally intelligent individuals and those with specific personality traits, such as conscientiousness and agreeableness (Zimmerman, 2008; van den Berg, 2003) will be more aware of their experience of workplace aggression, and will therefore report a lower incident of the experience (Salovey \& Mayer, 1990; Schutte, Malouff, Simunek, McKenley, \& Hollander, 2002). In support of each of these relationships, the findings demonstrated a series of negative relationship between workplace aggression and both emotional intelligence and four of the Big Five personality traits: conscientiousness; agreeableness; emotional stability and openness to experience. Therefore, it can be expected that an individual who is high in emotional intelligence and the aforementioned personality traits, while still susceptible to workplace aggression, is less likely to report that the experience is detrimental to them. Indeed, El and the four personality traits (conscientiousness, emotional stability, openness to experience and agreeableness) are negatively related to CWB's, turnover intent, physical symptoms and negative interpersonal relationships at home; and positively related to job satisfaction and OCB's. This would seem to suggest that these individuals are less likely to report experiencing negative strain based outcomes in the workplace. However, it is important to note moderation effects were not hypothesized or examined in the present study, and would therefore be appropriate for future studies around these variables.

Similarly, although not directly hypothesized, analyses were run to explore the relationship between aggressive cultural norms in the workplace and the 
same set of individual strain based outcomes. The findings of these analyses demonstrated support for a significant relationship between the aggressive workplace norms and each of the strain based outcomes. These findings would suggest that an organization that supports a culture of aggression is likely to have employees who report experiencing various forms of strain based outcomes raging from a decrease in job satisfaction to an increase in turnover intent. Along these same lines, and in further support of this notion, was the finding that the WAAMS was positively correlated to aggressive organizational cultural norms (Douglas \& Martinko, 2001; Kelloway \& Day, 2005). While seemingly obvious, this finding alone would seem to suggest that an aggressive culture would support workplace aggression. However, such an inference can be misguided should an organization have an aggressive culture, but also a well-established deterrent system for workplace aggression in place. Yet, based on the findings from this study, which not only showed support for a significant relationship between aggressive culture and workplace aggression, but also for aggressive culture and strain based outcomes, a reasonable inference can be drawn to a link between aggressive norms, workplace aggression, and resulting strain based outcomes. These inferences are further compelling when considering the findings that two-thirds of the study participants reported that they were aware of established organizational responses designed to address/deter workplace aggression; and of these two thirds, nearly fifty percent of those reported being aware of specific programs in existence within their own organization, including counseling to formal HR inquiries. This would seem to suggest that while 
aggressive cultures may be the norm in some organizations, the existence of organizational responses also seems to be to norm.

Additionally, considering the proposed link between the attributions an individual associates with their experience of workplace aggression and their experience of that same aggression, a series of analyses were run (Hershcovis, 2011; Nixon, 2011). The findings of these analyses supported the notion that the attributions, including perceptions of intent (Baron, 1977), intensity (Barling, 1996), and visibility (Baron, Neuman, \& Gedees, 1999), are all significantly related to the experience of the same strain based outcomes examined throughout this study. These findings suggest that should the target or workplace aggression believe that the perpetrator has a clear intent to commit the aggressive act; perceive the act to be highly visible to others, or, appraise the aggressive act as high in intensity; then the target is more likely to experience certain strain-based outcomes. From a big picture perspective, these findings act as a first step in supporting the proposition of Hershcovis (2011) that the perceptions of the individual have a direct impact on their experience of workplace aggression. More specifically, the question now becomes whether it is the attributions that an individual attaches to their experience of workplace aggression that can determine how that negative experience manifests in the individual.

The moderation analyses, however, indicated support for only two of the possible 18 moderating relationships. Specifically, both the intent and visibility attribution variables moderated the relationship between workplace aggression 
and job satisfaction. The finding of the first moderating relationship suggests that the strength of the relationship between workplace aggression and job satisfaction is dependent on the target's perceptions of the intent of the aggressive act. Unexpectedly, individuals experiencing high levels of workplace aggression reported higher job satisfaction when they felt strongly that the intent of the act was to cause harm (see Figure 3). Similarly, the second moderating relationship suggests that the strength of the relationship between workplace aggression and job satisfaction is dependent on the target's perceptions of how visible the aggressive act is. However, as in the previous case, individuals experiencing high levels of workplace aggression reported higher job satisfaction when they felt strongly that the aggressive act was highly visible (see Figure 4).

\section{Implications}

While the findings of the study have not supported the one factor model of workplace aggression, the slightly better fit of a five-factor higher-order model and the support for a significant relationship between the WAAMS and the existing five separate workplace aggression measures, would seem to suggest that it may be possible to evaluate workplace aggression as a global construct conceptualization, given that the measure is constructed as a "sum-of-the-parts"

of existing workplace aggression measures. From the organizational perspective, the implications of this "simplification" of workplace aggression are compelling in that organizations will be able to create and implement an easier and more focused process/procedure for evaluating workplace aggression, thereby lowering associated cost, and increase awareness. Organizations are generally 
driven by a desire to get the most out of their employees, and recognize the importance of creating at atmosphere that is responsive to their needs (Kelloway \& Day, 2005).

Moreover, while not directly supporting the one factor conceptualization of workplace aggression, the findings are compelling in that they do call the current measurement technique of this complex construct into question. Utilizing an existing one-factor measure, the findings have demonstrated support for the same strain based outcomes commonly associated with each of the separate workplace aggression measures. Further, as the five standard measures of this construct are significantly related to one another, the idea of a singular measure becomes even more intriguing to researchers and organizations alike, both of whom are interested in parsimony. .

Further supporting the implications of a simplified conceptualization and measurement process, the relationship between the WAAMS and strain-based outcomes are decisive as the same relationships also exist when evaluating workplace aggression using the standard five-factor approach. The significance of this relationship cannot be understated. From the perspective of the individual, they stand to experience loss on multiple fronts including tarnished reputations, a desire to leave the organization, decreased productivity, injury and psychological duress (O'Leary-Kelly, Griffin \& Glew, 1996). From the organizational standpoint, there is a significant financial cost associated with loss of productivity and legal costs (Bensimon, 1994), as well as costs associated with weakened employee morale, property damage and a rise in healthcare costs (O'Leary-Kelly, et. al., 
1996). Therefore, the benefit of a simplified and effective evaluative process to an organization are immense as they would be able to implement one measure of workplace aggression to evaluate the same individual outcomes that had previously required five separate measures, thereby reducing time and associated costs. Along these same lines, the significant relationships between the WAAMS and aggressive cultural norms in the workplace, and the relationship between Aggressive Norms and strain based outcomes, further supports the need for an organization to recognize the importance of creating a workplace atmosphere that is supportive to the worker. More specifically, as Bandura (1973) posited in his social learning perspective, individuals and organizations alike tend to model behavioral patterns, thereby creating normative behavioral patterns. This process, should it remain unchecked, could prove detrimental to an organization. An organization that is aware of its cultural norms can become responsive and incorporate corrective measures. This responsiveness will communicate to a worker that the organization is interested in their wellbeing, and may increase perceptions of organizational support (Rhoades \& Eisenberger, 2002).

Moreover, the findings relating both El and personality to workplace aggression would imply that an individual who is aware of their emotions and is high in a variety of personality traits including conscientiousness, agreeableness, emotional stability and openness to experience, is less likely to be impacted in the same negative way (e.g., in terms of strain based outcomes) as an individual lower on $\mathrm{El}$ and someone who is not high on those same personality traits. 
These insights into an individual can help an organization prepare for how an employee may respond to challenging behaviors and or norms such as workplace aggression (Zimmerman, 2008; van den Berg \& Feij, 2003; Schutte, et. al., 2002).

Additionally, the findings associated with the attribution variables, as they relate to strain-based outcomes, combined with the findings associated with these same attributions as moderators of the aggression/strain relationship, are thought provoking in that they shed light on the importance of perceptions in the development of strains. However, contrary to what was expected, the findings showed that individuals experiencing high levels of workplace aggression reported higher job satisfaction when they felt strongly that the aggressive act was highly visible or when there was an intent to cause harm. The implications of these unexpected findings are mixed in that they would seem to suggest that something else is at play in impacting these relationships. One possible explanation is cognitive dissonance theory which posits that when an individual experiences a situation that is uncomfortable and misaligned with their expectations, they work to reduce the "dissonance" and achieve a state of internal consistency or comfort (Festinger, 1957). In other words, when a target recognizes a perpetrators' intent to cause them harm, this awareness causes them discomfort, and drives them to neutralize the discomfort of the situation, thereby reducing the negative outcomes. In each of these unexpected moderator situations, it is possible that the target, aware of the attribution, was focused on 
neutralizing the effect and on achieving a balance (Cannon, 1932), thereby reducing the impact of the attribution variable.

\section{Limitations \& Future Directions}

Workplace aggression is a construct that researchers will need to continue examining with ardent fervor. However, in order to truly advance upon the existing knowledge base, researchers will need to continue examining not only the conceptualization of the construct, but also the unique nature in which individuals interpret and respond to the experience of workplace aggression. As a first step in this process, it is necessary to consider each of the limitations of the present study, and then, based on each of these limitation, to suggest a reasonable course of action /direction, for subsequent studies. The first limitation is the lack of support for the one factor global construct conceptualization of workplace aggression. This finding was clearly unexpected as an existing onefactor measure was utilized to examine each of the subsequent hypotheses. However, the findings which approached significance for the higher-order fivefactor model, coupled with the high correlations between each of the existing measures of workplace aggression, re-ignited confidence in the need for further examination of the workplace aggression construct. More specifically, the higherorder five-factor model, which suggests that workplace aggression can be evaluated as a "combination" of the existing five-factor measures, appears to align nicely with the construction of the WAAMS, which is, in essence, a one factor conceptualization comprised of "sub-scales" accounting for each of the existing five-factor measures of the construct. Further, the support for a 
correlation between the WAAMS and individual strain based outcomes, commonly associated with each of the five separate constructs, further supports the importance and feasibility of a more refined measurement technique.

A second limitation of this study was the absence of support for the hypothesized negative correlation between workplace aggression, as evaluated through the WAAMS, and OCB's. This actual finding of a significant positive correlation was especially puzzling as there was compelling support for each of the other strain based outcomes, there was a large sample size with adequate power, and the results and response rates were consistent across each of the study measures. Further, in order to explore this unexpected finding further, each OBC item was correlated separately with the aggression scale. The findings of this analysis demonstrated that 12 of the 20 items correlated positively with workplace aggression; one item, which asked about the frequency at which an individual picks up the meals of others at work, correlated negatively; and the remaining 7 items were not correlated to workplace aggression. Therefore, it seems likely that this finding may be due to the nature of the sample. Moreover, it is reasonable to think that individuals may be engaging in OCB's as a means of offsetting the impact of workplace aggression, thereby accounting for the positive relationship. Similarly, it is possible that cognitive dissonance may be playing a role here, as this would suggest that CWB's could serve as a means by which the target of the aggressive act works to reduce their feelings of dissonance and their experience of strain based outcomes stemming from the aggression (Festinger, 1957). Additionally, it is also possible that OCB's are deemed as 
socially desirable behaviors by the target, and necessary to be viewed in a positive light by others in the organization (Bolino, 1999). In other words, the negative experience of workplace aggression is not enough to prevent the target from engaging in acts that they have deemed socially desirable. Similarly, and in line with social exchange theory (Blau, 1964) the positive relationship may be due to the formation of an exchange relationship between the target and members of their peer network, in which the peer group agrees to provide support and a sense of security to the target in exchange for the targets agreement to align with the behavioral patterns of the group. Further, it may be possible that participants failed to properly interpret the directionality of the scale items. As this scale is widely used, and has demonstrated a high alpha of .89.94 , it seems unlikely that the lack of support is more likely due to participant error than to scale design. Therefore, future researchers may want to consider the source of the sample, which for the present study was M-Turk, and may instead want to choose specific organizations from a variety of industries. That way, with a large enough sample size, the findings can be more focused on job/industry type. Additionally, it might be beneficial to restrict the study to specific geographic areas so as to limit the impact of variability in workplace cultural norms associated with global cultural differences (Markus \& Kitayama, 1991). Aggressive cultural norms may have existed across this sample, but could mean something entirely different to each of the study participants (Markus \& Kitayama, 1991). Further, as the findings of the present study seem to suggest that individuals are largely aware of whether or not their organization has a 
response in place to address instances of workplace aggression, subsequent research may want to explore the extent of this responsiveness, and what it truly means in terms of an individual's experience of workplace aggression. In other words, could perceived organizational support (POS) act as a moderator of the relationships between workplace aggression and strain-based outcomes? (Rhoades \& Eisenberger, 2002). Similarly, when considering the attribution variables, especially perceived visibility, it may be these norms that contribute to how the target of workplace aggression perceives and responds to aggressive behaviors that are highly visible to others in the organization. More specifically, individuals' perceptions, along with their behaviors, may be conditioned by the cultural norms that exist within an organization. Therefore, subsequent research should explore these relationships, and should examine how workplace culture impacts the perceptions of an individual in their work environment.

Additionally, subsequent research may want to consider the implications of the findings around El and personality traits. More specifically, as El was found to be significantly and negatively correlated with workplace aggression and with strain based outcomes, it would seem like a reasonable next step to consider whether El could act as a moderator of the relationship between workplace aggression and strain based outcomes (Schutte, et. al., 2002; Salovey \& Mayer, 1990). The same subsequent examination could also be performed around various personality traits, which had similar significant negative correlations with workplace aggression. 
Further, in terms of the limitations associated with individual attribution variables, the findings around intent and perceived visibility, both of which acted as moderators of the relationship between workplace aggression and job satisfaction, would suggest that future studies should focus more directly on these moderating relationships. More specifically, as these findings seem to suggest that it is the ambiguous acts, or those acts not perceived as intentional or high in visibility, that are the most damaging to attitudes such as job satisfaction under frequent conditions of aggression, it may be advisable to explore whether an individual acknowledges or recognizes the aggressive act as opposed to focusing on which attribution they assign to it. Similarly, when considering the directionality of the moderating relationships, it might be beneficial to consider the implications of the social element. More specifically, when considering perceived visibility as the moderator, the unexpected directionality of the aggression/job sat relationship seems to suggest that perceptions of visibility may translate into increased social support. Under such circumstances it seems reasonable to assume that the presence of social support may reduce the impact of workplace aggression on job satisfaction (Chiaburu \& Harrison, 2008). The same interpretation of the element of social support may also be responsible for the increase in job satisfaction under condition of perceived high intent of workplace aggression behaviors. Additionally, future studies may want to consider the sample and source, as suggested above, as a means of examining these interactions more closely. Further, while existing research has highlighted the importance that these 
individual perceptions may play on the experience of negative workplace behaviors such as workplace aggression (Hershcovis, 2011; Nixon, 2011), future studies should be structured in such a way as to examine these perceptions more closely, perhaps through an examination of affect, facial cues, etc. (Brief \& Weiss, 2002). Adding an observational element might assist in removing some of the individual interpretive/reporting errors common in self report assessments, and even more significant in assessments around topics that can be uncomfortable for the participant and impacted by social desirability effects (Cronbach, 1970). One such technique, which would require, as previously suggested, a more refined organizational sample, is the Ecological momentary assessment method (EMA). This technique, which is a well-established method of naturalistic observation (Schwartz \& Stone, 1998), has been shown to reduce many of the limitations (i.e., directional interpretation of relationships, linking responses to context, etc.) commonly associated with self-report measures of workplace stressors such as aggression. This approach would allow the individuals responses to be captured in real time. However, this approach would also require a workplace environment where workplace aggression has already been detected as an organizational norm, or a workplace that has a previously identified high rate of workplace aggression incidences.

Further, in terms of the implications of self-report measures, it is important to consider how sensitive topics such as workplace aggression can impact the study participant, and thereby affect their reposes. More specifically, as discussed in Lee (1993), when an individual perceived that a research topic and 
or its content is potentially threatening, the accuracy of responses in adversely impacted. According to Farberow (1963), it is the perception that a topic is "taboo" that contributes to the creation of an emotional response in the test taker. In other words, the experience of taking the test may elicit feelings associated with an individuals own experience with the sensitive topic, in this case workplace aggression. Further, an individual may experience fear over reporting accurately due to concerns over how an organization would respond should they discover the responses. Individuals who participate in sensitive research have reported experiencing feelings of stress, intrusion, and fear of repercussions (Lee, 1993). Therefore, research exploring sensitive topics such as workplace aggression run the risk of data compromise, and must find ways to limit this through creative techniques. On the surface, M-Turk seemed to be such a technique as it has been shown to produce reliable date and demographically diverse samples (Buhrmester, Kwang, \& Gosling, 2011; Mason \& Suri, 2012; Paolacci, Chandler, \& Ipeirotis, 2010).

\section{Study Conclusions}

While failing to find support for the central hypothesis of this study, the one-factor global construct conceptualization of workplace aggression, the findings associated with other hypothesized and non-hypothesized relationships, were interesting and appear to pave the way for subsequent research into the construct of workplace aggression. While workplace aggression, in its current state, may not entirely support the classic notion of a one-factor construct, support exists for a reconceptualization of the existing measurement approach. 
The findings of the current study support the need for a simplification of the current state of workplace aggression research in terms of measurement of the construct alone. However, the findings also highlight the need for caution around the importance of not over-simplifying a clearly complex construct that appears to depend on a variety of individual variables, including, but likely not limited to personality, emotional intelligence, and perceptions/attributions. The implications for future research made above should account for a portion of possible steps forward in this area of exploration. However, it is certain, as with many other complex constructs that are influenced by variables specific to the individual, that subsequent research will uncover a variety of additional questions to be explored. This study, which was an advancement of existing streams of research, should be considered as an additional and significant step forward in uncovering the complexities of the workplace aggression construct. 


\section{REFERENCES}

Adams, A. (1992). Bullying at work: how to confront and overcome it. London: Virago.

Agervold, M., \& Mikkelsen, E. G. (2004). Relationships between bullying, psychosocial work environment and individual stress reactions. Work and Stress, 18, 336-351.

Aiken, L. S., \& West, S. G. (1991). Multiple regression: Testing and interpreting inter- actions. Newbury Park, CA: Sage.

Andersson, L.M., \& Pearson, C.M. (1999). Tit for tat? The spiraling effect of incivility in the workplace, The Academy of Management Review, 24, 452471.

Aquino,K.,Tripp,T. M.,\& Bies,R. J. (2001). How employees respond to personal offense: The effects of blame attribution, victim status, and offender status on revenge and reconciliation in the workplace. Journal of Applied Psychology, 86, 52-59.

Aryee, S., Chen, Z.X., Sun, L.Y., \& Debrah, Y.A. (2007). Antecedents and outcomes of abusive supervision: Test of a trickle down model. Journal of Applied Psychology, 92, 191-201.

Ashforth, B. (1997). Petty tyranny in organizations: A preliminary examination of antecedents and consequences. Canadian Journal of Administrative Sciences, 14, 126-140.

Bandura, A. (1973). Aggression: A social learning analysis. Englewood Cliffs, NJ: Prentice Hall.

Barki, H., \& Hartwick, J. (2001). Interpersonal conflict and its management in information system development. Mis Quarterly, 25, 195-228.

Barling, J. (1996). The prediction, experience, and consequences of workplace violence. In G. R. VandenBos \& E. Q. Bulatao (Eds.), Violence on the job: identifying risks and developing solutions (pp. 29-49). Washington, DC: American Psychological Association.

Baron, R.A. (1977). Human aggression. New York: Plenum Press.

Baron, R. A., Neuman, J. H., \& Geddes, D. (1999). Social and personal determinants of workplace aggression: Evidence for the impact of perceived injustice and the Type A behavior pattern. Aggressive Behavior, 25, 281-296.

Baumeister, R. F., Heatherton, T. F., \& Tice, D. M. (1994). Losing control: How and why people fail at self-regulation. Academic Press. 
Bennett, R. J., \& Robinson, S. L. (2000). Development of a measure of workplace deviance. Journal of applied psychology, 85, 349-360.

Bensimon, H. F. (1994). Violence in the workplace. Training and Development, 48, 26-32.

Blau, P. M. (1964). Exchange and power in social life. New York, NY: John Wiley \& Sons.

Bolger, N., DeLongis, A., Kessler, R. C., \& Schilling, E. A. (1989). Effects of daily stress on negative mood. Journal of Personality and Social Psychology, $57,808-818$.

Bolino, M. C. (1999). Citizenship and impression management: good soldiers or good actors? Academy of Management Review, 24, 82-98.

Bowling, N. A, \& Beehr, T. A. (2006). Workplace harassment from the victim's perspective: A theoretical model and meta-analysis. Journal of Applied Psychology, 91, 998-1012.

Brief, A. P., \& Weiss, H. M. (2002). Organizational behavior: Affect in the workplace. Annual Review of Psychology, 53, 279-307.

Brodsky, C. M. (1976). The harassed worker. Toronto, Ontario, Canada: Lexington Books, DC Heath.

Bruk-Lee, V., \& Spector, P. E. (2006). The social stressors-counterproductive work behaviors link: Are conflicts with supervisors and coworkers the same? Journal of Occupational Health Psychology, 11, 145-156.

Buhrmester, M., Kwang, T., \& Gosling, S. D. (2011). Amazon's Mechanical Turk a new source of inexpensive, yet high-quality, data? Perspectives on Psychological Science, 6, 3-5.

Burton, W. H. (1930). Probable next steps in the progress of supervision. Educational Method, 9, 401-405.

Cannon, W. B. (1932). The Wisdom of the Body. New York, NY: W. W. Norton.

Carter, S. (1998). Civility, manners, morals and the etiquette of democracy. New York: Harper Collins.

Chen, P. Y., \& Spector, P. E. (1992). Relationships of work stressors with aggression, withdrawal, theft and substance use: An exploratory study. Journal of occupational and organizational psychology, 65, 177-184.

Chiaburu, D. S., \& Harrison, D. A. (2008). Do peers make the place? Conceptual synthesis and meta-analysis of coworker effects on perceptions, attitudes, OCBs, and performance. Journal of Applied Psychology, 93, 1082-1103. 
Cohen, J., Cohen, P., West, S. G., \& Aiken, L. S. (2003). Applied multiple regression/correlation analysis for the behavioral sciences (3rd ed.). Hillsdale, NJ: Erlbaum.

Cortina, L. M., Magley, V. J., Williams, J. H., \& Langhout, R. D. (2001). Incivility in the workplace: Incident and impact. Journal of Occupational Health Psychology, 6, 64-80.

Costa, P. T., \& McCrae, R. R. (1992). Four ways five factors are basic. Personality and individual differences, 13, 653-665.

Cronbach, L. J. (1970). Essential of Psychological Testing (3rd Edition). New York: Harper \& Row.

DeLongis, A., Folkman, S., \& Lazarus, R. S. (1988). The impact of daily stress on health and mood: psychological and social resources as mediators. Journal of personality and social psychology, 54, 486-495.

Douglas, S. C., \& Martinko, M. J. (2001). Exploring the role of individual differences in the prediction of workplace aggression. Journal of Applied Psychology, 86, 547-559.

Duffy, M. K., Ganster, D. C., \& Pagon, M. (2002). Social undermining in the workplace. Academy of Management Journal, 45, 331-351.

Duffy, M., Ganster, D., Shaw, J., Johnson, J., \& Pagon, M. (2006). The social context of undermining behavior at work. Organizational Behavior and Human Decision Processes, 101, 105-126.

Eagly, A. H., \& Steffen, V. J. (1986). Gender and aggressive behavior: a metaanalytic review of the social psychological literature. Psychological bulletin, 100, 309-330.

Einarsen, S., \& Raknes, B, I. (1997). Harassment in the workplace and the victimization of men. Violence and Victims, 12, 247-263.

Einarsen, S. (2000). Harassment and bullying at work: A review of the Scandinavian approach. Aggression and Violent Behavior, 5, 371-401.

Einarsen, S., Hoel, H., \& Notelaers, G. (2009). Measuring exposure to bullying and harassment at work: Validity, factor structure and psychometric properties of the Negative Acts Questionnaire-Revised. Work \& Stress, 23, 24-44.

Farberow, N. (1963). Taboo topics. New York: Atherton Press.

Festinger, L. (1957). A theory of cognitive dissonance. California: Stanford University Press.

Fletcher, J.K. (1999). Disappearing acts. Cambridge, MA: The M.I.T. Press. 
Folkman, S. (1984). Personal control and stress and coping processes: A theoretical analysis. Journal of Personality and Social Psychology, 46, 839-852.

Folkman, S. \& Lazarus, R. S. (1986). Stress process and depressive symptomatology. Journal of Abnormal Psychology, 95, 107-113.

Folkman, S., Lazarus, R. S., Gruen, R. J., \& DeLongis, A. (1986). Appraisal, coping, health status, and psychological symptoms. Journal of personality and social psychology, 50, 571-579.

Fox, S., Spector, P. E., Bruursema, K., Kessler, S., \& Goh, A. (2007, August). Necessity is the mother of behavior: Organizational constraints, CWB and $O C B$. Paper presented at the meeting of the Academy of Management, Philadelphia, PA.

Fox, S., Spector, P. E., Goh, A., Bruursema, K., \& Kessler, S. R. (2012). The deviant citizen: Measuring potential positive relations between counterproductive work behaviour and organizational citizenship behaviour. Journal of Occupational and Organizational Psychology, 85, 199-220.

Frone, M.R. (2000). Interpersonal conflict at work and psychological outcomes: Testing a model among young workers. Journal of Occupational Health Psychology, 5, 246-255.

Ganster, D. C., \& Schaubroeck, J. (1991). Work stress and employee health. Journal of Management, 17, 235-271.

Gerhart, B., \& Rynes, S. L. (2003). Compensation: Theory, evidence, and strategic implications. Thousand Oaks, CA: Sage.

Giacalone, R. A., \& Greenberg, J. E. (1997). Antisocial behavior in organizations. Thousand Oaks, CA: Sage.

Goldberg, L. R. (1990). An alternative "description of personality": The Big-Five factor structure. Journal of Personality and Social Psychology, 59, 12161229.

Griffeth, R. W., Hom, P. W., \& Gaertner, S. (2000). A meta-analysis of antecedents and correlates of employee turnover: Update, moderator tests, and research implications for the next millennium. Journal of Management,26, 463-488.

Gosling, S. D., Rentfrow, P. J., \& Swann, W. B.(2003). A very brief measure of the Big-Five personality domains. Journal of Research in Personality, 37, 504-528.

Hackman, J. R., \& Oldham, G. R. (1975). Development of the job diagnostic survey. Journal of Applied Psychology, 60, 159-170. 
Hahn, S.E. (2000). The effects of locus of control on daily exposure, coping and reactivity to work interpersonal stressors: A diary study. Personality and Individual Differences, 29, 729-748.

Hauge, L. J., Skogstad, A., \& Einarsen, S. (2010). The relative impact of workplace bullying as a social stressor at work. Scandinavian Journal of Psychology, 51, 426-433.

Heinisch, D. A., \& Jex, S. M. (1997). Negative affectivity and gender as moderators of the relationship between work-related stressors and depressed mood at work. Work \& Stress, 11, 46-57.

Hershcovis, M. S., \& Barling, J. (2010). Towards a multi-foci approach to workplace aggression: A meta-analytic review of outcomes from different perpetrators. Journal of Organizational Behavior, 31, 24-44.

Hershcovis, M. S. (2011). "Incivility, social undermining, bullying... oh my!": A call to reconcile constructs within workplace aggression research. Journal of Organizational Behavior, 32, 499-519.

Hoobler, J. M., \& Brass, D. J. (2006). Abusive supervision and family undermining as displaced aggression. Journal of Applied Psychology, 91, 1125-1133.

Hornstein, H. A. (1996). Brutal Bosses and their pray. New York: Riverhead Books.

Hu, L. T., \& Bentler, P. M. (1999). Cutoff criteria for fit indexes in covariance structure analysis: Conventional criteria versus new alternatives. Structural equation modeling: a multidisciplinary journal, 6, 1-55.

Hynan, D. J., \& Grush, J. E. (1986). Effects of impuisivity, depression, provocation, and time on aggressive behavior. Journal of Research in Personality, 20, 158-171.

Jehn, K.A. (1995). A multimethod examination of the benefits and detriments of intragroup conflict. Administrative Science Quarterly, 40, 256-282.

Jehn, K. A. (1994). Enhancing effectiveness: An investigation of advantages and disadvantages of value-based intragroup conflict. International journal of conflict management, 5, 223-238.

Jex, S.M. (1998). Stress and job performance: Theory, research, and implications for managerial practice. Thousand Oaks, CA: Sage Publications, Ltd.

Jex, S.M., \& Beehr, T.A. (1991). Emerging theoretical and methodological issues in the study of work-related stress. Personnel and Human Resources Management, 9, 311-365. 
Jex, S. M., Beehr, T. A., \& Roberts, C. K. (1992). The meaning of occupational stress items to survey respondents. Journal of Applied Psychology, 77, 623-628.

Kamp, J., \& Brooks, P. (1991). Perceived organizational climate and employee counterproductivity. Journal of Business and Psychology, 5, 447-458.

Keashly, L., Trott, V., \& MacLean, L. M. (1994). Abusive behavior in the workplace: A preliminary investigation. Violence and Victims, 9, 341-357.

Keenan, A., \& Newton, T.J. (1985). Stressful events, stressors and psychological strains in young professional engineers. Journal of Occupational Behavior, 6, 151-156.

Kelloway, E. K., \& Day, A. L. (2005). Building healthy workplaces: What we know so far. Canadian Journal of Behavioural Science, 37, 223-235.

Khan, S. N., Qureshi, I. M., \& Ahmad, H. I. (2010). Abusive supervision and negative employee outcomes. European Journal of Social Sciences, 15, 490-500.

LaGrange, R. L., Ferraro, K. F., \& Supancic, M. (1992). Perceived risk and fear of crime: Role of social and physical incivilities. Journal of research in crime and delinquency, 29, 311-334.

Lazarus, R. S. (1966). Psychological Stress and the Coping Process. McGraw Hill, New York.

Lazarus, R. S., and Cohen, J. B. (1977). Environmental stress. In Altman, I., and Wohlwill, J. F.(eds.), Human Behavior and the Environment: Current Theory and Research, Plenum New York, pp. 89-127.

Lazarus, R. S.. \& Folkman. S. (1984). Stress, appraisal, and coping. New York: Springer.

LeBlanc, M., \& Kelloway, E. (2002). Predictors and outcomes of workplace violence and aggression. Journal of Applied Psychology, 87, 444-453.

Lee, R.M. (1993). Doing research on sensitive topics. Thousand Oaks, CA: Sage.

Lee, K., \& Allen, N. J. (2002). Organizational citizenship behavior and workplace deviance: the role of affect and cognitions. Journal of Applied Psychology, $87,131-142$.

Leymann, H. (1990). Mobbing and psychological terror at workplaces. Violence and Victims, 5, 119-126.

Leymann, H. (1996). The content and development of bullying at work. European Journal of Work and Organizational Psychology, 5, 165-184. 
Loeber, R., \& Hay, D. (1997). Key issues in the development of aggression and violence from childhood to early adulthood. Annual Review of Psychology, 48, 371-410.

Major, B., Zubek, J., Cooper, M. L., Cozzarelli, C., \& Richards. C. (1997). Mixed messages: Implications of social conflict and social support within close rela- tionships for adjustment to a stressful life event. Journal of Personality and Social Psychology, 72, 1349-1363.

Marks, J. (1996). In your face: Whatever happened to good manners? U.S. News \& World Report, 22 April, 66-72.

Markus, H. R., \& Kitayama, S. (1991). Culture and the self: Implications for cognition, emotion, and motivation. Psychological Review, 98, 224-253.

Mason, W., \& Suri, S. (2012). Conducting behavioral research on Amazon's Mechanical Turk. Behavior research methods, 44, 1-23.

Mathieu, J. E., \& Zajac, D. M. (1990). A review and meta-analysis of the antecedents, correlates, and consequences of organizational commitment. Psychological Bulletin, 108, 171-194.

Matthiesen, S. B., Raknes, B. I. \& Rokkum, O. (1989). Bullying at the worksite. Journal of the Norwegian Psychological Association, 26, 761-774.

Matthiesen, S. B. \& Einarsen, S. (2001). MMPI-2 configurations among victims of bullying at work. European Journal of Work and Organizational Psychology, 10, 467-484.

Mikkelsen, E. G. \& Einarsen, S. (2001). Bullying in Danish work-life: Prevalence and health correlates. European Journal of work and Organizational Psychology 10, 393-413.

Mikkelsen, E. G., \& Einarsen, S. (2002). Relationships between exposure to bullying at work and psychological and psychosomatic health complaints: The role of state negative affectivity and generalized self-efficacy. Scandinavian Journal of Psychology, 43, 397-405.

Mitchell, M. S., \& Ambrose, M. L. (2007). Abusive supervision and workplace deviance and the moderating effects of negative reciprocity beliefs. Journal of Applied Psychology, 92, 1159-1168.

Morrison, E. W., \& Robinson, S. L. (1997). When employees feel betrayed: A model of how psychological contract violation develops. Academy of management Review, 22, 226-256.

Muthen, L. K., \& Muthen, B. O. (1998). Mplus user's guide. Los Angeles: Muthen \& Muthen. 
Neuman, J. H. \& Baron, R. A. (1998). Workplace violence and workplace aggression: Evidence concerning specific forms, potential causes, and preferred targets. Journal of Management, 24, 391-419.

Neuman, J. H., \& Baron, R. A. (1997). Aggression in the workplace. In R. Giacalone \& J. Greenberg (Eds.), Anti-social behavior in organizations (pp. 37-67). Thousand Oaks, CA: Sage.

Niedl, K. (1996). Mobbing and well-being: Economic and personnel development implications. European Journal of Work and Organizational Psychology, 5, 239-150.

Nielsen, M. B., Matthiesen, S. B., \& Einarsen, S. (2010). The impact of methodological moderators on prevalence rates of workplace bullying. A meta-analysis. Journal of Occupational and Organizational Psychology, 83, 955-979.

Nixon, A. E. (2011). Charting a semantic jungle: A novel method for examining the moderators of workplace aggression (Doctoral dissertation), University of South Florida, Tampa, FL.

O'Connell, B., Young, J., Brooks, J., Hutchings, J., \& Lofthouse, R.N. (2000). Nurses' perceptions of the nature and frequency of aggression in general ward settings and high dependency areas. Journal of Clinical Nursing, 9, 602-610.

O'Leary-Kelly, A. M., Griffin, R. W., \& Glew, D. J. (1996). Organization-motivated aggression: A research framework. Academy of Management Review, 21, 225-253.

Olweus, D. (1978). Aggression in the schools: Bullies and whipping boys. Washington, DC: Hemisphere.

Olweus, D. (1991). Bully/victim problems among schoolchildren: Basic facts and effects of a school based intervention program. In K. Rubin \& D. Pepler (Eds.), The development and treatment of children aggression (pp. 411-448). Hillsdale, NJ: Erlbaum.

Olweus, D. (1993). Bullying at school. What we know and what we can do. Oxford, UK: Blackwell Publishers.

Oostrom, J.K. \& Mierlo H. (2008). An Evaluation of an aggression management training program to cope with workplace violence in the healthcare sector. Research in Nursing \& Health, 31, 320-328.

Paolacci, G., Chandler, J., \& Ipeirotis, P. G. (2010). Running experiments on amazon mechanical turk. Judgment and Decision making, 5, 411-419. 
Patchen, M. (1993) Reciprocity of coercion and cooperation between individuals and nations. In R.B. Felson \& J.T. Tedeschi (Eds.) Aggression and violence: Social interactionist perspectives. Washington, DC: American Psychological Association.

Pearsall, M. J., Ellis, A. P., \& Stein, J. H. (2009). Coping with challenge and hindrance stressors in teams: Behavioral, cognitive, and affective outcomes. Organizational Behavior and Human Decision Processes, 109, 18-28.

Pearson, C. M., Andersson, L. M., \& Porath, C. L. (2000). Assessing and attacking workplace incivility. Organizational Dynamics, 29, 123-137.

Pearson, C. M., Andersson, L. M. \& Wegner, J. W. (2001). When workers flout convention: A study of workplace incivility. Human Relations, 54, 13871419.

Pinkley, R. L. (1990). Dimensions of conflict frame: disputant interpretations of conflict. Journal of Applied Psychology, 75, 117-126.

Podsakoff, P. M., MacKenzie, S. B., Lee, J. Y., \& Podsakoff, N. P. (2003). Common method biases in behavioral research: A critical review of the literature and recommended remedies. Journal of Applied Psychology, 88, 879-903.

Porath, C.L. \& Pearson, C.M. (2000). Gender differences and the behavior of targets of workplace incivility: He 'dukes' it out, she 'disappears' herself. Paper presented at the Academy of Management, Toronto, Canada.

Restubog, S. L. D., Scott, K. L., \& Zagenczyk, T. J. (2011). When distress hits home: the role of contextual factors and psychological distress in predicting employees' responses to abusive supervision. Journal of Applied Psychology, 96, 713-729.

Rhoades, L., \& Eisenberger, R. (2002). Perceived organizational support: A review of the literature. Journal of Applied Psychology, 87, 698-714.

Roberts, C. S., \& Feetham, S. L. (1982). Assessing family functioning across three areas of relationships. Nursing Research, 31, 231-235.

Robinson, S.L., \& Bennett, R.J. (1995). A typology of deviant workplace behaviors: A multidimensional scaling study. Academy of Management Journal, 38, 555-572.

Rook, S. K. (1984). The negative side of social interaction: Impact on psychological well-being. Journal of Personality and Social Psychology, 46, 1097-1108. 
Rooney, J. A., Gottlieb, B. H., \& Newby-Clark, I. R. (2008). How support-related managerial behaviors influence employees: An integrated model. Journal of Managerial Psychology, 24, 410-427.

Salovey, P., \& Mayer, J. D. (1990). Emotional intelligence. Imagination, Cognition and Personality, 9, 185-211.

Schat, A. C. H., Desmarais, S., \& Kelloway, E. K. 2006. Exposure to workplace aggression from multiple sources: Validation of a measure and test of a model. Unpublished manuscript, McMaster University, Hamilton, Canada.

Schat, A. C. H., Frone, M., \& Kelloway, E. K. (2006). The prevalence of workplace aggression in the U.S. workforce: Findings from a national study. In E. K. Kelloway, J. Barling, \& J. J. Hurrell Jr. (Eds.), Handbook of workplace violence (pp. 579-606). Thousand Oaks, CA: Sage.

Schaubhut, N., Adams, G. A., \& Jex, S. M. (2004). Self-esteem as a moderator of the relationships between abusive supervision and two forms of workplace deviance. In annual meeting of the Society for Industrial Organizational Psychology, Chicago, IL.

Schwartz, J.E., \& Stone, A.A. (1993). Coping with daily work problems: Contributions of problem content, appraisals, and person factors. Work and Stress, 7, 47-62.

Schwartz, J. E., \& Stone, A. A. (1998). Strategies for analyzing ecological momentary assessment data. Health Psychology, 17, 6-16.

Schutte, N. S., Malouff, J. M., Simunek, M., McKenley, J., \& Hollander, S. (2002). Characteristic emotional intelligence and emotional well-being. Cognition and Emotion, 16, 769-785.

Selye, $\mathrm{H}$. (1946). The general adaptation syndrome and the diseases of adaptation. Journal of Clinical Endocrinology, 6, 117-230. doi:10.1210/jcem-6-2-117

Seyle, H. (1956). The Stress of life. New York: McGraw-Hill.

Selye, H. (1974). Stress without distress. Lippincott: New York.

Shirom, A., Toker, S., Berliner, S., \& Shapira, I. (2006). Burnout and risk of cardiovascular disease: evidence, possible causal paths, and promising research directions. Psychological Bulletin, 132, 327-353.

Smith, C.S., \& Sulsky, L. (1995). An investigation of job-related coping strategies across multiple stressors and samples. In L.R. Murphy, J.J. Hurrell, S.L. Sauter, \& G.P. Keita (Eds.), Job stress interventions (pp. 109-123). Washington, DC: American Psychological Association. 
Solomon, R.C. (1998). The moral psychology of business: care and compassion in the corporation. Business Ethics Quarterly, 8, 515-533.

Spector, P. E. (1985). Measurement of human service staff satisfaction: Development of the Job Satisfaction Survey. American Journal of Community Psychology, 13, 693-713.

Spector, P. E., Dwyer, D. J., \& Jex, S. M. (1988). Relation of job stressors to affective, health, and performance outcomes: A comparison of multiple source data. Journal of Applied Psychology, 73, 11-19.

Spector, P. E. (1998). A control model of the job stress process. In C. L. Cooper (Ed.). Theories of Organizational Stress (pp. 153-169). London: Oxford University Press.

Spector, P. E., \& Jex, S. M. (1998). Development of Four Self-Report Measures of Job Stressors and Strain: Interpersonal Conflict at Work Scale, Organizational Constraints Scale, Quantitative Workload Inventory, and Physical Symptoms Inventory. Journal of Occupational Health Psychology, 3, 356-367.

Sulea, C., Fine, S., Fischmann, G., Sava, F. A., \& Dumitru, C. (2013). Abusive supervision and counterproductive work behaviors: The moderating effects of personality. Journal of Personnel Psychology, 12, 196-200.

Tepper, B.J. (2000). Consequences of abusive supervision. Academy of Management Journal, 43, 178-190.

Tepper, B., Duffy, M., Henle, C., \& Lambert, L. (2006). Procedural injustice, victim precipitation, and abusive supervision. Personnel Psychology, 59, 101-123.

Tepper, B. J., Carr, J. C., Breaux, D. M., Geider, S., Hu, C., \& Hua, W. (2009). Abusive supervision, intentions to quit, and employees' workplace deviance: A power/dependence analysis. Organizational Behavior and Human Decision Processes, 109, 156-167.

VandenBos, G. R. \& Bulatao E. Q. (1996). Violence on the job: Identifying risks and developing solutions. Washington, DC: American Psychological Association.

Van den Berg, P. T., \& Feij, J. A. (2003). Complex relationships among personality traits, job characteristics, and work behaviors. International Journal of Selection and Assessment, 11, 326-339.

Verona, E., Reed, A., Curtin, J. J., \& Pole, M. (2007). Gender differences in emotional and overt/covert aggressive responses to stress. Aggressive Behavior, 33, 261-271. 
Vie, T. L., Glasø, L., \& Einarsen, S. (2011). Health outcomes and self-labeling as a victim of workplace bullying. Journal of Psychosomatic Research, 70, 37-43.

Vinokur, A. D., \& Van Ryn, M. (1993). Social support and undermining in close relationships: their independent effects on the mental health of unemployed persons. Journal of Personality and Social Psychology, 65, 350-359.

Vroom, V. \& Yetton, P. (1973). Leadership and decision-making. Pittsburgh, PA: University of Pittsburgh Press.

Wegner, J.W. (1996). Lawyers, learning and professionalism. Cleveland State Law Review, 43,191-216.

Williams, K., \& Alliger, G. M. (1994). Role stressors, mood spillover, and perceptions of work-family conflict in employed parents. Academy of Management Journal, 37, 837-868.

Wong, C. S., \& Law, K. S. (2002). The effects of leader and follower emotional intelligence on performance and attitude: An exploratory study. The Leadership Quarterly, 13, 243-274.

Workplace Bullying Institute. (2010). Results of the 2010 WBI U.S. workplace bullying survey. Retrieved from http://www.workplacebullying.org/wbiresearch/2010-wbi-national-survey/

Zellars, K. L., Perrewe, P. L., Hochwarter, W. A. (2000). Burnout in health care: the role of the five factors of personality. Journal of Applied Social Psychology, 30, 1570-1598.

Zellars, K. L., Tepper, B. J., \& Duffy, M. K. (2002). Abusive supervision and subordinates' organizational citizenship behavior. Journal of Applied Psychology, 87, 1068-1076.

Zimmerman, R. D. (2008). Understanding the impact of personality traits on individuals' turnover decisions: A meta-analytic path model. Personnel Psychology, 61, 309-348. 


\title{
APPENDICES
}

\author{
APPENDIX A
}

Measures and Scale Items

\section{Study Condition One:}

\section{Abusive Supervision Scale - Tepper, 2000}

Instructions: Please consider the following scale items and chose the answer choice that best represents the frequency of your own experience with abusive supervision at work.

1 = "I cannot remember him/her ever using this behavior with me"; 2 = "He/she very seldom uses this behavior with me"; $3=$ "He/she occasionally uses this behavior with me"; 4 = "He/she uses this behavior moderately often with me"; 5 = "He/she uses this behavior very often with me."

Each scale items begins with the statement, "My boss ... "

Ridicules me

Tells me my thoughts or feelings are stupid

Gives me the silent treatment

Puts me down in front of others Invades my privacy

Reminds me of my past mistakes and failures Doesn't give me credit for jobs requiring a lot of effort Blames me to save himself/herself embarrassment Breaks promises he/she makes Expresses anger at me when he/she is mad for another reason Makes negative comments about me to others Is rude to me Does not allow me to interact with my coworkers Tells me I'm incompetent Lies to me

\section{Negative Acts Questionnaire - Revised (NAQ-R) - Einarsen, 2009}

Instructions: Please consider the following scale items and chose the answer choice that best represents the frequency of your own experience with bullying at work.

$1=$ Never $; 2=$ Once or twice $; 3=$ Once or twice per week; $4=$ Most days; $5=$ Everyday. 
During the last month, how often have you been subjected to the following negative acts in the workplace?

Someone withholding information which affects your performance

Being ordered to do work below your level of competence

Having your opinions ignored

Being given tasks with unreasonable deadlines

Excessive monitoring of your work

Pressure not to claim something to which by right you are entitled (e.g. sick

leave, holiday entitlement, travel expenses)

Being exposed to an unmanageable workload

Being humiliated or ridiculed in connection with your work

Having key areas of responsibility removed or replaced with more trivial or unpleasant tasks

Spreading of gossip and rumors about you

Being ignored or excluded

Having insulting or offensive remarks made about your person, attitudes or your private life

Hint or signals from others that you should quit your job

Repeated reminders of your errors or mistakes

Being ignored or facing a hostile reaction when you approach

Persistent criticism of your errors or mistakes

Practical jokes carried out by people you don't get along with

Having allegations made against you

Being the subject of excessive teasing and sarcasm

Being shouted at or being the target of spontaneous anger

shoving, Intimidating behaviors such as finger-pointing, invasion of personal space,

blocking your way

Threats of violence or physical abuse or actual abuse

\section{Interpersonal Conflict at Work - Spector \& Jex’s (1998)}

Instructions: Please consider the following scale items and chose the answer choice that best represents the frequency of your own experience with Interpersonal Conflict at work.

1 = Never; 2 = Rarely; 3 = Sometimes; 4 = Quite Often; 5 = Very Often

How often do you get into arguments with others at work? How often do other people yell at you at work? How often are people rude to you at work? How often do other people do nasty things to you at work?

Social Undermining - Duffy, Ganster, \& Pagon, 2002 
Instructions: Please consider the following scale items and chose the answer choice that best represents the frequency of your own experience with undermining at work. The items are separated into two parts, the first of which is preceded by a stem indicating your supervisor as the source of the undermining behavior. While the second set of items is preceded by a stem indicating your coworker as the source of the social undermining behavior.

$1=$ Never $; 2=$ Once or twice $; 3=$ Once or twice per week; $4=$ Most days; $5=$ Everyday.

How often has your supervisor intentionally Hurt your feelings?

Put you down when you questioned work procedures? Undermined your effort to be successful on the job? Let you know they did not like you or something about you? Talked bad about you behind your back? Insulted you? Belittled you or your ideas? Spread rumors about you? Made you feel incompetent? Delayed work to make you look bad or slow you down? Talked down to you? Gave you the silent treatment? Did not defend you when people spoke poorly of you? How often has the coworker closest to you intentionally... Insulted you? Gave you the silent treatment? Spread rumors about you? Delayed work to make you look bad or slow you down? Belittled you or your ideas? Hurt your feelings? Talked bad about you behind your back? Criticized the way you handled things on the job in a way that was not helpful? Did not give as much help as they promised? Gave you incorrect or misleading information about the job? Competed with you for status and recognition? Let you know they did not like you or something about you? Did not defend you when people spoke poorly of you?

\section{Workplace Incivility Scale (WIS)- Cortina, Magley, Williams, \& Langhout, 2001}

Instructions: Please read the statement below, consider the following scale items, and chose the answer choice that best represents the frequency of your own experience with incivility at work. 
$1=$ Never $; 2=$ Once or twice $; 3=$ Once or twice per week; $4=$ Most days; $5=$ Everyday.

"During the past month while employed by your current employer, have you been in a situation where any of your superiors or coworkers?"

Put you down or was condescending to you?

Paid little attention to your statement or showed little interest in your

opinion?

Made demeaning or derogatory remarks about you?

Addressed you in unprofessional terms, either publicly or privately? Ignored or excluded you from professional camaraderie? Doubted your judgment on a matter over which you have responsibility? Made unwanted attempts to draw you into a discussion of personal matters?

\section{Aggressive Culture Scale - Modified - Douglas \& Martinko, 2001}

Instructions: For the following: Please read each statement and indicate how accurate you believe the statement to be by selecting the number on the scale which best describes your response.

1=Absolutely Not True; 2=Not True; 3=Neutral; 4=True; 5=Absolutely True

In this organization, employees are often engaged in verbal confrontations. In this organization, employees are often insulting each other. In this organization, employees are often threatening to do bad things to each other.

\section{Ten-Item Personality Inventory (TIPI) - Gosling, Rentfrow, \& Swann, 2003}

Instructions: Please consider each of the following personality characteristics that may or may not apply to you. Please select the answer choice which best indicates your level of agreement or disagreement with each pair of characteristics. Please note that you should rate the degree to which both characteristics applies to you, even if one applies more strongly that the other.

1=Disagree Strongly; $2=$ Disagree Moderately; $3=$ Disagree a Little; 4=Neither Agree or Disagree; 5=Agree a Little; 6=Agree Moderately; $7=$ Agree Strongly

I see myself as:

Extraverted, Enthusiastic Critical, Quarrelsome Dependable, Self-disciplined Anxious, Easily Upset Open to New Experiences, Complex 
Reserved, Quiet

Sympathetic, Warm

Disorganized, Careless

Calm, Emotionally Stable

Conventional, Uncreative

\section{Wong \& Law EI Scale (WLEIS) - Wong \& Law, 2003}

Instructions: Please consider each of the following statements and select the answer choice which best indicates your level of agreement or disagreement.

1=Disagree Strongly; 2=Disagree Moderately; 3=Disagree a Little; 4=Neither Agree or Disagree; $5=$ Agree a Little; $6=$ Agree Moderately; $7=$ Agree Strongly I have a good sense of why I have certain feelings most of the time. I have good understanding of my own emotions. I really understand what I feel.

I always know whether or not I am happy.

I always know my friends' emotions from their behavior.

I am a good observer of others' emotions.

I am sensitive to the feelings and emotions of others.

I have good understanding of the emotions of people around me.

I always set goals for myself and then try my best to achieve them.

I always tell myself I am a competent person.

I would always encourage myself to try my best.

_ I am able to control my temper so that I can handle difficulties rationally.

I am quite capable of controlling my own emotions.

I can always calm down quickly when I am very angry. I have good control of my own emotions.

\section{In the context of workplace aggression within your organization, please answer the following 3-Part Question.}

1. Does your organization have a process for recourse when experiencing workplace aggression? $\mathrm{Y}$ or $\mathrm{N}$.

2. Are you aware of any specific organizational response or process for those experiencing workplace aggression? $\mathrm{Y}$ or $\mathrm{N}$

3. If you answered yes to the previous question, what is the organizational response/s?

\section{Study Time 2:}

WAAMS - Nixon, 2011 
Instructions: The following scale asks about seven types of behaviors that you may have experienced at work. In addition, there are follow up questions for each of the behaviors you have experienced. However, if you have not experienced the behaviors, please skip to the next question. Please consider each of the following aggressive behavior scale item and sub-items and chose the answer choice that you feel most accurately represents your experience or perceptions about the given behavior.

1. How many times have you experienced verbal aggression at work (for example, someone yelled at, ridiculed, insulted you, or told you that you were incompetent) IN THE PAST MONTH?
Not at all
1
2
3
4
5 or more

1a. How many acts of verbal aggression were enacted by individuals in the following positions?

Customer/Patient: (\#) of acts

Coworker:

(\#) of acts
Supervisor:

(\#) of acts

1b. In general, you feel these acts of verbal aggression were intended to harm you.
Strongly
Disagree
Slightly
Slightly
Agree
Strongly
Disagree
Disagree Agree
Agree

1c. In general, you feel that when these acts of verbal aggression occurred, other people in your organization were aware of it.
Strongly
Disagree
Slightly
Slightly
Disagree
Disagree Agree
Agree
Strongly
Agree

1d. In general, how much do these acts of verbal aggression upset you?
Not at all
Slightly
Somewhat Moderatel
A lot
Greatly
y

2. How many times have you experienced intimidation at work (for example, threatening looks or postures) IN THE PAST MONTH?
Not at all
1
2
3
4
5 or more

2a. How many acts of intimidation were enacted by individuals in the following positions?

Customer/Patient:

Coworker:

(\#) of acts
Supervisor:

(\#) of acts

2b. In general, you feel these acts of intimidation were intended to harm you.
Strongly
Disagree
Slightly
Slightly
Agree
Strongly
Disagree
Disagree Agree
Agree

2c. In general, you feel that when these acts of intimidation occurred, other people in your organization were aware of it.

$\begin{array}{lllll}\begin{array}{l}\text { Strongly } \\ \text { Disagree }\end{array} & \text { Disagree } & \begin{array}{l}\text { Slightly } \\ \text { Disagree }\end{array} & \begin{array}{l}\text { Slightly Agree } \\ \text { Agree }\end{array} & \begin{array}{l}\text { Strongly } \\ \text { Agree }\end{array}\end{array}$


2d. In general, how much do these acts of intimidation upset you?

Not at all Slightly Somewhat $\begin{aligned} & \text { Moderatel A lot Greatly } \\ & y\end{aligned}$

3. How many times have you been excluded at work (for example, someone excluded you from social activities, gave you the silent treatment, or withheld work information) in THE PAST MONTH?
Not at all
2
3
4
5 or more

3a. How many acts of exclusion were enacted by individuals in the following positions?
Customer/Patient:
Coworker:
Supervisor:

(\#) of acts

(\#) of acts

(\#) of acts

3b. In general, you feel these acts of exclusion were intended to harm you.
Strongly
Disagree
Slightly
Slightly
Disagree Agree
Agree
Strongly
Disagree

3c. In general, you feel that when these acts of exclusion occurred, other people in your organization were aware of it.
Strongly
Disagree
Slightly
Slightly Agree
Strongly
Disagree
Disagree Agree
Agree

3d. In general, how much do these acts of exclusion upset you?
Not at all
Slightly
Somewhat
Moderate
A lot
Greatly
y

4. How many times have you been undermined at work (for example, someone made negative comments about you to others, tried to make you look bad, or sabotaged you) in THE PAST MONTH?
Not at all
2
3
4
5 or more

4a. How many acts of undermining were enacted by individuals in the following positions?

Customer/Patien (\#) of acts

Coworker:

(\#) of acts
Supervisor:

(\#) of acts

4b. In general, you feel these acts of undermining were intended to harm you.

Strongly

Disagree

Slightly

Disagree

Slightly

Agree

Agree

Strongly

Agree

4c. In general, you feel that when these acts of undermining occurred, other people in your organization were aware of it.

Strongly Disagree Slightly Slightly Agree Strongly Disagree Disagree Agree Agree

4d. In general, how much do these acts of undermining upset you?
Not at all
Slightly
Somewhat
Moderatel
A lot
Greatly 
5. How many times have you experienced rude behavior at work in THE PAST MONTH?

$\begin{array}{llllll}\text { Not at all } & 1 & 2 & 3 & 4 & 5 \text { or more }\end{array}$

5a. How many acts of rude behavior were enacted by individuals in the following positions?

Customer/Patient: Coworker: Supervisor:
(\#) of acts
(\#) of acts
(\#) of acts

5b. In general, you feel these acts of rude behavior were intended to harm you.

$\begin{array}{lllll}\begin{array}{l}\text { Strongly } \\ \text { Disagree }\end{array} & \text { Disagree } & \begin{array}{l}\text { Slightly } \\ \text { Disagree }\end{array} & \begin{array}{l}\text { Slightly Agree } \\ \text { Agree }\end{array} & \begin{array}{l}\text { Strongly } \\ \text { Agree }\end{array}\end{array}$

5c. In general, you feel that when these acts of rude behavior occurred, other people in your organization were aware of it.

Strongly Disagree Slightly Slightly Agree Strongly Disagree Disagree Agree Agree

$5 \mathrm{~d}$. In general, how much do these acts of rude behavior upset you?
Not at all
Slightly
Somewhat
Moderatel
A lot
Greatly
y

6. How many times have you experienced interpersonal conflict at work (For example, arguing with or having shouting matches with others at work) in THE PAST MONTH?
Not at all 1
2
3
4
5 or more

6a. How many acts of interpersonal conflict were enacted by individuals in the following positions?

Customer/Patient:

(\#) of acts

Coworker:

(\#) of acts
Supervisor:

(\#) of acts

6b. In general, you feel these acts of interpersonal conflict were intended to harm you.
Strongly
Disagree
Disagree
$\begin{array}{ll}\text { Slightly } & \text { Slightly } \\ \text { Disagree } & \text { Agree }\end{array}$
Agree
Strongly
Agree

6c. In general, you feel that when these acts of interpersonal conflict occurred, other people in your organization were aware of it.
Strongly
Disagree
Slightly
Slightly
Disagree Agree
Agree
Strongly
Agree

$6 \mathrm{~d}$. In general, how much do these acts of interpersonal conflict upset you? Not at all Slightly Somewhat Moderately A lot Greatly

7. How many times have you experienced physical aggression at work (for example, you have been hit, pushed, bit, spit on, or been hit with an object) in 
THE PAST MONTH?

$\begin{array}{llllll}\text { Not at all } & 1 & 2 & 3 & 4 & 5 \text { or more }\end{array}$

7a. How many times have you been injured by any of these acts of physical aggression?

$\begin{array}{llllll}\text { Not at all } & 1 & 2 & 3 & 4 & 5 \text { or more }\end{array}$

7b. How many acts of physical aggression were enacted by individuals in the following positions?

Customer/Patient:

(\#) of acts

Coworker:

(\#) of acts
Supervisor:

(\#) of acts

7c. In general, you feel these acts of physical aggression were intended to harm you.
Strongly
Disagree
Disagree
$\begin{array}{ll}\text { Slightly } & \text { Slightly } \\ \text { Disagree } & \text { Agree }\end{array}$
Agree
Strongly
Agree

7d. In general, you feel that when these acts of physical aggression occurred, other people in your organization were aware of it.
Strongly
Disagree
Slightly
Disagree
Slightly
Agree
Agree
Strongly
Disagree
Agree

\section{Not at all \\ Slightly \\ Somewhat Moderately A lot}

\section{Job Satisfaction Scale - Hackman \& Oldham, 1975}

Instructions: Please indicate how you personally feel about your job. Each of the statements below is something that a person might say about his or her job. You are to indicate your own personal feelings about your job by marking how much you agree with each of the statements.

1 = Strongly Disagree; 2 = Disagree; 3 = Neutral; 4 = Agree; 5 = Strongly Agree

Generally speaking, I am very satisfied with my job.

I frequently think I would like to change my current job.

I am generally satisfied with the kind of tasks I do at my job.

Turnover Intent - Spector, Dwyer, \& Jex, 1988

Instructions: Please consider the following scale item and chose the answer choice that best represents the frequency at which you think about and or consider leaving your current job.

1 = Never; 2 = Rarely; 3 = Sometimes; 4 = Often; 5 = Quite Often; 6 = Extremely Often 
How often have you seriously considered quitting your job?

\section{Organizational Citizenship Behavior Checklist (OCB-C) - Fox, Spector, Bruursema, Kessler \& Goh, 2012}

Instructions: Please read the statement below, consider the following scale items, and chose the answer choice that best represents the frequency at which you exhibit the following behaviors in your current job.

$1=$ Never $; 2=$ Once or Twice; $3=$ Once or Twice Per Month; $4=$ Once or Twice Per Week; 5 = Every Day

How often have you each of the following things on your present job?

Picked up meal for others at work

Took time to advise, coach, or mentor a co-worker.

Helped co-worker learn new skills or shared job knowledge.

Helped new employees get oriented to the job.

Lent a compassionate ear when someone had a work problem.

Lent a compassionate ear when someone had a personal problem.

Changed vacation schedule, work days, or shifts to accommodate co-

worker's needs.

Offered suggestions to improve how work is done.

Offered suggestions for improving the work environment.

Finished something for co-worker who had to leave early.

Helped a less capable co-worker lift a heavy box or other object.

Helped a co-worker who had too much to do.

Volunteered for extra work assignments.

Took phone messages for absent or busy co-worker.

Said good things about your employer in front of others.

Gave up meal and other breaks to complete work.

Volunteered to help a co-worker deal with a difficult customer, vendor, or co-

worker.

Went out of the way to give co-worker encouragement or express

appreciation.

Decorated, straightened up, or otherwise beautified common work space.

Defended a co-worker who was being "put-down" or spoken ill of by other coworkers or supervisor.

\section{Interpersonal \& Organizational Deviance Scale - Bennett \& Robinson, 2000 (Adapted)}

Instructions: Please read the statement below, consider the following scale items, and chose the answer choice that best represents the frequency at which you exhibit the following behaviors in your current job. 
$1=$ Never $; 2=$ Rarely $3=$ Occasionally; $4=$ Sometimes $; 5=$ Frequently; $6=$ Usually; 7 = Always.

Made fun of someone at work Said something hurtful to someone at work Made an ethnic, religious, or racial remark at work Cursed at someone at work Played a mean prank on someone at work Acted rudely toward someone at work Publicly embarrassed someone at work Taken property from work without permission Spent too much time fantasizing or daydreaming instead of working Falsified a receipt to get reimbursed for more money than you spent on business expenses Taken an additional or longer break than is acceptable at your workplace Come in late to work without permission Littered your work environment Neglected to follow your boss's instructions) Intentionally worked slower than you could have worked Discussed confidential company information with an unauthorized person Used an illegal drug or consumed alcohol on the job Put little effort into your work Dragged out work in order to get overtime

\section{Physical Symptoms Inventory (PSI) - Spector \& Jex, 1998}

Instructions: Please consider the following scale items and chose the answer choice that best represents the frequency at which you have experienced the following symptoms over the past month.

$1=$ Not at all; $2=$ Once or twice; $3=$ Once or twice per week; $4=$ Most days; $5=$ Everyday.

Over the past month, how often have you experienced each of the following symptoms?

An upset stomach or nausea

Trouble sleeping

Headache

Acid indigestion or heartburn

Eye strain

Diarrhea

Stomach cramps (Not menstrual)

Constipation

Ringing in the ears 


\section{Spousal Undermining Scale - Restubog, Scott, \& Zagenczyk, 2011}

Instructions: Using the following seven-point response scale, please rate the extent to which your spouse has engaged in each of these behaviors.

$1=\mathrm{He} / \mathrm{she}$ cannot remember using this behavior towards me

$2 \quad 3 \quad 4 \quad 5 \quad 6$

$7=\mathrm{He} / \mathrm{she}$ always use this behavior towards me

1. Acted in an unpleasant or angry manner towards me

2. Gave a critical remark on my ideas

3. Criticized me

4. Insulted me

5. Gave me the silent treatment 


\section{APPENDIX B}

Table 1

Construct Definitions, Assumptions, and Sample Overlapping Items (Hershcovis, 2011)

\begin{tabular}{|c|c|c|}
\hline Construct and Definition & $\begin{array}{l}\text { Construct Assumptions and } \\
\text { Distinguishing } \\
\text { Characteristics }\end{array}$ & $\begin{array}{l}\text { Sample of Items that Overlap with Other } \\
\text { Measures }\end{array}$ \\
\hline $\begin{array}{l}\text { Social Undermining } \\
\text { Definition: Behavior intended to } \\
\text { hinder, over time, the ability to establish } \\
\text { and maintain positive interpersonal } \\
\text { relationships, work-related success, and } \\
\text { favorable } \\
\text { reputation (Duffy, Ganster, \& } \\
\text { Pagon, 2002) }\end{array}$ & $\begin{array}{ll}- & \text { Intent } \\
\text { - } & \text { Affects specific outcomes } \\
\text { including } \\
\circ \quad \text { Relationships } \\
\circ \quad \text { Reputation } \\
\circ \quad \text { Work-related success }\end{array}$ & $\begin{array}{ll} & \text { Put you down when you questioned work } \\
- & \text { procedures } \\
\text { - } & \text { Talked bad about you behind your back } \\
\text { - } & \text { Insulted you } \\
\text { - } & \text { Spread rumors about you } \\
\text { - } & \text { Delayed woul incompetent } \\
& \text { you down } \\
-\quad & \text { Talked down to you } \\
- & \text { Gave you the silent treatment } \\
- & \text { Belittled you or your ideas } \\
- & \text { Criticized the way you handled things on the } \\
& \text { job in a way that was not helpful } \\
\end{array}$ \\
\hline $\begin{array}{l}\text { Incivility } \\
\text { Definition: Low intensity deviant acts, } \\
\text { such as rude and } \\
\text { discourteous verbal and nonverbal } \\
\text { behaviors enacted towards another } \\
\text { organizational member with ambiguous } \\
\text { intent to harm (Andersson \& Pearson, } \\
\text { 1999). }\end{array}$ & $\begin{array}{ll}\text { - } & \text { Low intensity } \\
\text { - } & \text { Ambiguous intent }\end{array}$ & $\begin{array}{l}\text { - } \quad \text { Put you down in a condescending way } \\
\text { Made demeaning or derogatory remarks } \\
\text { about you } \\
\text { Paid little attention to your statement or } \\
\text { showed little interest in your opinion } \\
\text { - } \quad \text { gnored or excluded you from social } \\
\text { camaraderie } \\
\text { - Made unwanted attempts to draw you into } \\
\text { discussion of personal matters }\end{array}$ \\
\hline $\begin{array}{l}\text { Bullying } \\
\text { Definition: Situations where a } \\
\text { person repeatedly and over a } \\
\text { period of time is exposed to } \\
\text { negative acts (i.e. constant abuse, } \\
\text { offensive remarks or teasing, ridicule or } \\
\text { social exclusion) on the part of co- } \\
\text { workers, supervisors or subordinates } \\
\text { (Einarsen, 2000). }\end{array}$ & $\begin{array}{ll}- & \text { Persistent } \\
\text { - } & \text { Frequent } \\
& \text { Power imbalance }\end{array}$ & $\begin{array}{ll}\text { - } & \text { Ridicule } \\
\text { - } & \text { Repeated reminders of your blunders } \\
\text { - } & \text { Insulting teasing } \\
\text { - } & \text { Slander or rumors about you } \\
\text { - } & \text { Social exclusion from co-workers or work } \\
\text { - } & \text { Veroup activities } \\
\text { - } & \text { Devaluation of your work and efforts } \\
\text { - } & \text { Neglect of your opinions or views }\end{array}$ \\
\hline $\begin{array}{l}\text { Abusive Supervision } \\
\text { Definition: The sustained display of } \\
\text { hostile verbal and non-verbal behaviors, } \\
\text { excluding physical contact (Tepper, } \\
\text { 2000). }\end{array}$ & $\begin{array}{l}\text { - Excludes physical } \\
\text { Contact } \\
\text { Experience of aggression } \\
\text { from a supervisor is } \\
\text { different from experience of } \\
\text { aggression from someone } \\
\text { else } \\
\text { - Sustained }\end{array}$ & $\begin{array}{ll}\text { - } & \text { Ridicules me } \\
\text { - } & \text { Gives me the silent treatment } \\
\text { - } & \text { Puts me down in front of others } \\
\text { - } & \text { Invades my privacy } \\
\text { - } & \text { Reminds me of my past mistakes or } \\
\text { - } & \text { Failures } \\
\text { - } & \text { Others negative comments to me about } \\
\text { - } & \text { Tells me I'm incompetent }\end{array}$ \\
\hline $\begin{array}{l}\text { Interpersonal Conflict } \\
\text { Definition: An organizational } \\
\text { stressor involving disagreements } \\
\text { between employees (Spector \& } \\
\text { Jex, 1998). }\end{array}$ & $\begin{array}{l}\text { - No clear differentiating } \\
\text { features }\end{array}$ & $\begin{array}{l}\text { - How often are people rude to you at work? } \\
\text { - How often do other people do nasty things to } \\
\text { - } \quad \text { Hou at work? } \\
\end{array}$ \\
\hline
\end{tabular}


Table 2

Participants By Industry

\begin{tabular}{r|c}
\hline Industry & Percentage \\
\hline Education & $14.2 \%$ \\
Technology & $32.9 \%$ \\
Healthcare & $8.2 \%$ \\
Legal & $1.8 \%$ \\
Government & $5.5 \%$ \\
Non-Profit & $2.7 \%$ \\
Science & $2.3 \%$ \\
Research & $3.7 \%$ \\
Other & $28.8 \%$
\end{tabular}


Table 3 (with dichotomous variables)

Means, Standard Deviations, Coefficient Alphas and Correlations between all Study Variables

\begin{tabular}{|c|c|c|c|c|c|c|c|c|c|c|c|c|}
\hline Variables & $\mathrm{M}$ & SD & 1 & 2 & 3 & 4 & 5 & 6 & 7 & 8 & 9 & 10 \\
\hline $\begin{array}{l}\text { 1. Abusive } \\
\text { Supervision }\end{array}$ & 25.20 & 12.43 & (.96) & & & & & & & & & \\
\hline 2. Bullying & 36.27 & 17.05 & $.82^{* *}$ & $(.97)$ & & & & & & & & \\
\hline $\begin{array}{l}\text { 3. Interpersonal } \\
\text { Conflict }\end{array}$ & 7.23 & 3.47 & $.71^{\star *}$ & $.78^{\star \star}$ & $(.90)$ & & & & & & & \\
\hline 4. Incivility & 11.54 & 5.59 & $.68^{* *}$ & $.81^{* *}$ & $.68^{* \star}$ & (.92) & & & & & & \\
\hline $\begin{array}{l}\text { 5. Social } \\
\text { Undermining }\end{array}$ & 39.96 & 18.04 & $.78^{* *}$ & $.88^{* *}$ & $.77^{\star \star}$ & $.82^{\star *}$ & (.98) & & & & & \\
\hline $\begin{array}{l}\text { 6. Aggressive } \\
\text { Culture }\end{array}$ & 6.03 & 2.93 & $.58^{\star \star}$ & $.60^{* *}$ & $.65^{\star *}$ & $.58^{* *}$ & $.65^{\star *}$ & $(.86)$ & & & & \\
\hline $\begin{array}{l}\text { 7. Openness to } \\
\text { Experience }\end{array}$ & 10.21 & 2.42 & $-.22^{\star *}$ & $-.27^{\star *}$ & $-.21^{\star *}$ & $-.23^{\star *}$ & $-.29^{* *}$ & $-.24^{\star *}$ & (.62) & & & \\
\hline 8. Extraversion & 7.93 & 3.24 & -.07 & -.07 & .00 & -.10 & -.08 & -.07 & $.27^{\star *}$ & $(.71)$ & & \\
\hline 9. Agreeableness & 10.82 & 2.47 & $-.29^{\star \star}$ & $-.29^{\star *}$ & $-.26^{\star \star}$ & $-.26^{\star *}$ & $-.32^{\star *}$ & $-.21^{\star *}$ & $.31^{* *}$ & .05 & $(.61)$ & \\
\hline $\begin{array}{l}10 . \\
\text { Conscientiousness }\end{array}$ & 11.22 & 2.39 & $-.33^{\star *}$ & $-.41^{\star *}$ & $-.38^{* *}$ & $-.32^{* *}$ & $-.39^{* *}$ & $-.31^{* *}$ & $.39^{\star *}$ & $.15^{*}$ & $.42^{\star *}$ & $(.58)$ \\
\hline $\begin{array}{l}\text { 11. Emotional } \\
\text { Stability }\end{array}$ & 9.98 & 2.79 & $-.28^{\star \star}$ & $-.28^{\star *}$ & $-.27^{\star \star}$ & $-.29^{* *}$ & $-.33^{* *}$ & $-.25^{\star *}$ & $.24^{* *}$ & $.28^{* *}$ & $.48^{* *}$ & $.47^{* *}$ \\
\hline $\begin{array}{l}\text { 12. Emotional } \\
\text { Intelligence }\end{array}$ & 82.98 & 15.07 & $-.21^{* *}$ & $-.33^{* *}$ & $-.28^{* *}$ & $-.25^{\star *}$ & $-.34^{\star *}$ & $-.30^{* *}$ & $.44^{* *}$ & $.22^{* *}$ & $.44^{\star *}$ & $.59^{\star *}$ \\
\hline 13. Turnover & 2.94 & 1.49 & $.40^{* *}$ & $.36^{* *}$ & $.36^{* *}$ & $.37^{* *}$ & $.38^{* *}$ & $.43^{* *}$ & -.12 & $-.14^{*}$ & $-.25^{\star *}$ & $-.22^{\star *}$ \\
\hline 14. OCB's & 58.89 & 15.35 & $.20^{* *}$ & $.27^{\star *}$ & $.29^{\star \star}$ & $.15^{\star}$ & $.15^{\star}$ & .03 & $.16^{*}$ & $.26^{* *}$ & .08 & .08 \\
\hline 15. CWB's & 35.20 & 20.89 & $.57^{\star *}$ & $.60^{* *}$ & $.51^{* *}$ & $.45^{\star *}$ & $.53^{* *}$ & $.33^{* *}$ & $-.17^{\star}$ & .00 & $-.29^{* *}$ & $-.35^{\star *}$ \\
\hline $\begin{array}{l}\text { 16. Physical } \\
\text { Symptoms }\end{array}$ & 21.43 & 7.60 & $.39^{* \star}$ & $.48^{* *}$ & $.33^{\star *}$ & $.45^{\star *}$ & $.53^{\star \star}$ & $.28^{\star \star}$ & -.11 & -.09 & $-.19^{* *}$ & $-.19^{* *}$ \\
\hline $\begin{array}{l}\text { 17. Spousal } \\
\text { Undermining }\end{array}$ & 126.51 & 6.66 & $.39^{* \star}$ & $.39^{* *}$ & $.36^{* *}$ & $.32^{* *}$ & $.36^{* *}$ & $.19^{\star \star}$ & -.11 & -.09 & $-.24^{\star *}$ & $-.28^{\star *}$ \\
\hline 18. Job Satisfaction & 10.52 & 2.95 & $-.24^{\star *}$ & $-.25^{\star \star}$ & $-.18^{\star \star}$ & $-.27^{\star *}$ & $-.23^{\star *}$ & $-.35^{\star *}$ & $.16^{*}$ & $.18^{\star \star}$ & $.19^{\star *}$ & $.22^{\star *}$ \\
\hline $\begin{array}{l}\text { 19. WAAMS } \\
\text { Aggression }\end{array}$ & 14.21 & 7.15 & $.62^{* *}$ & $.72^{* *}$ & $.64^{\star \star}$ & $.67^{\star *}$ & $.67^{\star *}$ & $.48^{* *}$ & $-.25^{\star \star}$ & .00 & $-.30^{\star \star}$ & $-.39^{\star *}$ \\
\hline 20. WAAMS Intent & 18.58 & 9.01 & $.59^{* *}$ & $.58^{* *}$ & $.59^{\star *}$ & $.59^{* *}$ & $.56^{\star *}$ & $.49^{* *}$ & $-.29^{\star *}$ & -.05 & $-.24^{* *}$ & $-.38^{* *}$ \\
\hline $\begin{array}{l}\text { 21. WAAMS } \\
\text { Visibility }\end{array}$ & 20.16 & 8.84 & $.48^{* *}$ & $.48^{* *}$ & $.50^{* *}$ & $.48^{* *}$ & $.49^{* \star}$ & $.43^{\star *}$ & $-.21^{\star *}$ & .01 & $-.18^{*}$ & $-.34^{\star *}$ \\
\hline $\begin{array}{l}\text { 22. WAAMS } \\
\text { Intensity }\end{array}$ & 18.72 & 9.36 & $.50^{\star *}$ & $.52^{* *}$ & $.50^{* *}$ & $.52^{* *}$ & $.53^{\star *}$ & $.40^{* *}$ & $-.25^{\star \star}$ & -.07 & $-.25^{\star *}$ & $-.37^{\star *}$ \\
\hline
\end{tabular}

Intensity

${ }^{* * *} \mathrm{p}<.001 ; \mathrm{N}-$ Range: $162-219$

$.52^{\star *} \quad .53^{\star *}$

Note. ${ }^{*} p<.05,{ }^{* *} p<.01,{ }^{* \star *} \mathrm{p}<.001 ; \mathrm{N}$-Range: $162-219$ 
Table 4 (with dichotomous variables)

Means, Standard Deviations, Coefficient Alphas and Correlations between all Study Variables (continued)

$\begin{array}{llllllllll}\text { Variables } & 11 & 12 & 13 & 14 & 15 & 16 & 17 & 18 & 19\end{array}$ 1. Abusive

Supervision

2. Bullying

3. Interpersonal

Conflict

4. Incivility

5. Social

Undermining

6. Aggressive

Culture

7. Openness to

Experience

8. Extraversion

9. Agreeableness

10

Conscientiousness

11. Emotional

Stability

12. Emotional

Intelligence

$.45^{* *} \quad(.94)$

13. Turnover

$-.29^{* *}-.26^{\star *}$

14. OCB's

$.08 \quad .27^{\star *}$

$(-)$

15. CWB's

16. Physical

Symptoms

17. Spousal

Undermining

18. Job

Satisfaction

19. WAAMS

Aggression

20. WAAMS Intent

$.30^{* *} \quad-.19^{* *}$

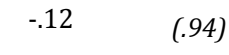

$\begin{array}{llll}.27^{* *} & -.19^{* *} & .35^{* *} & .19^{* *}\end{array}$

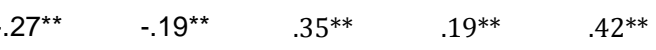

(.97)

(.89)

$-.26^{\star *}-.25^{\star *}$

$.19^{* *} \quad .54^{* *}$

$.41^{* *}$

(.93)

$\begin{array}{llllll}.25^{* *} & .35^{* *} & -.72^{* *} & .35^{* *} & -.14^{*} & -.24^{* *}\end{array}$

$-.03$

$-.26^{* *} \quad-.32^{* *} \quad .44^{* *}$

$.22^{* *}$

$.62^{* *}$

$.45^{* *}$

$.46^{* *}$

$(.79)$

21. WAAMS

$-.21^{\star *}-.22^{\star *}$

$.32^{* *}$

$.50 * *$

$.31^{* *}$

$.36^{* *}$

$-.29 * *$

Visibility

$-.17^{* *} \quad-.21^{* *} \quad .24^{* *} \quad .25^{* *}$

$.46^{* *}$

$.26^{* *}$

$.31^{* *} \quad-.20^{*}$

$.20^{*} \quad .69^{* *}$

(.87)

22. WAAMS

$-.28^{* *}$

$.32^{* *}$

$.40^{* *}$

$.32^{* *}$

$.32^{* *}$

$-.29^{* *}$

$.72^{* *}$

$87^{* *}$

Note. ${ }^{*} p<.05,{ }^{* *} p<.01,{ }^{* * *} \mathrm{p}<.001 ; \mathrm{N}$-Range: $162-219$ 
Table 5

Summary of Results from the CFA Analyses

\begin{tabular}{|c|c|c|c|c|}
\hline Model & $\begin{array}{c}\text { Chi Square } \\
\left(x^{2} \& d f\right)\end{array}$ & $\begin{array}{c}\text { Standard Root Squared } \\
\text { Residual (SRMR) }\end{array}$ & $\begin{array}{c}\text { Root Mean Square Error } \\
\text { of Approximation } \\
\text { (RMSEA \& 90\% Cl) }\end{array}$ & $\begin{array}{l}\text { Akaike Information } \\
\text { Criterion } \\
\text { (AIC) }\end{array}$ \\
\hline One Factor Model & $9011.84(\mathrm{df}=2627)$ & .07 & $.11(\mathrm{Cl}=[.11, .12])$ & 27476.24 \\
\hline Five Factor Model & $7710.61(\mathrm{df}=2617)$ & .06 & $.10(\mathrm{Cl}=[.10, .10])$ & 26195.01 \\
\hline $\begin{array}{l}\text { Higher-order Five } \\
\text { Factor Model }\end{array}$ & $7719.05(\mathrm{df}=2622)$ & .06 & $.10(\mathrm{Cl}=[.10, .10])$ & 26193.45 \\
\hline
\end{tabular}


Table 6

Moderated Regression Analyses for Workplace Aggression, Strain Based Outcomes and Workplace Aggression Nuance Variables as Moderators

\begin{tabular}{|c|c|c|c|c|c|c|c|c|c|c|c|c|}
\hline \multirow[t]{2}{*}{ 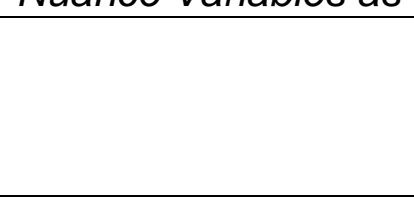 } & \multicolumn{4}{|c|}{$\underline{\text { Turnover Intent }}$} & \multicolumn{4}{|c|}{ OCB's } & \multicolumn{4}{|c|}{ CWB's } \\
\hline & $\beta$ & $\mathrm{R}^{2}$ & $\Delta \mathrm{R}^{2}$ & $\Delta \mathrm{F}$ & $\beta$ & $\mathrm{R}^{2}$ & $\Delta \mathrm{R}^{2}$ & $\Delta \mathrm{F}$ & $\beta$ & $\mathrm{R}^{2}$ & $\Delta \mathrm{R}^{2}$ & $\Delta \mathrm{F}$ \\
\hline $\begin{array}{l}\text { Step } 1 \\
\text { Workplace Aggression }\end{array}$ & $.48^{* * *}$ & & & & $.17^{*}$ & & & & $.63^{* * *}$ & & & \\
\hline $\begin{array}{l}\text { Step } 2 \\
\text { Intent } \\
\text { Step } 3\end{array}$ & .00 & & & & $.41^{* * *}$ & & & & .03 & & & \\
\hline $\begin{array}{l}\text { Workplace Aggression } \\
\text { X Intent }\end{array}$ & -.05 & .23 & .00 & .34 & .16 & .12 & .02 & 2.61 & .12 & .41 & .01 & 2.20 \\
\hline
\end{tabular}

\begin{tabular}{|c|c|c|c|c|c|c|c|c|c|c|c|c|}
\hline $\begin{array}{l}\text { Step } 1 \\
\text { Workplace Aggression }\end{array}$ & $.44^{\star \star \star}$ & & & & .12 & & & & $.62^{\star \star \star}$ & & & \\
\hline $\begin{array}{l}\text { Step } 2 \\
\text { Intensity }\end{array}$ & .02 & & & & .15 & & & & -.16 & & & \\
\hline $\begin{array}{l}\text { Workplace Aggression } \\
\text { X Intensity }\end{array}$ & -.11 & .20 & .00 & 1.40 & .02 & .03 & .00 & .04 & -.12 & .41 & .01 & 2.40 \\
\hline
\end{tabular}

\begin{tabular}{|c|c|c|c|c|c|c|c|c|c|c|c|c|}
\hline $\begin{array}{l}\text { Step } 1 \\
\text { Workplace Aggression }\end{array}$ & $.44^{* * *}$ & & & & $.17^{*}$ & & & & $.64^{\star \star \star}$ & & & \\
\hline $\begin{array}{l}\text { Step } 2 \\
\text { Perceived Visibility } \\
\text { Step } 3\end{array}$ & -.13 & & & & $.23^{*}$ & & & & .01 & & & \\
\hline $\begin{array}{l}\text { Workplace Aggression } \\
\text { X Perceived Visibility }\end{array}$ & -.16 & .22 & .02 & 3.40 & .03 & .06 & .00 & .08 & .08 & .41 & .00 & 1.04 \\
\hline
\end{tabular}


Table 7

Moderated Regression Analyses for Workplace Aggression, Strain Based Outcomes and Workplace Aggression Nuance Variables as Moderators (continued)

\begin{tabular}{|c|c|c|c|c|c|c|c|c|c|c|c|c|}
\hline & \multicolumn{4}{|c|}{ Physical Symptoms } & \multicolumn{4}{|c|}{$\frac{\text { Interpersonal Relationships at }}{\underline{\text { Home }}}$} & \multicolumn{4}{|c|}{ Job Satisfaction } \\
\hline & $\beta$ & $\mathrm{R}^{2}$ & $\Delta \mathrm{R}^{2}$ & $\Delta \mathrm{F}$ & $\beta$ & $\mathrm{R}^{2}$ & $\Delta R^{2}$ & $\Delta \mathrm{F}$ & $\beta$ & $\mathrm{R}^{2}$ & $\Delta \mathrm{R}^{2}$ & $\Delta \mathrm{F}$ \\
\hline $\begin{array}{l}\text { Step } 1 \\
\text { Workplace Aggression }\end{array}$ & $.45^{\star \star \star}$ & & & & $.46^{* * *}$ & & & & $-.30^{* * *}$ & & & \\
\hline $\begin{array}{l}\text { Step } 2 \\
\text { Intent } \\
\text { Step } 3\end{array}$ & -.07 & & & & .00 & & & & -.08 & & & \\
\hline $\begin{array}{l}\text { Workplace Aggression X } \\
\text { Intent }\end{array}$ & -.06 & .21 & .00 & .46 & .09 & .22 & .01 & 1.0 & $.24^{*}$ & $.13^{*}$ & $.03^{*}$ & $5.89^{*}$ \\
\hline
\end{tabular}

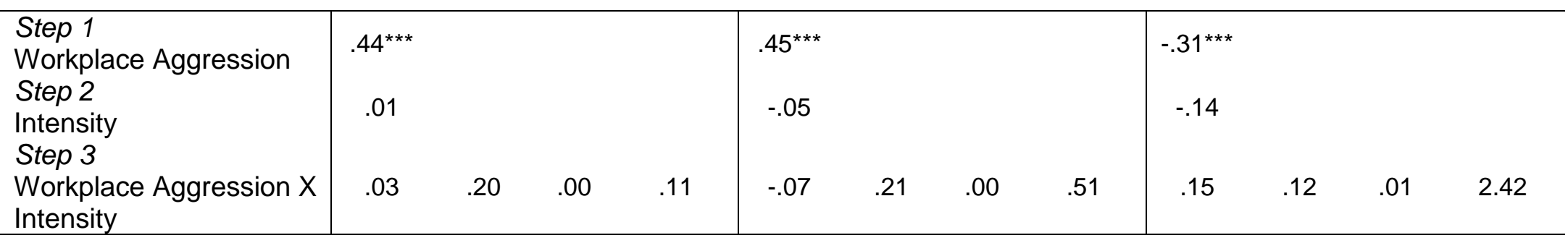

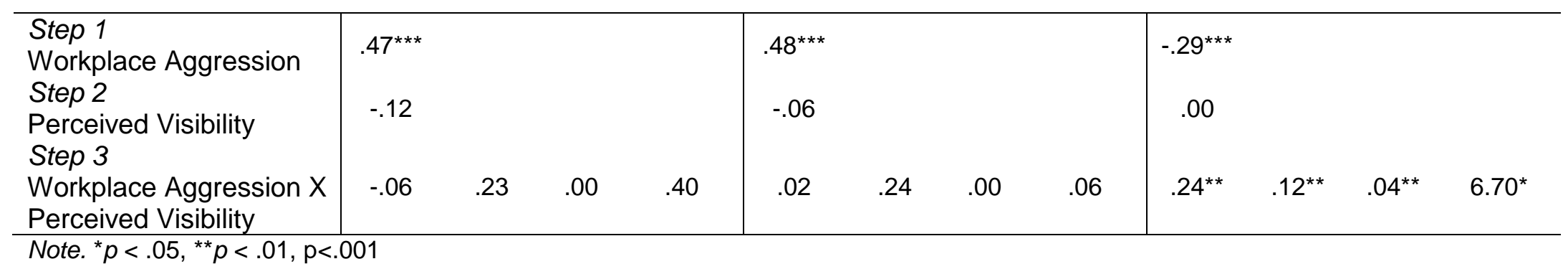


Table 8

Sample of Organizational Responses to Workplace Aggression, as Reported by Participants

Participant $\quad$ Organizational Response

1 "A remediation policy-employees must go through a counseling program"

2 "HR department will meet with all involved parties to mediate the situation"

3 "If there is aggression, you document what happened and when, and then you contact your union rep/union"

4 "If workplace aggression occurs, HR will investigate to determine if corrective action is needed"

5 "Managerial intervention, written warnings, attending trainings"

6 "My company has a toll-free hotline that you can call and handle any situation within the company"

7 "Talk to your supervisor about the issue"

8 "There is a team of employees from various levels and departments within the company"

9 "Zero tolerance for workplace aggression"

10 "Will give a memo to the worker by the organization"

Note. The following four categories of organizational responses emerged: counseling programs; mediation processes; training programs; and written/verbal warning systems. 


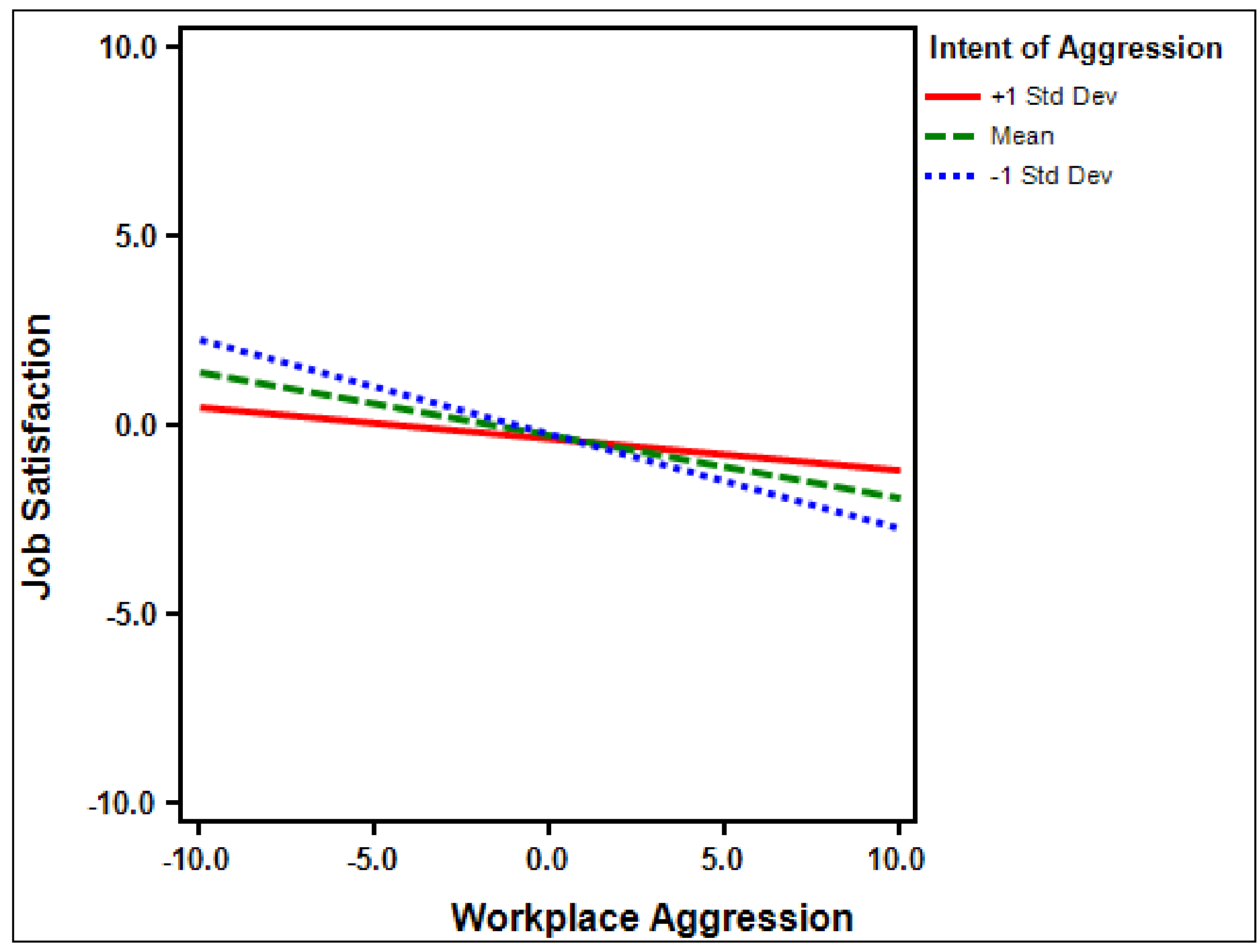

Figure 3. Intent moderates the relationship between workplace aggression and job satisfaction. 


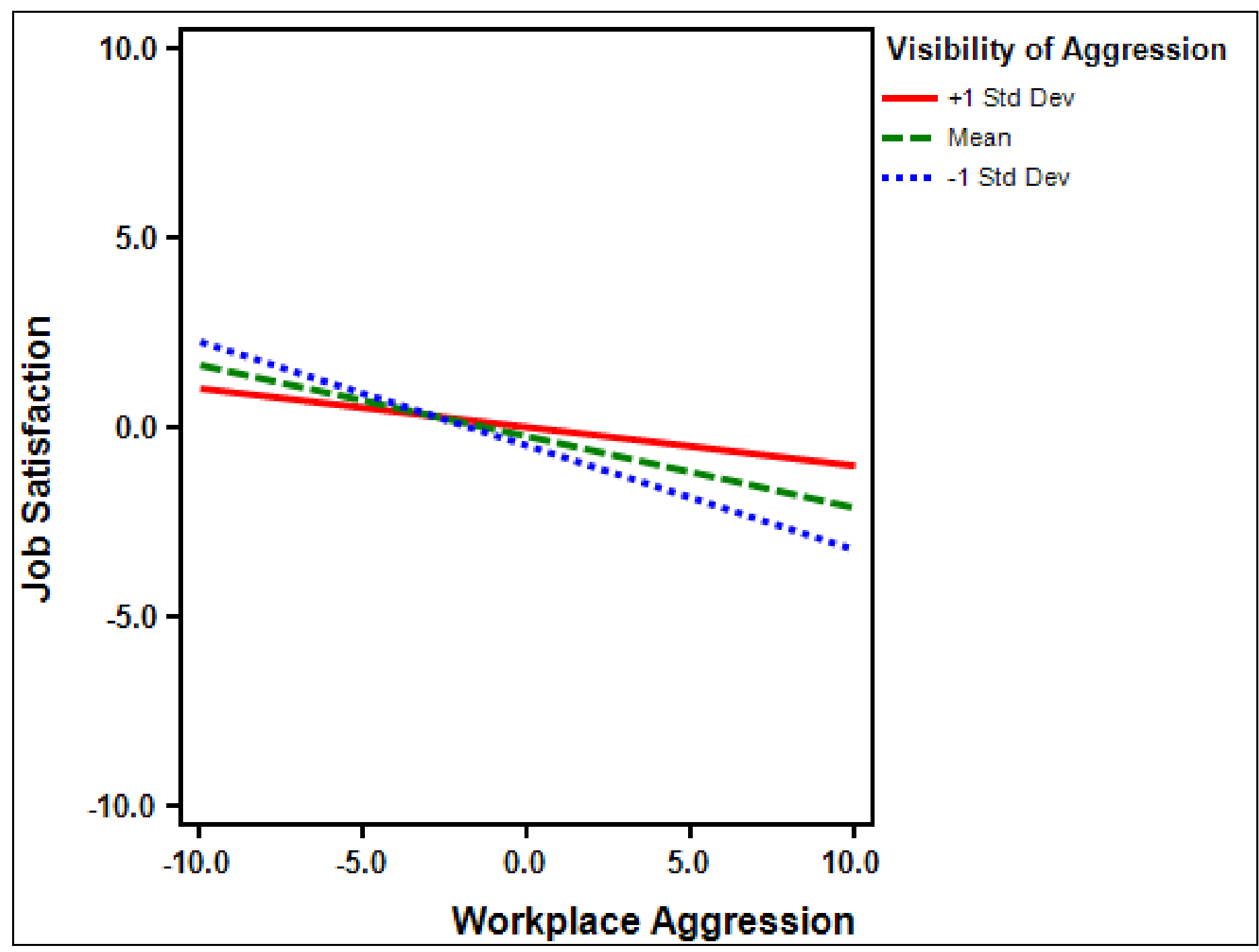

Figure 4. Perceived visibility moderates the relationship between workplace aggression and job satisfaction. 


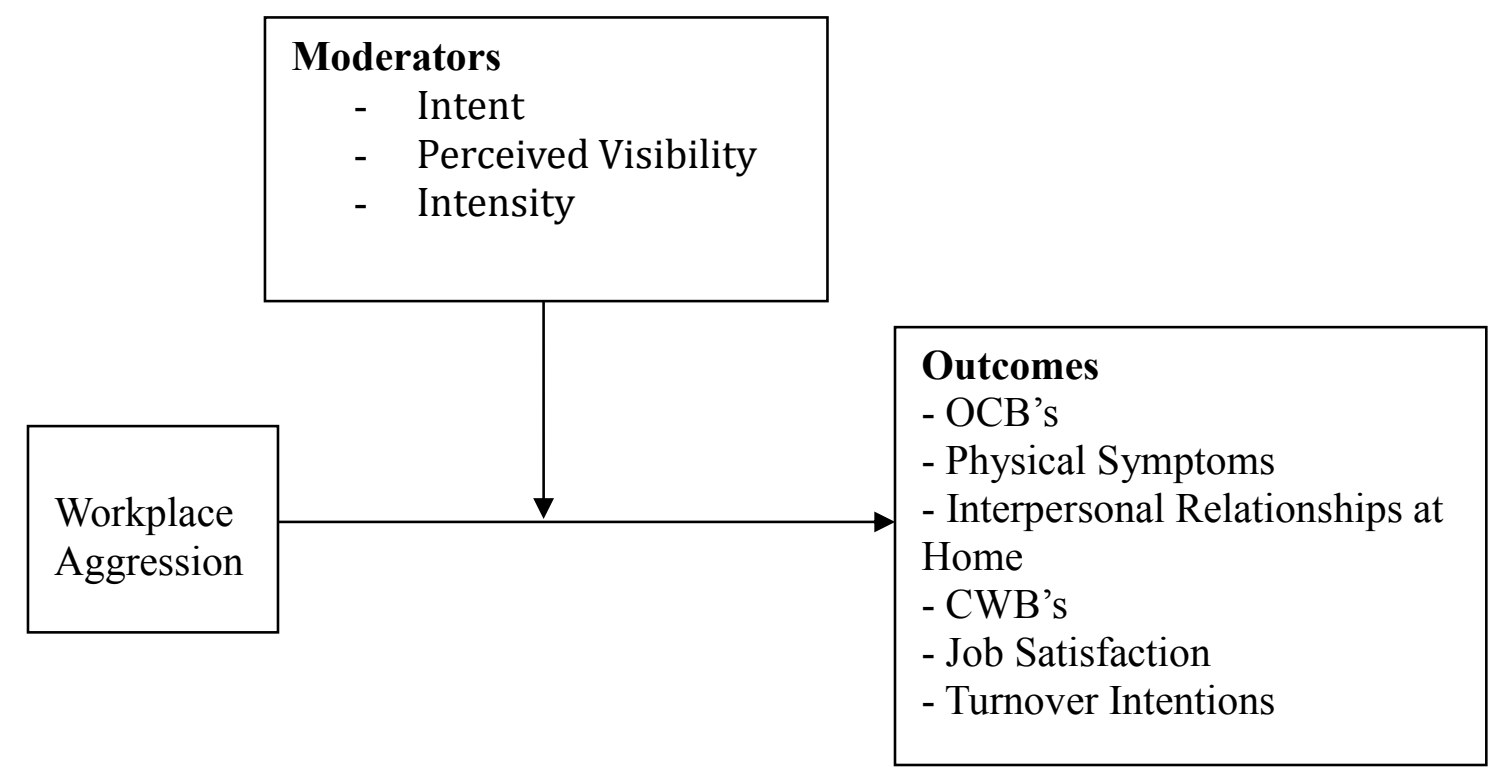

Figure 5. Moderated regression analyses for workplace aggression, strain based outcomes and workplace nuance variables as moderators. 
VITA

JASON KENNETH STEINERT

Born, Meriden, Connecticut

$1997-2001$

B.A., Psychology

Fairfield University

Fairfield, Connecticut

2002-2003

M.S.W., Social Work

New York University

New York, New York

2008-2011

M.S., Industrial Organizational

Psychology

Florida International University

Miami, Florida

2011-2015

Doctoral Candidate

Florida International University

Miami, Florida

\section{PUBLICATIONS AND PRESENTATIONS}

Steinert, J. \& Michel, J. (2011). Stress type: Does the appraisal affect health and performance outcomes? Poster presentation at the 2011 annual meeting of the American Psychological Association, Washington, DC.

Steinert, J., Newness, K., Rutherford, K., \& Michel, J. (2012). The experience of stress: Do role-outcomes mediate health outcomes. Poster presentation at the 2012 annual meeting of the American Psychological Association, Orlando, FI.

Steinert, J., Newness, K., \& Viswesvaran, C. (2012). Social selection: Should organizations use Facebook in screening applicants? Poster presentation at the 2012 annual meeting of IOOB, Orlando, FL.

Newness, K., Steinert, J., \& Viswesvaran, C. (2012). Saving face: Effects of personality on posting inappropriate social network content. Poster presentation at the 2012 annual meeting of the American Psychological Association, Orlando, $\mathrm{Fl}$.

McNall, L., Michel, J., Steinert, J., Rogachefsky, A., \& Jean-Baptiste, C. (2012). Work-school conflict and enrichment: Results from two studies. Poster 
presentation at the 2012 annual meeting of the Society for Industrial Organizational Psychology, San Diego, CA.

Steinert, J. \& Morshed, A. (2013). "A Day in the Life of a General Manager": A Case Study of Assessment Center Use in a Global Leadership Program. Breakout/Symposium at the 2013 annual meeting of the UK AC Conference, London, UK.

Newness, K., Steinert, J., \& Viswesvaran, C. (2013). Effects of personality on social network disclosure: Do emotionally intelligent individuals post inappropriate content? Psychological Topics, 21, 473-486. 